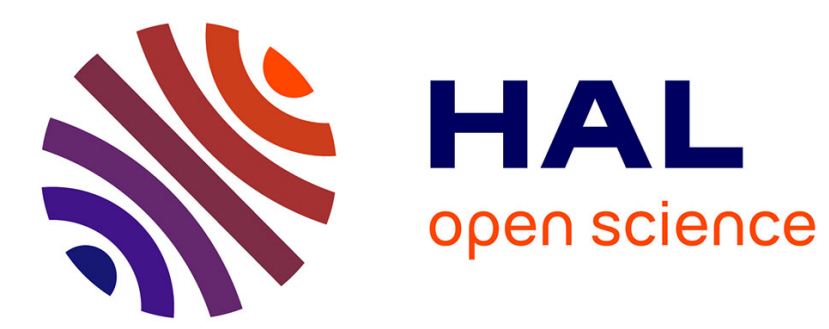

\title{
Buyer Alliances in Vertically Related Markets
}

Hugo Molina

\section{- To cite this version:}

Hugo Molina. Buyer Alliances in Vertically Related Markets. 2021. hal-03340176

\section{HAL Id: hal-03340176 \\ https://hal.inrae.fr/hal-03340176}

Preprint submitted on 10 Sep 2021

HAL is a multi-disciplinary open access archive for the deposit and dissemination of scientific research documents, whether they are published or not. The documents may come from teaching and research institutions in France or abroad, or from public or private research centers.
L'archive ouverte pluridisciplinaire HAL, est destinée au dépôt et à la diffusion de documents scientifiques de niveau recherche, publiés ou non, émanant des établissements d'enseignement et de recherche français ou étrangers, des laboratoires publics ou privés. 


\title{
Buyer Alliances in Vertically Related Markets*
}

\author{
Hugo Molina ${ }^{\dagger}$
}

August 4, 2021

\begin{abstract}
Alliances of buyers to negotiate input prices with suppliers are commonplace. Using pre- and post-alliances data on household purchases of bottled water, I develop a structural model of bilateral oligopoly to estimate the effects of three alliances formed by retailers on their bargaining power vis-à-vis manufacturers and retail prices paid by consumers. Results provide evidence of a countervailing buyer power effect that reduces retail prices by roughly 7\%. Exploring determinants of buyer power, I find that changes in retailers' bargaining ability play an important role in the countervailing force exerted by the alliances which, otherwise, would have not been profitable.
\end{abstract}

Keywords: Bilateral oligopoly, Countervailing buyer power, Bargaining, Antitrust policy. JEL classification: C78, D43, L11, L13, L14, L41, L81.

*This article is based on Chapter 2 of my doctoral dissertation at École polytechnique (CREST) and INRA (ALISS). I am indebted to my doctoral advisors, Céline Bonnet and Claire Chambolle, for their advice and encouragement. I am also grateful to Marie-Laure Allain, Raïcho Bojilov, Zohra Bouamra-Mechemache, Estelle Cantillon, Enrico Camarda, Stéphane Caprice, Philippe Choné, Xavier D'Haultfœuille, Jan De Loecker, Liran Einav, Alon Eizenberg, Sebastian Fleitas, Germain Gaudin, Gautam Gowrisankaran, Philip Haile, Laurent Linnemer, Julien Monardo, Pauline Mourot, Aviv Nevo, Helena Perrone, Patrick Rey, Ruben Savelkoul, Howard Smith, Yutec Sun, Frank Verboven, Thibaud Vergé, Ao Wang and Lionel Wilner for helpful discussions and suggestions. I would also like to thank seminar participants at CREST, Toulouse School of Economics, DIW Berlin, KU Leuven, University of London (Birkbeck College), European Commission (DG Comp), Mines ParisTech (CERNA), and Paris School of Economics as well as workshop and conference participants at CEPR (Leuven, 2018), EARIE (Athens, 2018), BECCLE 2019, ALISS-ECOPUB 2019, and the 2020 World Congress of the Econometric Society for their valuable comments. I gratefully acknowledge financial support from the IO research group at KU Leuven. All remaining errors are mine.

†Université Paris-Saclay, INRAE, UR ALISS, 94205, Ivry-sur-Seine, France; hugo.molina@inrae.fr; https://sites.google.com/site/hugomolinaresearch/ 


\section{Introduction}

The formation of alliances by groups of economic agents to bargain with other agents is a widespread phenomenon. Typical examples include labor unions which negotiate wages with employers on behalf of workers, buyer alliances formed by retailers to negotiate wholesale prices with food manufacturers (Colen et al., 2020), group purchasing organizations through which hospitals join forces to bargain with their suppliers (Burns and Lee, 2008). ${ }^{1}$ How collective bargaining and market concentration affect negotiation outcomes has long been a subject of economic inquiry (Segal, 2003). While the conventional wisdom suggests that size and group membership confer a bargaining advantage (Galbraith, 1952), theory provides ambiguous predictions and empirical evidence remain sparse. ${ }^{2}$

Leveraging a unique case on the French food retail sector in 2014, this article attempts to provide a comprehensive analysis of the effects of three buyer alliances formed by retailers on their bargaining with manufacturers and retail prices paid by consumers. For tractability, I focus on the bottled water industry which features a classic example of bilateral oligopoly where retailers interact with a highly concentrated upstream market including three large manufacturers. Using household-level scanner data on bottled water purchases for the years 2013 (pre-alliances periods) and 2015 (post-alliances periods), I take advantage of the quasi-experimental variation created by the formation of buyer alliances to explore determinants of buyer power and analyze their effects on market outcomes.

My empirical approach is outlined as follows. I start with a descriptive analysis which provides evidence of a substantial decline in the retail prices of national brands sold by retailers involved in an alliance after the formation of buyer alliances. To explore mechanisms underlying this retail price drop and analyze the effects on the surplus division in the vertical chain, I use a structural model of demand and supply. The demand-side includes a standard discrete choice model in which I incorporate observed heterogeneity in consumer preferences using the household-level (micro) data (e.g., Berry, Levinsohn and Pakes, 2004; Goolsbee and Petrin, 2004). The supply-side extends the model of Bonnet, Bouamra-Mechemache and Molina (2018) by constructing an empirical framework suitable for the analysis of buyer alliances in bilateral oligopolies. The framework includes a

\footnotetext{
${ }^{1}$ Other real-world examples can be found in the pharmaceutical industry (e.g., pharmacy benefit managers negotiate drug prices for health insurers and employers), the market for academic journals (Jeon and Menicucci, 2017), the U.S. cable television industry (Chipty and Snyder, 1999), the U.S. retail hardware market or the aircraft sector (Dana, 2012).

${ }^{2}$ For example, Chipty and Snyder (1999) provide ambiguous theoretical results and find no empirical support for the claim that horizontal mergers confer a bargaining advantage in the cable television industry. DiNardo and Lee (2004) obtain similar findings regarding unionization.
} 
two-stage game in which manufacturers and retailers engage in simultaneous and secret bilateral negotiations to determine wholesale prices of products and where retailers subsequently compete in retail prices on the downstream market. Given the presence of contracting externalities, I use the "Nash-in-Nash" bargaining solution (Horn and Wolinsky, 1988a) as a surplus division rule in the vertical chain.

Lacking data on negotiated wholesale prices, I rely on estimates of consumer demand as well as on the set of equations characterizing necessary conditions for a Nash equilibrium in retail prices to recover the marginal costs of retailers before and after the formation of buyer alliances (e.g., Villas-Boas, 2007). To analyze the determinants of these inferred marginal costs, I specify a retail marginal cost function in terms of two additive components. The first component corresponds to the marginal cost of production and distribution for bottled water products, which I assume to be constant in quantity and that includes a structural error term reflecting unobserved cost factors as in Gowrisankaran, Nevo and Town (2015). The second component is the price-cost margins of manufacturers resulting from the bargaining process with retailers and whose (closed-form) expression derives from the first-order conditions of the "Nash-in-Nash" solution. A key innovation of my approach is to exploit the variation in (inferred) retail marginal costs caused by the alliances to estimate changes on three determinants of bargaining power: (i) the status quo position of manufacturers and retailers in each bilateral negotiation, (ii) theirs costs from making price concessions during the course of negotiations, and (iii) their bargaining ability.

Given that the observed retail price change following the alliances can be rationalized by unobserved shocks, I place restrictions on demand and cost unobservables that are similar in spirit to Miller and Weinberg (2017). In particular, my identification assumptions rely on the presence of products remaining outside the scope of the alliances to control for common changes in demand and cost unobservables before versus after the alliances. Then, conditional on a set of control variables, I interpret the formation of buyer alliances as an exogenous shifter of the bargaining environment in the vertical chain to form moment conditions and estimate structural parameters.

Results show that the share of industry profit captured by retailers increases from $68.87 \%$ in the pre-alliances periods to $83.77 \%$ in the post-alliances periods, indicating that retailers have gained bargaining power vis-à-vis manufacturers. To quantify the effects attributable to the formation of the alliances, I leverage the model and parameter estimates to simulate equilibrium market outcomes absent buyer alliances. I find that the observed post-alliances retail prices of national brands sold by retailers involved in an alliance are, on average, 7.10\% lower than they would have been absent buyer alliances. I also obtain that the 
(quantity-weighted) price-cost margins of manufacturers and the industry profit are respectively $54.11 \%$ and $3.41 \%$ lower relative to the counterfactual scenario without the alliances. This result provides empirical evidence of a countervailing buyer power effect that generates a sizeable wholesale and retail price decrease to the detriment of manufacturers and the bottled water industry. In two other counterfactual experiments, I investigate the determinants underlying buyer power in the vertical chain. I find that changes in the relative bargaining ability of retailers vis-à-vis manufacturers play an important role in the countervailing force and the profitability of buyer alliances. In the absence of this bargaining effect, results indicate that there is at least one retailer in each buyer alliance which is worse off bargaining as an alliance member than bargaining alone, which is reminiscent of the jointbargaining paradox first observed by Harsanyi (1977). I show that this paradox stems from a bargaining force previously unexplored in empirical works: the nondiscrimination effect of buyer alliances which affects the willingness of manufacturers and retailers to accept price concessions in negotiations. ${ }^{3}$

The present article is in line with an extensive literature on buyer power which, dating back to Galbraith (1952) and its concept of countervailing power, analyzes the potential for large buyers to secure lower input prices (see Snyder, 2008, for a comprehensive survey). Earlier theoretical works on buyer alliances and unionization have identified that the concavity of the gains that a manufacturer obtains from reaching an agreement is a key determinant of countervailing power. ${ }^{4,5}$ A recent stream of the literature has also found that the ability of a buyer alliance to coordinate the purchasing policy of its members is an important source of countervailing buyer power. For instance, an alliance can heighten upstream competition by reducing the number of manufacturers to deal with (Inderst and Shaffer, 2007; Dana, 2012; Chen and Li, 2013; Allain, Avignon and Chambolle, 2020), ${ }^{6}$ improve the status quo position of retailers by engaging in negotiations with multiple manufacturers (Chae and Heidhues, 2004a), or increase the outside option of retailers when dealing with a powerful manufacturer (Caprice and Rey, 2015). My contribution to this line of research

\footnotetext{
${ }^{3} \mathrm{~A}$ buyer alliance generates a nondiscrimination effect when its members obtain similar trading terms for the purchase of a national brand.

${ }^{4}$ See Horn and Wolinsky (1988b) when workers are substitutes and Chipty and Snyder (1999) when costs are convex. Inderst and Montez (2019) have shown that this condition does not necessarily extends to settings with multiple manufacturers in which adjustments of trades are allowed upon bilateral disagreement.

${ }^{5}$ Theoretical analysis of downstream market concentration (e.g., retail merger) have also examined conditions for countervailing buyer power (Dobson and Waterson, 1997; Iozzi and Valletti, 2014; Gaudin, 2018). A critical difference with buyer alliances is that the reduction in the number of retailers at the downstream level puts upward pressure on retail prices, which tends to blur the analysis of pure countervailing power effects.

${ }^{6}$ Sorensen (2003) and Ellison and Snyder (2010) provide empirical support for this theory. Jeon and Menicucci (2019) show that this countervailing force relies on a precommitment of buyers to limit their purchases to a subset of manufacturers (e.g., exclusive purchase).
} 
is twofold. On the one hand, I highlight that a buyer alliance which negotiates wholesale prices on behalf of multiple retailers enhances the relative status quo position of its members vis-à-vis manufacturers in the event of bilateral disagreement. ${ }^{7}$ On the other hand, I show that the countervailing force of this status quo effect may be undermined by the nondiscrimination effect of an alliance which negotiates similar trading terms for its members, resulting in ambiguous theoretical predictions on buyer power.

This article also draws on a growing body of empirical work that makes use of the "Nash-in-Nash" bargaining solution to estimate models of buyer-seller relationships with contracting externalities (e.g., Draganska, Klapper and Villas-Boas, 2010; Crawford and Yurukoglu, 2012). Prior articles in this literature have primarily relied on ex-ante structural analysis to study the effects of market concentration on bargaining outcomes. ${ }^{8}$ Using premerger data on hospital prices, Gowrisankaran, Nevo and Town (2015) estimate a model of hospital-insurer bargaining and find that a hospital merger would have significantly raised prices despite the existing buyer power of insurers. Ho and Lee (2017) focus on the impact of insurer concentration in a bilateral oligopoly model which incorporates hospital-insurer bargaining over hospital prices and insurer-employer bargaining over premiums. In their simulation results, they find that a countervailing buyer power in the form of lower hospital prices and premiums arises upon the removal of an insurer when employers impose premium constraints through bargaining. Using an oligopoly model of bargaining, Grennan (2013) estimates the likely effects of a group purchasing organization that negotiates with medical device manufacturers on behalf of multiple independent hospitals. He underscores that the profitability of group purchasing depends ultimately on an unexplored bargaining effect: a change in the bargaining ability of hospitals. My contribution to this literature is to provide an ex-post analysis of market concentration through buyer alliances and estimate the effects on three sources of bargaining power. In particular, I extend Grennan's (2013) work to bilateral oligopolies and provide more direct evidence that shifts in bargaining abilities constitute an important source of profitability for buyer alliances. ${ }^{9}$ I also shed light on a countervailing buyer power effect which, unlike Ho and Lee (2017), benefits retailers and consumers and arises absent any constraints on retail price setting. Consistent with

\footnotetext{
${ }^{7}$ This bargaining effect can be related to the curvature of the manufacturer's value from reaching an agreement which is concave when retailers are substitutes (e.g., Horn and Wolinsky, 1988b).

${ }^{8}$ Another strand of the literature has studied the effects of concentration through mergers (e.g., Lewis and Pflum, 2017; Craig, Grennan and Swanson, 2021) or buyer alliances (Dubois, Lefouili and Straub, 2021) on negotiated prices across a broad range of markets using reduced-form analysis. Though insightful, this approach provides limited guidance on the mechanisms underlying buyer power and their implications for welfare.

${ }^{9}$ This finding can also be related to Lewis and Pflum (2015) who estimate that greater bargaining ability explain the fact that hospital systems are able to negotiate higher prices with insurers than individual hospitals.
} 
Galbraith's (1952) view, these results offer new empirical evidence on the underlying determinants of buyer power and their effects on welfare which, since the substantial rise of large retailers these last decades (e.g., Hortaçsu and Syverson, 2015), have become a central issue for competition authorities. ${ }^{10}$

The remainder of this article is structured as follows. Section 2 sheds light on the main economic forces at play when two retailers form a buyer alliance. Section 3 introduces relevant features of buyer alliances in the French food retail sector, the data used in the empirical analysis, and reduced-form evidence on the evolution of retail prices before and after the formation of buyer alliances. Section 4 describes the structural model of demand and supply, discusses identification and estimation, and presents the empirical results. Section 5 presents the counterfactual simulations and Section 6 concludes.

\section{Theoretical insights}

The effects generated by a buyer alliance can be appreciated in a simple setting of vertical relations as shown in Figure 1. A monopoly manufacturer, $M$, sells its brand to two symmetric retailers, $R_{1}$ and $R_{2}$, indexed by $r=1,2$, competing for consumers on a downstream market. Firms operate under constant returns to scale, incurring a unit cost of production and distribution which are normalized to 0 for simplicity.

In the benchmark case depicted in Figure 1a, each retailer $r$ simultaneously and secretly engages in a bilateral negotiation with $M$ to determine its linear wholesale price $w_{r}$ before competing for consumers by setting its retail price $p_{r}$. A modeling difficulty of the bargaining game is the prevalence of contracting externalities due to the competition at one level of the vertical chain (that is, the surplus to be divided in one negotiation depends on the outcome of the other negotiation). To overcome this issue in a tractable way, the literature has leveraged the solution concept of Horn and Wolinsky (1988a), commonly referred to as "Nash-in-Nash" bargaining solution. This concept considers that each wholesale price is determined according to the two-person Nash bargaining solution (Nash, 1950), taking the wholesale prices from other bargains as given. ${ }^{11}$ Applied to the benchmark setting where retailers have no alternative manufacturer to deal with in the event of bilateral disagreement,

\footnotetext{
${ }^{10}$ As emphasized in Carlton and Israel (2011), the proper antitrust treatment of conduct and market structure changes that create or enhance buyer power remains an unsettled question. For instance, the Federal Trade Commission and the Department of Justice have adopted conflicting views on the treatment of buyer power in recent merger reviews (Hemphill and Rose, 2018).

${ }^{11}$ The terminology "Nash-in-Nash" has been coined by Collard-Wexler, Gowrisankaran and Lee (2019) who highlight that this solution concept can be interpreted as a Nash equilibrium in wholesale prices negotiated by pairs of firms according to the Nash's axiomatic theory of bargaining. See Section 4.2 for further details.
} 
Figure 1: Vertical market structure

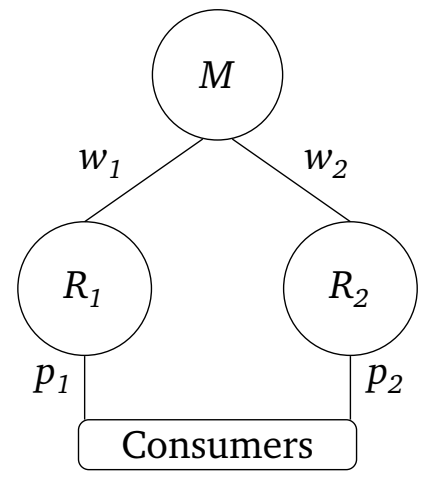

(a) Benchmark: No alliance

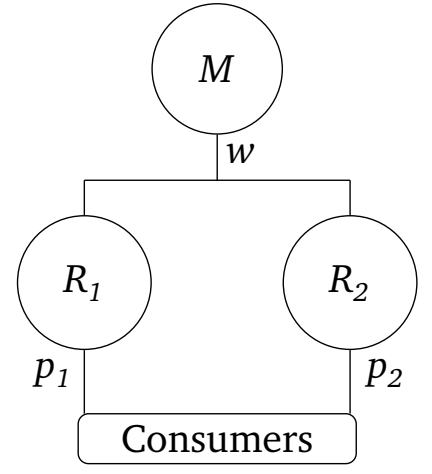

(b) Buyer alliance

the "Nash-in-Nash" solution implies that the status quo payoff of retailer $r$ in its negotiation with $M$ is zero. However, purchases of the other retailer confer to $M$ a positive status quo payoff in its negotiation with retailer $r$. As a result, $M$ has a stronger bargaining position than retailers in each bilateral bargain.

In the situation depicted in Figure 1b, retailers join forces by negotiating a common wholesale price $w$ through a buyer alliance which aims at maximizing their joint profit. Hence, only one bilateral negotiation remains affecting (i) the relative status quo position of firms, (ii) their costs of making price concessions, and (iii) their bargaining ability. In what follows, I provide a non-technical discussion of each bargaining effect using Figures 2 and 3 as illustrative examples and I refer to Appendix S1 of the Supplemental Material for a more formal analysis.

Status quo effect (joint delisting decision). The status quo effect of a buyer alliance can be grasped by considering an intermediate case in which retailers join forces through a buyer alliance but keep negotiating their wholesale prices separately and secretly. By coordinating the purchasing policy of its members, I assume that the alliance endows each retailer a veto power in the spirit of Caprice and Rey (2015). This implies that, in the event of bilateral disagreement with one retailer, all retailers of the alliance jointly delist $M$ 's brand from their shelves, which deteriorates the status quo payoff of $M$ and undermines its bargaining power vis-à-vis retailers. ${ }^{12}$ Figure 2 illustrates this effect by characterizing different bargaining situations between $M$ and retailer $r$, taking as given the wholesale price negotiated with the other retailer. The $x$-axis measures retailer $r$ 's profit $\left(\pi_{r}\right)$ and the $y$-axis $M$ 's profit $\left(\pi_{M}\right)$. Starting from the benchmark case, the status quo payoff of $M\left(d_{M}\right)$ and retailer $r\left(d_{r}\right)$ are

\footnotetext{
${ }^{12}$ This effect is absent from Caprice and Rey (2015) who instead focus on the polar case in which $M$ makes take-it-or-leave-it offers, implying that its status quo position is irrelevant to the bargaining outcome.
} 
Figure 2: Effects on the bargaining frontier and the Nash solution

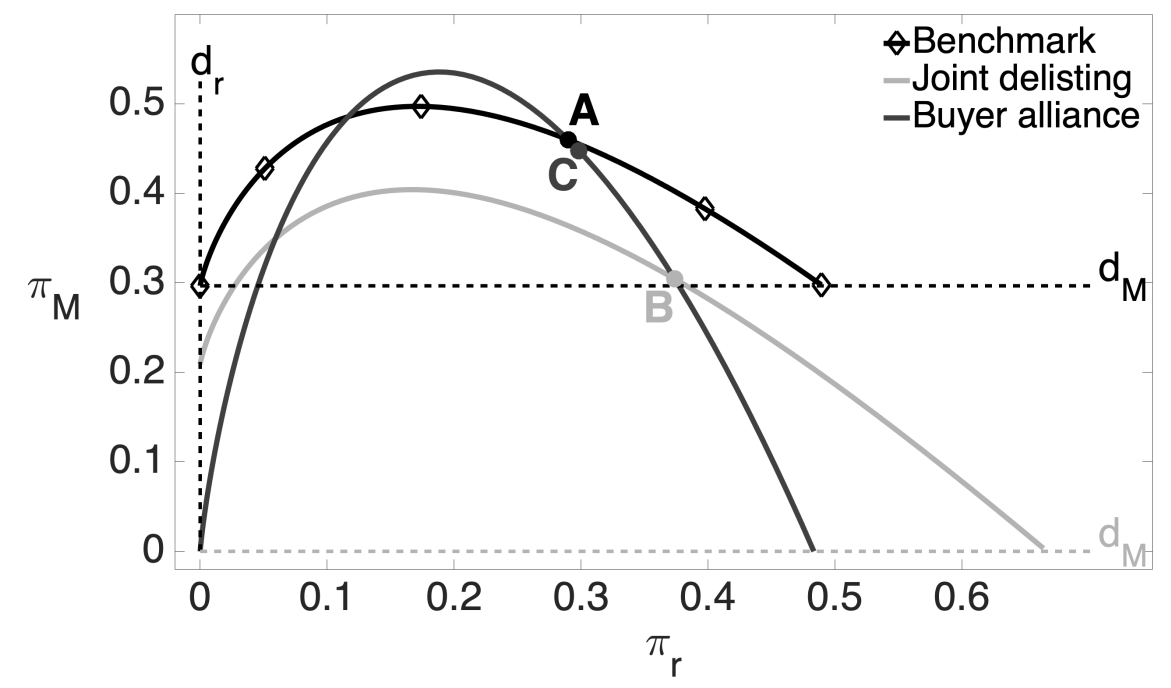

\begin{abstract}
Notes: This figure depicts different bargaining situations between $M$ and retailer $r$. It is drawn under a logit demand system, two symmetric retailers, and zero marginal cost of production and distribution (see Appendix S2 of the Supplemental Material for further details on the generating process). The $x$-axis measures retailer $r$ 's profit $\left(\pi_{r}\right)$ and the $y$-axis measures $M$ 's profit $\left(\pi_{M}\right)$. The horizontal and vertical dotted lines show respectively the status quo payoff of $M\left(d_{M}\right)$ and retailer $r\left(d_{r}\right)$. The black curve with diamond markers, the grey, and the black curve without markers represent the set of all feasible agreement points (bargaining frontier) under the benchmark case, the joint delisting decision case, and the buyer alliance case respectively. The point $\mathrm{A}, \mathrm{B}$, and $\mathrm{C}$ locate the symmetric Nash bargaining solution on each bargaining frontier.
\end{abstract}

respectively depicted by the horizontal and vertical black dotted lines. The black curve with diamond markers represents the set of all feasible agreement points (bargaining frontier), where the symmetric Nash bargaining solution is located at point A (bargaining weights of firms are equal to 0.5). Note that the concave shape of this bargaining frontier stems from the fact that the negotiated price $w_{r}$ affects both the allocation of surplus between firms and the total surplus to be divided $\left(\pi_{M}+\pi_{r}\right) .{ }^{13}$ As previously described, the buyer alliance decreases M's status quo payoff from 0.3 to 0 as shown by the downward shift in $d_{M}$ (grey dotted line). Under this joint delisting decision scenario, the bargaining frontier is represented by the grey curve and the symmetric Nash bargaining solution by the point B. As a result, the status quo effect of the buyer alliance increases retailers' profits at the expense of $M$.

It is worth mentioning that the countervailing force of this status quo effect can be more broadly related to a result first identified in the wage bargaining literature (e.g., Horn and Wolinsky, 1988b). In particular, it has been shown that collective bargaining is beneficial when the gains perceived by the employer (manufacturer) from its bilateral agreements

\footnotetext{
${ }^{13}$ This is a consequence of the well-known double marginalization (Spengler, 1950). As $w_{r}$ gets higher, $\pi_{M}$ increases and $\pi_{r}$ decreases, but $\pi_{M}+\pi_{r}$ may either increase or decrease (for large values of $w_{r}$, $\pi_{M}$ may decrease as well). Under efficient contracting (e.g., lump-sum payments), the shape of this bargaining frontier would instead be a straight line with slope -1 (see, e.g., Grennan, 2014).
} 
are concave, which arises when workers (retailers) are substitutes. In settings of vertical relations with linear contracting, I show that collective bargaining generates another force previously unexplored in the literature: the nondiscrimination effect.

Nondiscrimination effect. The buyer alliance described in Figure 1b enables retailers to obtain similar trading terms when purchasing M's brand. Hence, there is just one bilateral negotiation in which $M$ cannot price-discriminate between retailers. As formally shown in Appendix S1 of the Supplemental Material, this nondiscrimination effect alters firms' relative costs of making price concessions in bargaining (see also O'Brien, 2014, in the context of input price discrimination). ${ }^{14}$ The intuition is as follows. On the one hand, a retailer making a price concession to $M$ does no longer suffer from a competitive disadvantage on the downstream market due to a higher marginal cost because this concession is shared with its rival. On the other hand, M's concession cost increases because price concessions are given to both retailers at the same time. Consequently, the nondiscrimination effect of a buyer alliance implies that costs of making price concessions are less (resp. more) painful for retailers (resp. $M$ ), which reinforces the bargaining power of $M$ vis-à-vis retailers. This effect is illustrated in Figure 2 where the black curve represents the bargaining frontier under the buyer alliance. Compared to the grey curve in which wholesale price discrimination arises, the slope of the black curve is steeper, indicating that it is easier to transfer surplus from the retailers to $M$ through the wholesale price $w .{ }^{15}$ The symmetric Nash bargaining solution located at point $\mathrm{C}$ shows that the division of surplus shifts to the benefit of $M$.

Bargaining ability effect. A number of recent empirical works have highlighted that changes in market conditions are likely to affect the bargaining ability of firms, which may have important implications for predicting market outcomes (e.g., Grennan, 2013; Lewis and Pflum, 2015; Arons, Doudchenko and Yurukoglu, 2019; Grennan and Swanson, 2020). ${ }^{16}$ While various interpretations have been advanced to explain asymmetries in the bargaining ability of firms ${ }^{17}$ the literature on $n$-person bargaining games can provide some insights

\footnotetext{
${ }^{14}$ The cost of making a price concession can be understood as the marginal effect of agreeing upon a higher (resp. lower) wholesale price on the retailer's profit (resp. M's profit).

${ }^{15} M$ has to bear more losses to increase retailer $r$ 's profit under the black curve than under the grey curve.

${ }^{16}$ For instance, Grennan and Swanson (2020) provide evidence that heterogeneity in bargaining abilities can reflect asymmetric information. This underscores the importance of accounting for changes in the bargaining ability of firms when analyzing changes in market conditions that affect transparency.

${ }^{17}$ For instance, Roth (1979) suggests that the presence of asymmetries in firms' bargaining ability can be based on some information or other factors that are "outside" the model. Binmore, Rubinstein and Wolinsky (1986) argue that this can reflect asymmetries in the probability that each firm is selected to make proposal at each bargaining period, asymmetries in the patience of firms, or asymmetries in firms' beliefs about the likelihood that a bargaining breakdown occurs due to an exogenous event.
} 
on the effects of buyer alliances. Kalai (1977) introduced the asymmetric Nash bargaining solution on the ground that a bargainer representing the interest of multiple players should be treated more favorably by the Nash solution (see also Roth, 1979). ${ }^{18}$ By interpreting the situation depicted in Figure $1 \mathrm{~b}$ as a 3-person bargaining game where the alliance negotiates on behalf of two retailers, Kalai (1977) offers support for a change in bargaining abilities to the benefit of retailers. In Figure 2, this effect would simply shift the point $\mathrm{C}$ to the right along the black curve, thereby increasing the profit of retailers to the detriment of $M$. While Kalai's (1977) theory provides an axiomatic foundation to the bargaining ability effect of buyer alliances, I acknowledge that a more formal grounding based on noncooperative bargaining games is beyond the scope of this article. Bearing these considerations in mind, I develop an empirical approach to infer changes in bargaining abilities while remaining fairly agnostic about the precise mechanisms at play. ${ }^{19}$

Alliance profitability. Additional insights can be obtained from Figure 3 which presents the profitability of forming an alliance according to the bargaining weight of retailer 1 ( $x$-axis) and retailer 2 ( $y$-axis) vis-à-vis $M$. For the sake of simplicity, I consider that the bargaining weight of the alliance equals the highest bargaining weight of both retailers (i.e., the bargaining ability effect of the alliance only benefits the weakest retailer). The figure shows that asymmetries among retailers make the formation of an alliance less likely. ${ }^{20}$ In particular, a powerful retailer which negotiates low wholesale prices has less incentive to form an alliance when its rival is a weak bargainer. ${ }^{21}$ The insight underlying this instability result is that the (potential) gain of bargaining power from forming an alliance must compensate for the losses of having a more competitive downstream rival. By making the purchasing conditions more uniform across retailers, the profitability of a buyer alliance formed by two asymmetric retailers depends ultimately on a bargaining ability effect that benefits not only the weakest but also the strongest retailer. Interestingly, this finding echoes another result

\footnotetext{
${ }^{18} \mathrm{~A}$ reformulation of this theory using the notion of multiple "right to talk" (or "right to make a proposal") has been suggested in the literature (e.g., Chae and Heidhues, 2004b). More specifically, in a random-proposer bargaining protocol where each firm has an exogenous probability of being selected to become a proposer, forming a coalition of multiple firms increases the chance to make proposals, which improves the bargaining power of coalition members vis-à-vis other trading partners.

${ }^{19}$ Other approaches impose further structure by parameterizing the bargaining ability in terms of observed firm and market characteristics (e.g., Lewis and Pflum, 2015; Arons, Doudchenko and Yurukoglu, 2019).

${ }^{20}$ When a retailer's bargaining weight gets closer to 1 (i.e., it makes a take-it-or-leave-it offer to $M$ ), grey areas in which the alliance is unprofitable tend to shrink because the nondiscrimination effect vanishes. Despite this effect, a buyer alliance need not be profitable as it improves the competitiveness of the rival retailer on the downstream market.

${ }^{21}$ Although side payments could in principle solve this issue, there are likely to breach antitrust law and to be difficult to implement in practice (see, e.g., the discussion on page 64 of Inderst and Shaffer, 2007).
} 
Figure 3: Profitability of a buyer alliance

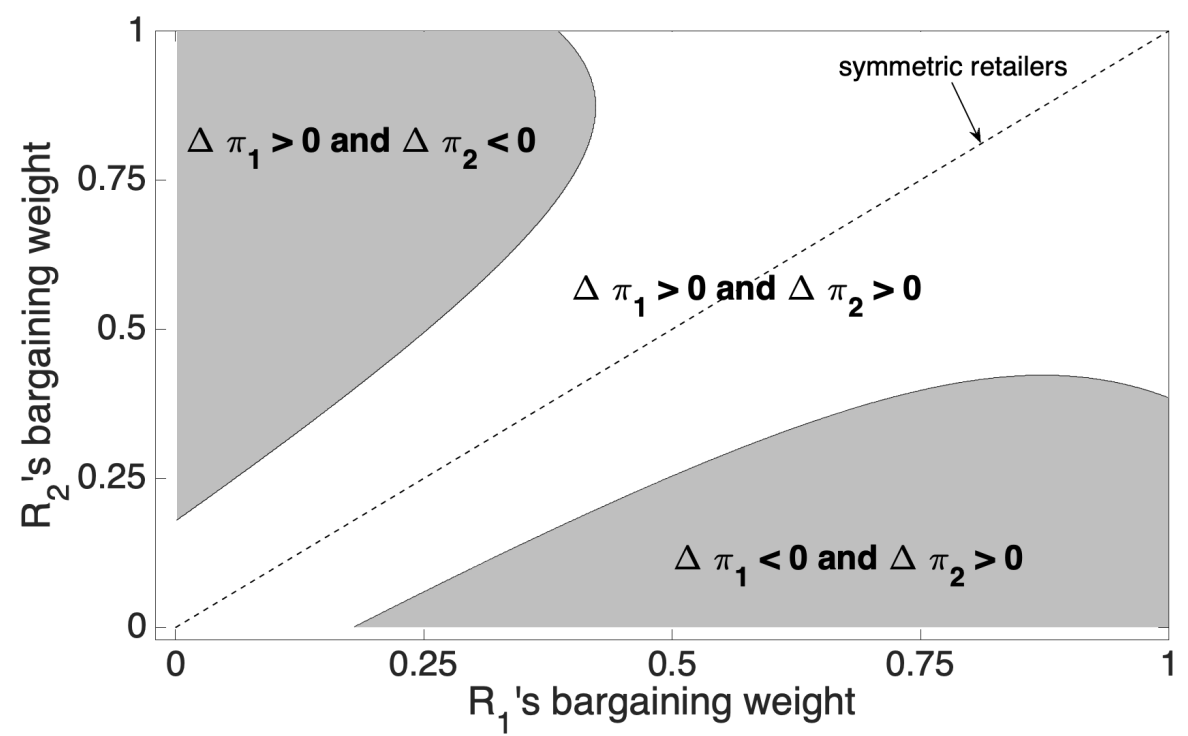

Notes: This figure depicts changes in the profit of retailers following the formation of a buyer alliance $\left(\Delta \pi_{r}\right)$. It is drawn under a setting similar to Figure 2, except that retailers may have asymmetric bargaining weights vis-à-vis $M$. Bargaining weights are from a two-dimensional grid where the $x$-coordinates and $y$-coordinates vary between 0 and 0.999 with an increment of 0.001 . For every point in the grid, I solve the system (10) in Appendix S2 of the Supplement Material to recover the equilibrium retail prices and profits of retailers. When retailers have asymmetric bargaining weights, I assume that the bargaining weight of the alliance equals the highest bargaining weight of both retailers.

in the wage bargaining literature suggesting that unions among homogeneous workers are easier to form (Jun, 1989).

Summary. Shedding light on the main bargaining forces at play, this theoretical analysis shows that a buyer alliance of two competing retailers generates ambiguous effects on buyer power. While the status quo effect and the bargaining ability effect are likely to reinforce the bargaining power of retailers vis-à-vis manufacturers, the nondiscrimination effect reduces their strength. The profitability of forming a buyer alliance is also questionable as it may reduce the competitive advantage of a retailer vis-à-vis its downstream rivals. In the remainder of this article, I analyze the formation of buyer alliances from an empirical perspective using insights developed in this section to guide my approach and interpret the economics behind my estimates.

\section{Industry background, data and descriptive analysis}

My empirical application focuses on the formation of three buyer alliances on the French food retail sector in 2014. This section introduces the relevant industry background, the alliances, the data, and a descriptive analysis of changes in retail prices following the year 
of the alliances.

\subsection{Industry background}

Seven large retailers (Carrefour, Cora, Groupe Auchan, Système U, ITM Entreprises, Groupe Casino, and Leclerc) and hard discounters (e.g., Lidl, Aldi) compete on the French food retail sector to attract consumers in their stores. Every year, from November to February, each retailer engages in annual negotiations with food manufacturers to determine wholesale prices of products. ${ }^{22}$ In 2008, the "Loi de Modernisation Economique" allowed retailers to obtain discriminatory wholesale prices with the purpose of intensifying competition and decreasing retail prices paid by consumers (Allain, Chambolle and Turolla, 2019). In 2014, six of the large retailers joined forces with one of its downstream rival to negotiate common wholesale prices, giving rise to the formation of three buyer alliances: (i) Carrefour and Cora, (ii) Système U and Groupe Auchan, and (iii) ITM Enterprises and Groupe Casino. ${ }^{23}$ The scope covered by these alliances was limited to the wholesale price negotiations of products sold under national brands by large manufacturers only, thereby excluding private labels (store brands), fresh products (e.g., fruit and vegetables), and products supplied by small and medium enterprises. In conjunction with the French Senate, the Minister for the Economy referred the French competition authority which issued an opinion on the potential anticompetitive effects of such operations (see Autorité de la concurrence, 2015). Recognizing that complex economic forces were at play, the authority did not challenge the alliances but advocated for more scrutiny by imposing a prior notification for the formation of any new buyer alliance in the food retail sector.

For tractability motives, my analysis focuses on the bottled water industry which is an attractive laboratory for studying the effects generated by the formation of buyer alliances for at least two reasons. First, this industry is characterized by a bilateral oligopoly structure in which three large national brand manufacturers operate on the upstream market (Nestlé, Danone, and Groupe Alma). Second, with more than $80 \%$ of total sales made in supermar-

\footnotetext{
${ }^{22}$ Some anecdotal evidence indicate that these negotiations are particularly fierce. As a matter of fact, retailers have been repeatedly convicted of unfair trade practices over the past few years (e.g., in 2015 the Paris Court of Appeal condemned Leclerc, one of the seven largest retailers, to reimburse more than $€ 61$ million to its suppliers for unfair practices during the $2009-2010$ annual negotiations).

${ }^{23}$ While endogenizing the formation of the alliances is well beyond the scope of this article, the change in input price discrimination regulation and the long-run consequences of the economic crisis in 2008 have been advanced as explanatory factors for this wave of buyer consolidation (see Autorité de la concurrence, 2015). More specifically, it has been claimed that the aforementioned retailers have decided to join forces in negotiations with the purpose of reducing their purchasing costs and maintaining their competitiveness on the downstream market. In line with the empirical literature on mergers, my analysis abstracts away from these considerations and take retailers' decisions to form buyer alliances as given.
} 
ket chains, the retail distribution is the principal outlet for bottled water manufacturers.

\subsection{Data}

I use household-level scanner data including 550, 059 purchases of bottled water in France collected by Kantar WorldPanel from March to December 2013 (pre-alliances) and March to December 2015 (post-alliances). ${ }^{24}$ The data consist of a panel of households representative of the French population who record their grocery purchases for home consumption. Recorded information for each purchase of bottled water include the date of the purchase, the quantity bought, the per-unit price of the bottled water (henceforth referred to as the retail price), and some of its main attributes such as the brand name, the type of water (mineral, sparkling) and whether it is flavoured or not. The data also provide details about the store at which each purchase was made such as its name, its size area, and its type (e.g., traditional food store, supermaket, hypermarket). I also have access to household characteristics such as the age of the household head or an income-reported interval for each household in the panel.

I focus on purchases of bottled water at stores with a size area above four hundred square meters and which belong either to one of the seven largest retailers or to a hard discounter. Among the purchases made at these stores, I select the 11 most purchased national brands as well as all purchases of private labels. Each selected national brand is produced by one of the three manufacturers (Nestlé produces 5 brands, Danone produces 4 brands, and Groupe Alma produces 2 brands). Private labels are distinguished according to four types of bottled water (mineral or spring water and still or sparkling water) and their manufacturers are assumed to be vertically integrated with the retailers (i.e., there is no bargaining over their wholesale prices). Other purchases in the sample are lumped together under the label "outside good" and include flavoured water, national brands with a small purchased frequency, and bottled water purchased at small stores. Finally, I define a product as a brand-retailer combination, resulting in a total of 111 differentiated products. ${ }^{25}$

Using a revealed-preference dataset on consumer choice, I have no information on products other than those purchased by consumers during their shopping trips (that is, I do not observe the choice set available to each consumer). To address this issue, I define the market as being all purchases of bottled water for home consumption in France within a month.

\footnotetext{
${ }^{24}$ I use the terms "household" and "consumer" interchangeably throughout this article.

${ }^{25}$ More precisely, I consider that a national brand sold by two retailers corresponds to two different products. Note that this definition aggregates different package sizes of bottled water.
} 
Table 1: Descriptive statistics for manufacturers and retailers

\begin{tabular}{|c|c|c|c|c|}
\hline & \multicolumn{2}{|c|}{ Market share } & \multicolumn{2}{|c|}{ Retail price } \\
\hline & pre-alliances & post-alliances & pre-alliances & post-alliances \\
\hline \multicolumn{5}{|l|}{ Upstream level: } \\
\hline Manufacturer 1 & $\begin{array}{l}15.69 \\
(1.07)\end{array}$ & $\begin{array}{l}16.72 \\
(0.48)\end{array}$ & $\begin{array}{c}0.53 \\
(0.02)\end{array}$ & $\begin{array}{c}0.48 \\
(0.01)\end{array}$ \\
\hline Manufacturer 2 & $\begin{array}{l}10.86 \\
(0.43)\end{array}$ & $\begin{array}{l}10.57 \\
(0.28)\end{array}$ & $\begin{array}{c}0.46 \\
(0.01)\end{array}$ & $\begin{array}{c}0.43 \\
(0.02)\end{array}$ \\
\hline Manufacturer 3 & $\begin{array}{l}13.09 \\
(0.76)\end{array}$ & $\begin{array}{l}14.71 \\
(0.95)\end{array}$ & $\begin{array}{c}0.22 \\
(0.00)\end{array}$ & $\begin{array}{c}0.19 \\
(0.01)\end{array}$ \\
\hline Private labels & $\begin{array}{l}23.40 \\
(0.54)\end{array}$ & $\begin{array}{l}21.31 \\
(0.40)\end{array}$ & $\begin{array}{c}0.26 \\
(0.00)\end{array}$ & $\begin{array}{c}0.26 \\
(0.00)\end{array}$ \\
\hline \multicolumn{5}{|l|}{ Downstream level: } \\
\hline Retailer 1 & $\begin{array}{l}14.84 \\
(0.36)\end{array}$ & $\begin{array}{l}14.21 \\
(0.51)\end{array}$ & $\begin{array}{c}0.40 \\
(0.01)\end{array}$ & $\begin{array}{c}0.37 \\
(0.01)\end{array}$ \\
\hline Retailer 2 & $\begin{array}{c}1.78 \\
(0.16)\end{array}$ & $\begin{array}{c}1.86 \\
(0.18)\end{array}$ & $\begin{array}{c}0.43 \\
(0.02)\end{array}$ & $\begin{array}{c}0.39 \\
(0.02)\end{array}$ \\
\hline Retailer 3 & $\begin{array}{c}7.31 \\
(0.43)\end{array}$ & $\begin{array}{c}7.20 \\
(0.48)\end{array}$ & $\begin{array}{c}0.42 \\
(0.01)\end{array}$ & $\begin{array}{c}0.40 \\
(0.01)\end{array}$ \\
\hline Retailer 4 & $\begin{array}{c}4.94 \\
(0.21)\end{array}$ & $\begin{array}{c}5.99 \\
(0.17)\end{array}$ & $\begin{array}{c}0.40 \\
(0.01)\end{array}$ & $\begin{array}{c}0.37 \\
(0.01)\end{array}$ \\
\hline Retailer 5 & $\begin{array}{c}8.97 \\
(0.76)\end{array}$ & $\begin{array}{c}8.94 \\
(0.40)\end{array}$ & $\begin{array}{c}0.40 \\
(0.01)\end{array}$ & $\begin{array}{c}0.37 \\
(0.01)\end{array}$ \\
\hline Retailer 6 & $\begin{array}{c}4.62 \\
(0.19)\end{array}$ & $\begin{array}{c}4.75 \\
(0.25)\end{array}$ & $\begin{array}{c}0.42 \\
(0.01)\end{array}$ & $\begin{array}{c}0.39 \\
(0.01)\end{array}$ \\
\hline Retailer 7 & $\begin{array}{l}14.48 \\
(0.67)\end{array}$ & $\begin{array}{l}14.17 \\
(0.53)\end{array}$ & $\begin{array}{c}0.39 \\
(0.01)\end{array}$ & $\begin{array}{c}0.37 \\
(0.01)\end{array}$ \\
\hline Retailer 8 & $\begin{array}{c}6.10 \\
(0.10)\end{array}$ & $\begin{array}{c}6.19 \\
(0.30)\end{array}$ & $\begin{array}{c}0.26 \\
(0.01)\end{array}$ & $\begin{array}{c}0.26 \\
(0.01)\end{array}$ \\
\hline Outside good & $\begin{array}{l}36.96 \\
(1.52)\end{array}$ & $\begin{array}{l}36.69 \\
(0.78)\end{array}$ & - & - \\
\hline
\end{tabular}

Notes: Market shares in percentage are calculated according to the number of household purchases. Average retail prices are in euro per liter. Standard deviation in parenthesis refer to variation across markets for the year 2013 (pre-alliances) and 2015 (post-alliances). Remark that I am not permitted to reveal names of manufacturers and retailers due to confidentiality regarding Kantar WorldPanel data.

Then, I compute a monthly average (deflated) retail price for each product. ${ }^{26}$ Considering the most popular brands of bottled water sold by the largest retailers in France, I make the assumption that every consumer in the sample has made its purchasing decision among the 111 differentiated products (plus the outside good) sold at their corresponding monthly retail price.

Table 1 reports descriptive statistics about the market shares and retail prices of products for each manufacturer and retailer before and after the formation of buyer alliances (see

${ }^{26}$ The retail price of product $j$ in market $t$ is constructed as follows: $p_{j, t}=\frac{\sum_{i} \mathbb{1}_{i, j, t} p_{i, j, t} q_{i, j, t}}{\sum_{i} \mathbb{1}_{i, j, t} q_{i, j, t}}$, where $\mathbb{1}_{i, j, t}$ is an indicator equals to 1 if consumer $i$ has purchased product $j$ in market $t, p_{i, j, t}$ is the retail price paid by the consumer, and $q_{i, j, t}$ is the quantity purchased (in liter). 
Appendix A for additional statistics). In the pre-alliances periods, market shares of national brand manufacturers range from $10.86 \%$ to $15.69 \%$ and private labels account for a substantial portion of total bottled water purchases (23.40\%). Private labels are on average twice less expensive than national brands of manufacturers 1 and 2. However, manufacturer 3's national brands are on average cheaper than private labels. This suggests that there is a strong heterogeneity between national brands in the retail price dimension. ${ }^{27}$ In the post-alliances periods, the average retail price of private labels remains unchanged relative to the pre-alliances periods. In contrast, the average retail price of each national brand manufacturer is substantially lower, reducing the price gap between national brands and private labels. Market shares of manufacturers 1 and 2 increase while sales of private labels decrease relative to the pre-alliances periods.

The table also shows substantial variation of market shares across retailers, ranging from $1.78 \%$ for the smallest to $14.84 \%$ for the largest retailer in the pre-alliances periods. As further shown in Table 8 of Appendix A, sales of national brands constitute the largest portion of retailers' market shares, except for retailer 8 whose total sales are composed at $87 \%$ of private labels. Retail prices of products sold by retailers which have not formed any alliance in 2014 (that is, retailers 7 and 8) are on average lower than the retail prices charged by other retailers (see also Table 8 of Appendix A). This price gap, however, decreases in the post-alliances periods. In what follows, I consider a descriptive analysis of retail prices to explore the dynamic of this price variation.

\subsection{Descriptive retail price analysis}

Figure 4 displays the time path of average retail prices of three product groups: (i) national brands sold by retailers which have formed a buyer alliance in 2014, (ii) national brands sold by retailers 7 and 8 which have not formed any alliance in 2014, and (iii) private labels which have all been excluded from the scope of the alliances. The figure shows that the average retail price of national brands sold by retailers involved in an alliance experienced a sharp decrease from about $€ 0.46$ to $€ 0.42$ after the formation of buyer alliances. While a decline in the retail prices of national brands sold by retailers 7 and 8 is also observed in the year following the alliances, the average retail price of private labels remains stable over time.

To quantify this retail price variation, I conduct an event-study analysis. After collapsing

\footnotetext{
${ }^{27}$ This heterogeneity may be partly explained by cost differences as manufacturer 3's leading brand is a spring water extracted from 32 underground sources throughout France.
} 
Figure 4: Retail price trends

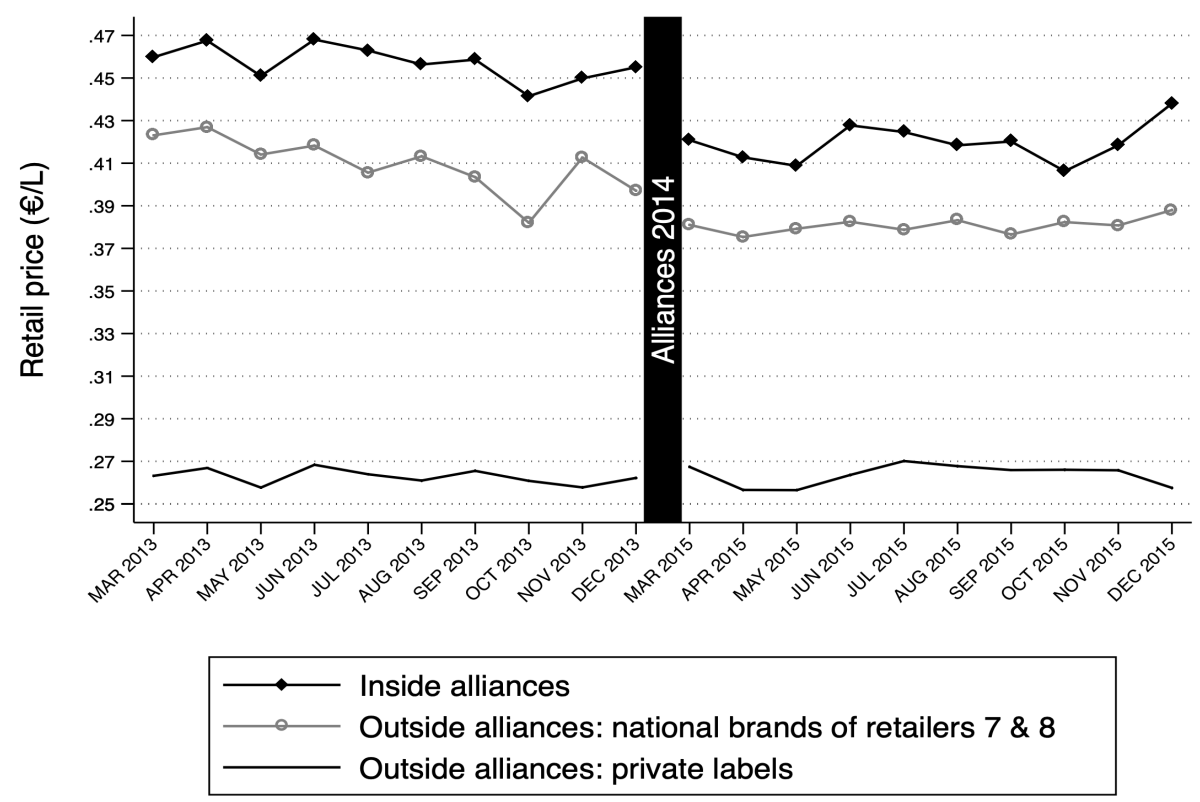

Notes: The black line with diamond markers is the average retail price trend of national brands sold by retailers which have formed a buyer alliance in 2014. The gray line with circle markers is the average retail price trend of national brands sold by retailers 7 and 8 which have not formed any alliance. The black line without markers is the average retail price trend of private labels sold by all retailers.

the data at the product-market level, I estimate the following reduced-form pricing equation:

$$
\begin{aligned}
\ln p_{j, t}= & \beta_{j}+\beta_{t}+\beta_{t}^{\text {in }} \mathbb{1}\{\text { national brand }\}_{j, t} \times \mathbb{1}\{\text { alliance }\}_{j, t} \\
& +\beta_{t}^{\text {out }} \mathbb{1}\{\text { national brand }\}_{j, t} \times \mathbb{1}\{\text { retailers } 7 \& 8\}_{j, t}+u_{j, t}
\end{aligned}
$$

where $\ln p_{j, t}$ is the natural $\log$ retail price of product $j$ in market $t, \beta_{j}$ and $\beta_{t}$ are product and market fixed effects controlling for the cross-sectional and time variation in the retail prices of products, and $u_{j, t}$ is an error term capturing unobserved factors which affect retail prices. The indicator variables $\mathbb{1}\{\text { national brand }\}_{j, t}, \mathbb{1}\{\text { alliance }\}_{j, t}$, and $\mathbb{1}$ \{retailers $\left.7 \& 8\right\}_{j, t}$ are respectively equal to 1 if product $j$ in market $t$ is a national brand, if it is sold by a retailer involved in an alliance in 2014, and if it is sold by either retailer 7 or 8 . The parameters of interest in (1) are the fixed effects $\beta_{t}^{\text {in }}$ and $\beta_{t}^{\text {out }}$. They measure the evolution of the log retail price difference between national brands sold by a retailer involved in an alliance and private labels $\left(\beta_{t}^{\text {in }}\right)$, and the evolution of the log retail price difference between national brands sold by retailer 7 or 8 and private labels $\left(\beta_{t}^{\text {out }}\right)$. One can interpret these parameters as a measure of the effect of the alliances on retail prices under the two following assumptions. First, the retail prices of private labels have not been affected by the alliance formation. Second, private labels and national brands face comparable demand and supply conditions 
Figure 5: Event study

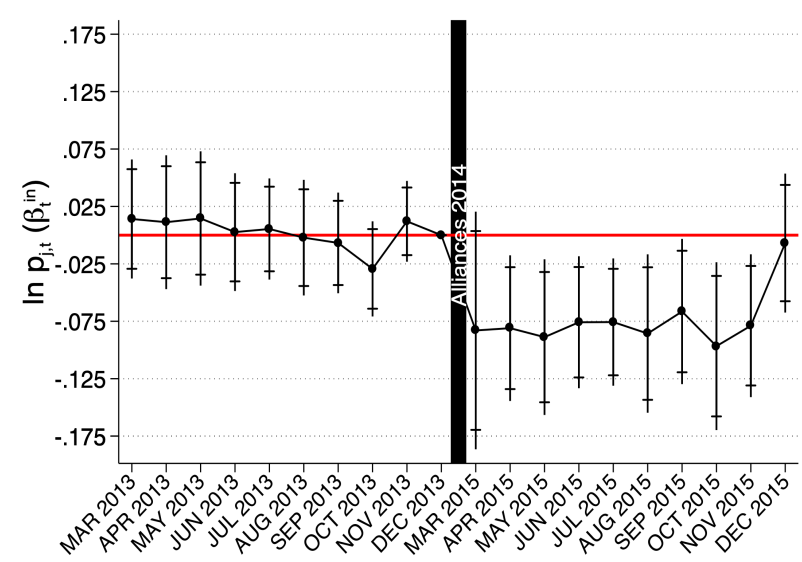

(a) Inside alliances

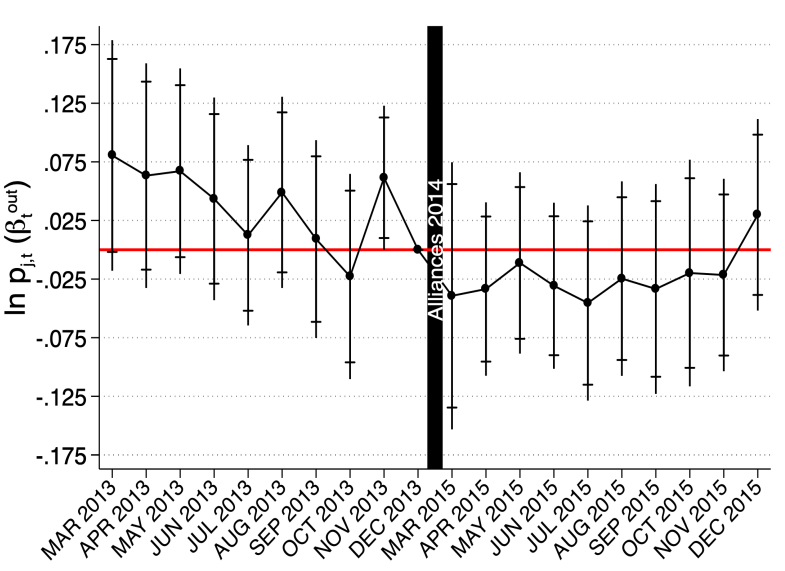

(b) Outside alliances: retailers $7 \& 8$

Notes: OLS estimates of the coefficients $\beta_{t}^{\text {in }}$ and $\beta_{t}^{\text {out }}$ from the regression model (1). The number of observations is 2,192 and the $R^{2}$ adjusted equals 0.99 . Capped-bars and bars indicate respectively the $90 \%$ and $95 \%$ confidence intervals with standard errors clustered at the product level (111 clusters). The coefficients $\beta_{t}^{\text {in }}$ and $\beta_{t}^{\text {out }}$ for December 2013 are normalized to zero (base period). Percentage changes in retail prices can be obtained from the following transformation of the estimated parameters: $100(\exp (\beta)-1)$.

such that their retail prices would have followed the same trend absent buyer alliances. ${ }^{28} \mathrm{I}$ estimate equation (1) by ordinary least squares (OLS) with standard errors clustered at the product level. ${ }^{29}$ Figures $5 \mathrm{a}$ and $5 \mathrm{~b}$ display the estimation results (see Appendix B.2 for a similar event-study analysis alliance-by-alliance).

Figures 5 a shows that the trend in retail prices of national brands sold by retailers involved in an alliance during the pre-alliances periods is stable and not statistically different from that of private labels. In the post-alliances periods, however, there is a clear trend break in which most parameters are significantly negative with values around -0.075 . This suggests that, after the formation of buyer alliances, the average retail price of national brands sold by a member of an alliance has decreased by $7.23 \%$ relative to that of private labels. Figure $5 \mathrm{~b}$ also indicates that the retail prices of national brands sold by retailers 7 and 8 do not trend differently from the retail prices of private labels in the pre-alliances periods. In the post-alliances periods, the estimates show a slight decrease in the retail prices of their national brands. While suggesting that retailers compete in strategic complements, the estimates also indicate that the price response of retailers 7 and 8 to the formation of the alliances is not statistically significant.

As a result, this preliminary analysis provides descriptive evidence that the retail prices

\footnotetext{
${ }^{28}$ Although not perfect, private labels are often used as a control group in the retrospective merger literature (see, e.g., Ashenfelter and Hosken, 2010; Weinberg and Hosken, 2013).

${ }^{29}$ Clustering at more aggregated levels such as brand-retailer (89 clusters) or manufacturer-retailer-type of water (75 clusters) yields qualitatively similar results. In Appendix B.1, I also consider the "aggregation" approach suggested by Bertrand, Duflo and Mullainathan (2004) as an alternative solution for the serial correlation of retail prices.
} 
of national brands sold by retailers involved in an alliance sharply decreased in the postalliances periods. Several shortcomings are however worth mentioning. While the event study reveals a strong correlation between the decrease in retail prices of national brands and the formation of buyer alliances, caution regarding its causal interpretation is warranted. ${ }^{30}$ Furthermore, this analysis does not provide any guidance on the mechanisms underlying changes in retail prices and their implications for the industry profit and its division between manufacturers and retailers, which are matters of intense political and antitrust debates. In what follows, I develop a structural model of demand and supply to explicitly address these issues.

\section{Empirical framework}

This section introduces the structural model of demand and supply that I take to data. I first describe the demand-side which models consumer choices for bottles of water in supermarket chains. Then, I turn to the supply-side which models the bottled water industry as a bilateral oligopoly.

\subsection{Consumer demand for bottled water}

\subsubsection{Demand model}

I consider a demand system which derives from a standard discrete choice model of consumer behavior. More specifically, I use a multinomial logit model with observed heterogeneity to accommodate rich substitution patterns among products.

Suppose that each consumer $i=1, \ldots, N_{t}$ in the sample chooses among $J_{t}+1$ alternatives indexed from $j \in\left\{0, \ldots, J_{t}\right\} \equiv \mathscr{J}_{t}$ at each shopping trip in market $t$. Alternative $j=0$ is referred to as the composite "outside good", while other alternatives correspond to $J_{t}$ products called "inside goods". ${ }^{31}$ Each inside good $j$ is associated to a brand $b=1, \ldots, B-$ where $b(j)$ labels the brand of good $j$ - sold by a retailer $r=1, \ldots, R$ - where $r(j)$ denotes the retailer which distributes good $j$.

The indirect utility function of consumer $i$ from purchasing inside good $j$ in market $t$ is

\footnotetext{
${ }^{30}$ Ideally, I would use as a control group the same national brands sold by retailers in adjacent markets where the alliances did not occur. However, the national scope of the alliances precludes the presence of such products in my data.

${ }^{31}$ Terms "good" and "product" are used interchangeably and refer to alternatives in the choice set $\mathscr{J}_{t}$.
} 
specified as follows:

$$
U_{i, j, t}=\phi x_{\text {spark }(j)}+\psi_{i} x_{\text {mineral }(j)}-\alpha_{i} p_{j, t}+\beta_{0}+\beta_{t}+\beta_{b(j)}+\beta_{r(j)}+\xi_{j, t}+\epsilon_{i, j, t}
$$

where $x_{\text {spark(j) }}$ and $x_{\text {mineral (j) }}$ are indicator variables for sparkling and mineral water, $p_{j, t}$ is the retail price, $\beta_{0}$ is a constant term capturing the mean utility in the population generated by time-invariant characteristics common to all inside goods, $\beta_{t}$ are market fixed effects controlling for changes over time in the valuation of characteristics common to all inside goods, $\beta_{b(j)}$ and $\beta_{r(j)}$ are respectively brand and retailer fixed effects which capture the mean valuation of time-invariant characteristics specific to each brand and each retailer, $\xi_{j, t}$ is a structural error which embeds the mean utility generated by product characteristics unobserved to the econometrician, and $\epsilon_{i, j, t}$ is a stochastic term representing unobserved consumerspecific preferences. The parameter $\phi$ captures consumer preferences for sparkling water. Consumer preferences for mineral water $\psi_{i}$ and their sensitivity to price $\alpha_{i}$ are allowed to vary across consumers. More specifically, I use functions of observed household attributes to incorporate consumer heterogeneity in these parameters:

$$
\psi_{i}=\psi+\psi_{g\left(a g e_{i}\right)} \text { and } \alpha_{i}=\alpha+\alpha_{g\left(y_{i}\right)}
$$

where $\psi$ and $\alpha$ capture respectively the mean valuation for mineral water and the mean retail price sensitivity of consumers, $\psi_{\left.\text {g(age }_{i}\right)}$ measures the heterogeneity in consumer preferences for mineral water which varies according to the group of household $i$ 's head age labelled by $g\left(a g e_{i}\right)$, and $\alpha_{g\left(y_{i}\right)}$ measures the heterogeneity in the retail price sensitivity of consumers which varies according to consumer $i$ 's income group labelled by $g\left(y_{i}\right)$.

The indirect utility that consumer $i$ receives from choosing the outside good in market $t$ is normalized as follows: $U_{i, 0, t}=\epsilon_{i, 0, t}$.

Assuming that each consumer in the sample is a utility maximizer (i.e., he chooses one unit of the good that gives him the highest utility) and that $\epsilon_{i, j, t}$ is independently and identically distributed from the standard Gumbel distribution (also known as type I extreme value distribution), the probability that consumer $i$ selects product $j \in \mathscr{J}_{t} \backslash\{0\}$ in market $t$ is:

$$
s_{i, j, t}=\frac{\exp \left(\phi x_{\text {spark }(j)}+\psi_{i} x_{\text {mineral }(j)}-\alpha_{i} p_{j, t}+\beta_{0}+\beta_{t}+\beta_{b(j)}+\beta_{r(j)}+\xi_{j, t}\right)}{1+\sum_{k=1}^{J_{t}} \exp \left(\phi x_{\text {spark }(k)}+\psi_{i} x_{\text {mineral }(k)}-\alpha_{i} p_{k, t}+\beta_{0}+\beta_{t}+\beta_{b(k)}+\beta_{r(k)}+\xi_{k, t}\right)}
$$

In what follows, I consider identification and estimation of the vector of demand parameters $\theta^{d} \equiv\left(\theta_{1}^{d^{\top}}, \theta_{2}^{d^{\top}}\right)^{\top}$, where $\theta_{1}^{d} \equiv\left(\beta^{\top}, \phi, \psi, \alpha\right)^{\top}$ is a vector including the mean taste 
parameters and $\theta_{2}^{d} \equiv\left(\boldsymbol{\psi}^{o \top}, \boldsymbol{\alpha}^{o^{\top}}\right)^{\top}$ is a vector of parameters capturing the heterogeneity in consumer preferences (the superscript " $T$ " denotes the transpose operator). ${ }^{32,33}$

\subsubsection{Identification and estimation of consumer demand}

Identification assumptions. As stressed in Berry (1994), identification of $\boldsymbol{\theta}^{d}$ can be jeopardized by the classical endogeneity problem of the retail price variable. Whenever retailers observe the realization of demand shocks for unobserved product characteristics before setting retail prices, $p_{j, t}$ is likely to be correlated with $\xi_{j, t}$. To address this issue and obtain consistent estimates of consumer preferences, I follow Berry, Levinsohn and Pakes (2004). I define $\delta_{j, t} \equiv \phi x_{\text {spark }(j)}+\psi x_{\text {mineral }(j)}-\alpha p_{j, t}+\beta_{0}+\beta_{t}+\beta_{b(j)}+\beta_{r(j)}+\xi_{j, t}$, which subsumes the mean utility level of product $j \in \mathscr{J}_{t} \backslash\{0\}$. Combined with micro data, this approach allows to identify the vector of mean utility levels $\delta \equiv\left(\delta_{1,1}, \ldots, \delta_{J_{T}, T}\right)^{\top}$ as well as $\theta_{2}^{d}$ without any restriction on the distribution of the structural error $\xi_{j, t}$.

Identification of $\theta_{1}^{d}$ requires further assumptions. I rely on an instrumental variable approach which consists in finding at least one variable that affects retail prices by shifting supply (costs or markups of retailers) but not preferences for unobserved attributes of bottled water. I consider two instrumental variables. Under the assumption that observable product characteristics are uncorrelated with $\xi_{j, t}$ (Berry, Levinsohn and Pakes, 1995), I use the number of products competing with product $j$ and sold by rivals of retailer $r(j) .{ }^{34}$ The second instrument is based on insights developed in Berry and Haile (2014) and applied by Miller and Weinberg (2017) to the analysis of horizontal mergers in oligopoly. By interpreting the formation of buyer alliances as an exogenous shifter of the bargaining environment in the vertical chain, I use its indicator variable $(\mathbb{1} \text { \{national brand }\}_{j, t} \times \mathbb{1}\{\text { alliance }\}_{j, t} \times$ $\mathbb{1}$ \{post-alliances $\}_{t}$ ) as instrument for the retail price variable. ${ }^{35}$ Given the presence of brand, retailer, and market fixed effects in (2), exogeneity of this instrument relies on the assumption that changes in the structural error of national brands sold by retailers involved in an alliance, before versus after the alliances, are not systematically different from changes in

\footnotetext{
${ }^{32}$ The vector of parameters $\beta$ includes the constant term, brand, retailer, and market fixed effects.

${ }^{33}$ The vector $\psi^{\circ}$ contains all parameters that govern the (observed) heterogeneity in consumer preferences for mineral water according to the age of household head (e.g., $\psi_{g\left(\text { age }_{i}\right)}$ for household $i$ ). Similarly, $\boldsymbol{\alpha}^{o}$ stands for the vector of parameters that capture the (observed) heterogeneity in the retail price sensitivity of consumers according to their income group.

${ }^{34}$ The main motive for this instrument is that retail prices depend on the number of products offered by competing retailers through equilibrium retail margins (e.g., a retailer with a small number of rival products is more likely to have higher margins). As emphasized in Armstrong (2016), however, this instrument may lose its identifying power when the number of products per market becomes large.

${ }^{35}$ This indicator can be interpreted as a cost shifter for retailers given that the primary motive for the alliances is to reduce wholesale prices paid by retailers to manufacturers. The descriptive retail price analysis in Section 3.3 provides direct evidence on the relevance of this instrument.
} 
the structural error of national brands sold by retailers 7 and 8 and private labels. ${ }^{36}$

Estimation procedure. I follow the two-step estimation procedure of Berry, Levinsohn and Pakes (2004). Using household-level scanner data, I first estimate the vectors of parameters $\delta$ and $\theta_{2}^{d}$ by generalized method of moments (GMM) (Hansen, 1982). Because $\delta$ has $\sum_{t=1}^{T} J_{t}=2,192$ elements, I concentrate these parameters out of the objective function using the contraction procedure of Berry, Levinsohn and Pakes (1995) to save computational time. Formally, I minimize a GMM criterion function over $\theta_{2}^{d}$ (outer loop) using a nested fixed point algorithm to recover $\delta$ for each trial value of $\theta_{2}^{d}$ (inner loop). This GMM estimator is defined as:

$$
\hat{\theta}_{2}^{d} \equiv \underset{\theta_{2}^{d}}{\operatorname{argmin}} \mathbf{g}^{d}\left(\boldsymbol{\delta}\left(\theta_{2}^{d}\right), \theta_{2}^{d}\right)^{\top} \mathbf{g}^{d}\left(\boldsymbol{\delta}\left(\theta_{2}^{d}\right), \theta_{2}^{d}\right)
$$

where $\mathbf{g}^{d}\left(\boldsymbol{\delta}\left(\theta_{2}^{d}\right), \theta_{2}^{d}\right)$ is a $K \times L$-dimensional vector of micro-moments. The micro-moment $g_{k, l}^{d}$ is given by:

$$
g_{k, l}^{d}=\sum_{t=1}^{T} \sum_{j=1}^{J_{t}} \sum_{i=1}^{N_{t}}\left(\mathbb{1}_{i, j, t}-s_{i, j, t}\left(\boldsymbol{\delta}_{t}\left(\boldsymbol{\theta}_{2}^{d}\right), \theta_{2}^{d}\right)\right) x_{j, t}^{(k)} D_{i, t}^{(l)}
$$

where $\delta_{t} \equiv\left(\delta_{1, t}, \ldots, \delta_{J_{t}, t}\right)^{\top}, \mathbb{1}_{i, j, t}$ is an indicator equals 1 if consumer $i$ has purchased product $j$ in market $t, x_{j, t}^{(k)}$ is the $k$ th attribute of product $j$ in market $t$ (e.g., mineral water), and $D_{i, t}^{(l)}$ is the $l$ th observed attribute of consumer $i$ in market $t$ (e.g., age). As shown in Train (2009, p. 63), these micro-moments are equivalent to the maximum likelihood firstorder conditions of the logit demand model. I refer to Appendix S3 of the Supplemental Material for further details about the moments and the estimation procedure.

For the second step, I use the estimated $\delta\left(\hat{\theta}_{2}^{d}\right)$ and I consider the following linear model: $\delta\left(\hat{\theta}_{2}^{d}\right)=\phi x_{\text {spark(j) }}+\psi x_{\text {mineral }(j)}-\alpha p_{j, t}+\beta_{0}+\beta_{t}+\beta_{b(j)}+\beta_{r(j)}+\xi_{j, t}$. The vector of mean taste parameters $\theta_{1}^{d}=\left(\beta^{\top}, \phi, \psi, \alpha\right)^{\top}$ is estimated using a two-stage least square estimator (TSLS) where instrumental variables are the number of products offered by rival retailers and the indicator variable for the formation of buyer alliances.

\footnotetext{
${ }^{36}$ This assumption would be violated if, for instance, every retailer involved in an alliance reorganizes its retail services (e.g., change in shelf display), thereby affecting consumer preferences for unobserved attributes in the post-alliances periods. Given that the focus of the alliances is on the negotiation of wholesale prices, I can reasonably assume that such a coordinated change in retail services is unlikely to occur.
} 


\subsection{Downstream competition and manufacturer-retailer bargaining}

Setup. I model the French bottled water industry as a bilateral oligopoly. In each market $t$, $F$ multi-product manufacturers deal with $R$ multi-product retailers to supply their products to consumers. Let $\mathscr{J}_{f, t}$ be the set of products owned by manufacturer $f$ and $\mathscr{J}_{r, t}$ the set of products distributed by retailer $r$ in market $t$ such that $\bigcup_{f=1}^{F} \mathscr{J}_{f, t}=\bigcup_{r=1}^{R} \mathscr{J}_{r, t}=\mathscr{J}_{t} \backslash\{0\}$. Define respectively the (per-market) profit function of manufacturer $f$ and retailer $r$ as follows:

$$
\begin{aligned}
\pi_{f, t} & \equiv \sum_{j \in \mathscr{I}_{f, t}}\left(w_{j, t}-\mu_{b(j), t}\right) M_{t} s_{j, t}\left(\mathbf{p}_{t}, \theta^{d}\right) \\
\pi_{r, t} & \equiv \sum_{j \in \mathscr{I}_{r, t}}\left(p_{j, t}-w_{j, t}-c_{j, t}\right) M_{t} s_{j, t}\left(\mathbf{p}_{t}, \boldsymbol{\theta}^{d}\right)
\end{aligned}
$$

where $w_{j, t}$ is the wholesale price of product $j$ in market $t, \mu_{b(j), t}$ and $c_{j, t}$ are respectively the constant marginal cost of production for brand $b(j)$ and the constant marginal cost of distribution for product $j$ in market $t,{ }^{37} M_{t}$ denotes the total quantity purchased on the market ("market size"), and $s_{j, t}$ is the predicted market share of product $j$ in market $t$ written as a function of retail prices - denoted by the $J_{t}$-dimensional vector $\mathbf{p}_{t}-$ and demand parameters $\theta^{d}$ only for the sake of clarity. ${ }^{38}$

Timing, information, and equilibrium concept. I consider a two-stage game in which firms interact as follows. In the first stage, manufacturers and retailers engage in simultaneous and secret bilateral negotiations over linear wholesale prices of products. In the second stage, retailers compete in retail prices with "interim unobservability" on the downstream market (Rey and Vergé, 2004, 2020). ${ }^{39}$

As outlined in Section 2 and following recent empirical works on bargaining with externalities (e.g., Crawford and Yurukoglu, 2012; Grennan, 2013; Gowrisankaran, Nevo and Town, 2015; Ho and Lee, 2017), I employ the "Nash-in-Nash" bargaining solution to determine the division of surplus between manufacturers and retailers. This bargaining protocol can be interpreted as a delegated agents model in which separate representatives are

\footnotetext{
${ }^{37}$ I make the simplifying assumption that marginal costs of production only vary across brands of bottled water to identify the price-cost margins of manufacturers in the post-alliances periods where manufacturers cannot price-discriminate between retailers of a buyer alliance (details are provided in Appendix E.2.2). A similar assumption is used in Villas-Boas (2009) who studies the effects of banning wholesale price discrimination. While this restriction is maintained in my notations, it has no implication for the identification of the price-cost margins of manufacturers in the pre-alliances periods.

${ }^{38}$ The market share $s_{j, t}$ is computed by aggregating consumer-level market shares in $(3): s_{j, t}=\frac{1}{N_{t}} \sum_{i=1}^{N_{t}} s_{i, j, t}$.

${ }^{39}$ This implies that the outcome of each retailer's negotiations remains secret to other retailers.
} 
(simultaneously) sent by firms to each bilateral negotiation to bargain over trading terms on their behalf. Given that each delegated agent participates in only one negotiation and cannot communicate with its counterparts (even those coming from the same firm), it is assumed that they hold "passive-beliefs" over deals reached elsewhere (McAfee and Schwartz, 1994). ${ }^{40}$ In a bilateral oligopoly framework, this bargaining model implies that firms behave schizophrenically, delegated negotiators have "passive-beliefs", and contracts are binding (see Rey and Vergé, 2020, for a microfoundation). ${ }^{41}$ Assuming complete information about the cost of production and distribution for each product offered, I solve this two-stage game proceeding backwards.

Remark on the contractual form. I consider negotiations over simple linear wholesale prices, which gives rise to the presence of double marginalization. To motivate this modeling assumption over more sophisticated contractual forms, I rely on Section 3.3 which provides descriptive evidence that the retail prices of national brands substantially declined following the year of the alliances. ${ }^{42}$ Under nonlinear tariffs (e.g., two-part tariffs), this variation can only be rationalized through cost savings caused by the alliances. ${ }^{43}$ Under linear tariffs, however, a change in the distribution of bargaining power that mitigates double marginalization can also explain this retail price drop. I argue that the cost savings argument is implausible for at least two reasons. First, as described in Section 3.1, the alliances only cover the wholesale price negotiations of national brands and do not have the purpose of restructuring the distribution system of retailers. Second, empirical studies on mergers have documented that cost savings are long-run consequences and take roughly two years after a merger to materialize (e.g., Focarelli and Panetta, 2003; Ashenfelter, Hosken and Weinberg, 2015), which is well beyond the time span covered by my data. Hence, assuming that there

\footnotetext{
${ }^{40} \mathrm{~A}$ bargainer is said to have "passive-beliefs" about outcomes of other negotiations when he holds the same beliefs in all circumstances (even in the event of disagreement).

${ }^{41}$ More precisely, Rey and Vergé (2020) show that the "Nash-in-Nash" bargaining solution with linear contracts replicates the equilibrium outcome of a noncooperative bargaining game with a random-proposer protocol, delegated agents, and "passive beliefs". Collard-Wexler, Gowrisankaran and Lee (2019) provide an alternative noncooperative foundation which relaxes restrictions imposed by delegation but assumes that wholesale tariffs do not affect the gains from trade in bilateral negotiations (e.g., lump-sum payments).

${ }^{42}$ Luco and Marshall (2020) rely on a similar approach to infer the contractual form used in vertical relations. Leveraging the variation created by vertical mergers, they find evidence in favor of a double marginalization in the soft drink industry, which typically arises under linear wholesale prices.

${ }^{43}$ This reasoning is based on Rey and Vergé (2020) who show in a framework similar to mine that equilibrium nonlinear tariffs are necessarily cost-based (i.e., the per-unit prices reflect marginal costs of production). This implies that retail prices simply replicate the outcome of a multi-product oligopoly and are never affected by the distribution of bargaining power in the vertical chain. In addition, Caprice and Rey (2015) show that the formation of a buyer alliance under two-part tariffs is either neutral or increases retail prices by solving the manufacturer's opportunism problem (e.g., McAfee and Schwartz, 1994). Hence, absent cost savings, theoretical predictions under nonlinear tariffs are in stark contrast with the variation observed in my data.
} 
is no unobserved demand or cost shocks unrelated to the formation the alliances which affect only national brands purchased by an alliance, linear wholesale prices are arguably more appropriate to explain the variation observed in the data than nonlinear tariffs that would give rise to cost-based marginal wholesale prices. ${ }^{44,45}$

\subsubsection{Stage 2: Downstream competition}

I assume that retail prices are determined in a pure-strategy Nash equilibrium where each retailer holds "passive beliefs" over the wholesale contracts formed by manufacturers and its downstream rivals. ${ }^{46}$ Using (5b), the maximization problem of retailer $r$ in market $t$ is given by $\max _{\left\{p_{j, t}\right\}_{j \in q_{r}, t}} \pi_{r, t}$, implying that the pricing behavior of retailers is characterized by the following system of first-order conditions:

$$
s_{k, t}\left(\mathbf{p}_{t} ; \theta^{d}\right)+\sum_{j \in \mathscr{F}_{r(k), t}}\left(p_{j, t}-w_{j, t}-c_{j, t}\right) \frac{\partial s_{j, t}}{\partial p_{k, t}}\left(\mathbf{p}_{t} ; \theta^{d}\right)=0 \quad \forall k \in \mathscr{J}_{t} \backslash\{0\}
$$

Based on (6), Berry and Haile (2014) show that identification of the price-cost margins and the marginal costs of retailers directly follows from identification of the demand model described in Section 4.1. ${ }^{47}$ Importantly, this places no restriction on the structure of retailers' marginal costs. By inverting (6), I show in Appendix E.1 that one can recover the $J_{t}$-dimensional vector of price-cost margins of retailers denoted by $\gamma_{t}$. The $j$ th element of $\gamma_{t}$ is given by:

$$
p_{j, t}-w_{j, t}-c_{j, t}=\gamma_{j, t}\left(\mathbf{S}_{\mathbf{p}_{t}}, s_{t}\right)
$$

\footnotetext{
${ }^{44}$ This finding contrasts with Bonnet and Dubois (2010) who provide empirical evidence in favor of twopart tariff contracts with resale price maintenance using a model in which manufacturers make public takeit-or-leave-it offers to retailers. It is worth noting, however, that their analysis of the French bottled water industry focuses on the years 1998 to 2000 where input price discrimination was banned and the Galland Act prevented retailers to resale below the per-unit invoice price set by manufacturers (but "off-invoice" rebates were allowed). Because these rules generated inflationary effects, the Galland Act has been repealed and input price discrimination allowed to reinvigorate retail competition, implying that the regulatory environment during the time period covered by my data radically differs from their analysis.

${ }^{45}$ Several rationale have been advanced for the use of simple linear wholesale prices in bilateral oligopolies. For instance, Crawford and Yurukoglu (2012) argue that committing to linear pricing avoids the dissipation of profits when retailers engage in a fierce downstream competition.

${ }^{46}$ Following Berry, Levinsohn and Pakes (1995) and related literature, I assume the existence of a Nash equilibrium in retail prices.

${ }^{47}$ Following Berry and Haile (2014), two conditions ensure invertibility of (6) and, in turn, identification of retailers' marginal costs: (i) the differentiability of market shares with respect to retail prices, and (ii) that some products are strict substitutes in retail prices while others are weak substitutes from one another. The discrete choice model described in Section 4.1 belongs to the class of demand models satisfying these conditions.
} 
where $\mathbf{S}_{\mathbf{p}_{t}}$ is the $J_{t} \times J_{t}$ matrix of first partial derivatives $\frac{\partial s_{k, t}}{\partial p_{j, t}}$ and $s_{t}$ is the $J_{t}$-dimensional vector of market shares. Using (7), the marginal cost of retailers for each product $j \in \mathscr{J}_{t} \backslash\{0\}$ is obtained as follows: $w_{j, t}+c_{j, t}=p_{j, t}-\gamma_{j, t}$. As shown in Section 4.2.4, it turns out that retailers' marginal costs are key ingredients to the identification of firms' bargaining power in the vertical chain.

\subsubsection{Stage 1: Manufacturer-retailer bargaining in the pre-alliances periods}

In the pre-alliances periods, each manufacturer bilaterally bargains with each retailer to determine wholesale prices of its products. The resolution of this stage can be described as follows.

Bargaining between manufacturer $f$ and retailer $r$ over $w_{j, t}$. Consider the bilateral negotiation between manufacturer $f$ and retailer $r$ over the wholesale price $w_{j, t}$, where $j \in$ $\mathscr{J}_{f, t} \cap \mathscr{J}_{r, t}$. Following previous assumptions, terms of trade are determined by the Nash bargaining solution taking as given outcomes of other negotiations and anticipating the impact on retailer $r$ 's pricing behavior in stage 2 . Hence, the equilibrium wholesale price $w_{j, t}^{*}$ solves the following Nash bargaining problem:

$$
w_{j, t}^{*} \equiv \underset{w_{j, t}}{\operatorname{argmax}}\left(\pi_{f, t}-d_{f, t}^{-j}\right)^{\lambda_{f, r}^{p r e}}\left(\pi_{r, t}-d_{r, t}^{-j}\right)^{1-\lambda_{f, r}^{p r e}}
$$

where $\lambda_{f, r}^{\text {pre }} \in[0,1]$ corresponds to the bargaining weight of manufacturer $f$ when negotiating with retailer $r$ in the pre-alliances periods, and $\pi_{f, t}$ and $\pi_{r, t}$ are the profit of firms defined in (5a) and (5b). The terms $d_{f, t}^{-j}$ and $d_{r, t}^{-j}$ denote respectively the status quo payoffs of manufacturer $f$ and retailer $r$ in the event of bilateral disagreement:

$$
\begin{aligned}
& d_{f, t}^{-j}=\sum_{k \in \mathscr{F}_{f, t} \backslash\{j\}}\left(w_{k, t}^{*}-\mu_{b(k), t}\right) M_{t} \tilde{s}_{k, t}^{-j}\left(\tilde{\mathbf{p}}_{t}^{-j} ; \theta^{d}\right) \\
& d_{r, t}^{-j}=\sum_{k \in \mathscr{I}_{r, t} \backslash\{j\}}\left(\tilde{p}_{k, t}^{-j}-w_{k, t}^{*}-c_{k, t}\right) M_{t} \tilde{s}_{k, t}^{-j}\left(\tilde{\mathbf{p}}_{t}^{-j} ; \theta^{d}\right)
\end{aligned}
$$

where $w_{k, t}^{*}$ is the (anticipated) equilibrium wholesale price of product $k \neq j, \tilde{\mathbf{p}}_{t}^{-j}$ is the $J_{t^{-}}$ dimensional vector of out-of-equilibrium retail prices when product $j$ is no longer offered 
on market $t:^{48}$

$$
\tilde{\mathbf{p}}_{t}^{-j}[k, 1]= \begin{cases}\infty & \text { if } k=j \\ \tilde{p}_{k, t}^{-j} & \text { if } j \neq k \text { and } j, k \in \mathscr{J}_{r, t} \\ p_{k, t} & \text { otherwise }\end{cases}
$$

and $\tilde{s}_{k, t}^{-j}$ is the market share of each product $k$ remaining on the market:

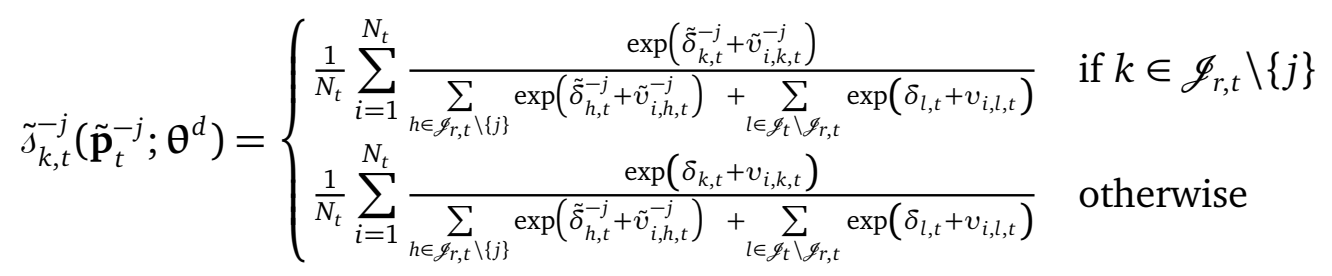

where $v_{i, k, t} \equiv \psi_{g\left(\text { age }_{i}\right)} x_{\text {mineral }(k)}-\alpha_{g\left(y_{i}\right)} p_{k, t}, \tilde{v}_{i, k, t}^{-j} \equiv \psi_{g\left(\text { age }_{i}\right)} x_{\text {mineral }(k)}-\alpha_{g\left(y_{i}\right)} \tilde{p}_{k, t}^{-j}$, and $\tilde{\delta}_{k, t}^{-j} \equiv$ $\phi x_{\text {spark }(k)}+\psi x_{\text {mineral }(k)}-\alpha \tilde{p}_{k, t}^{-j}+\beta_{0}+\beta_{t}+\beta_{b(k)}+\beta_{r(k)}+\xi_{k, t}$. From (8), I can derive the set of first-order conditions characterizing the surplus division in each bilateral negotiation in market $t$ :

$$
\underbrace{\left(1-\lambda_{f(j), r(j)}^{\text {pre }}\right)\left(\pi_{f(j), t}-d_{f(j), t}^{-j}\right) \frac{\partial \pi_{r(j), t}}{\partial w_{j, t}}}_{\text {retailer } r(j) \text { 's bargaining power }}+\underbrace{\lambda_{f(j), r(j)}^{\text {pre }}\left(\pi_{r(j), t}-d_{r(j), t}^{-j}\right) \frac{\partial \pi_{f(j), t}}{\partial w_{j, t}}}_{\text {manufacturer } f(j) \text { 's bargaining power }}=0 \quad \forall j \in \mathscr{J}_{t} \backslash\{0\}
$$

where $f(j)$ indexes the manufacturer of product $j$. As discussed in Section 2, (9) shows that the bargaining power of a firm involved in a bilateral negotiation depends on three different factors (see also Appendix S1 of the Supplemental Material). The first corresponds to the firm's bargaining ability which is captured by the bargaining weight $\lambda_{f(j), r(j)}^{\text {pre }}$. The second is the (incremental) gains from trade obtained by its trading partner, which derive from the difference between the trading partner's profits when all agreements are formed and its status quo payoffs. The third factor is the cost bear from making price concessions, which is captured by the derivative of the firm's profits with respect to the wholesale price.

By inverting the system (9) in a similar vein as for the inversion of (6) to recover the price-cost margins of retailers, I can obtain a closed-form expression for the $J_{t}$-dimensional vector of manufacturers' price-cost margins in the pre-alliances periods, denoted by $\boldsymbol{\Gamma}_{t}^{\text {pre }}$ (all computations follow Bonnet, Bouamra-Mechemache and Molina (2018) and are described

\footnotetext{
${ }^{48}$ Following the "interim unobservability" assumption, only retailer $r$ is able to observe this bargaining breakdown and react accordingly in stage 2. Computational details about these counterfactual out-ofequilibrium retail prices are given in Appendix G.1.
} 
in Appendix E.2.1). The $j$ th element of $\Gamma_{t}^{\text {pre }}$ is given by:

$$
w_{j, t}-\mu_{b(j), t}=\Gamma_{j, t}^{p r e}\left(s_{t}, \mathbf{S}_{\mathbf{p}_{t}}, \mathbf{S}_{\mathbf{p}_{t} \mathbf{p}_{t}}, \tilde{\mathbf{S}}_{\Delta t}^{p r e} ; \lambda^{p r e}\right)
$$

where $\lambda^{\text {pre }}$ is a $J_{t}$-dimensional vector of manufacturers' bargaining weight with $\lambda^{\text {pre }}[j, 1]=$ $\lambda_{f(j), r(j)}^{\text {pre }}, \mathbf{S}_{\mathbf{p}_{t} \mathbf{p}_{t}}$ is an array of $J_{t}$ matrices of second partial derivatives $\frac{\partial^{2} s_{j, t}}{\partial p_{k, t} \partial p_{l, t}}$ denoted by $\mathbf{S}_{\mathbf{p}_{k, t} \mathbf{p}_{t}}$ (each matrix $\mathbf{S}_{\mathbf{p}_{k, t} \mathbf{p}_{t}}$ being of $J_{t} \times J_{t}$ dimension), and $\tilde{\mathbf{S}}_{\Delta t}^{\text {pre }}$ is a $J_{t} \times J_{t}$ matrix of difference in market shares $s_{k, t}\left(\mathbf{p}_{t} ; \theta^{d}\right)-\tilde{s}_{k, t}^{-j}\left(\tilde{\mathbf{p}}_{t}^{-j} ; \theta^{d}\right)$.

\subsubsection{Stage 1: Manufacturer-retailer bargaining in the post-alliances periods}

In the post-alliances periods, each manufacturer engages in bilateral negotiations with alliances of retailers to determine wholesale prices of its products. Before considering the resolution of this bargaining stage, I introduce the following notations. Let $a(j)$ denote the alliance of retailers purchasing product $j,{ }^{49} \mathscr{J}_{a, t}$ is the set of products purchased by the alliance $a$, and $\mathscr{J}_{b, t}$ is the set of products sold under the brand $b$. In line with Section 2, I consider that a buyer alliance negotiates on behalf of its members and aims at maximizing their joint profits. Furthermore, retailers involved in the alliance $a$ obtain nondiscriminatory trading terms when purchasing brand $b$ : e.g., $w_{j, t}=w_{k, t}=w_{a, b, t} \forall j, k \in \mathscr{J}_{a, t} \cap \mathscr{J}_{b, t} .{ }^{50}$

Bargaining between manufacturer $f$ and the buyer alliance a over $w_{j, t}$. Consider the bilateral negotiation between manufacturer $f$ (offering brand $b$ ) and the alliance $a$ over the wholesale price of product $j \in \mathscr{J}_{a, t} \cap \mathscr{J}_{b, t}$ : i.e., $w_{j, t}=w_{a, b, t}$. Taking as given outcomes of other negotiations and anticipating the impact on the pricing behavior of every retailer involved in the alliance $a$ in stage 2 , the equilibrium wholesale price $w_{a, b, t}^{*}$ solves the following Nash bargaining problem:

$$
w_{a, b, t}^{*} \equiv \underset{w_{a, b, t}}{\operatorname{argmax}}\left(\pi_{f, t}-d_{f, t}^{-a, b}\right)^{\lambda_{f, a}^{\text {post }}}\left(\pi_{a, t}-d_{a, t}^{-a, b}\right)^{1-\lambda_{f, a}^{\text {post }}}
$$

where $\lambda_{f, a}^{\text {post }} \in[0,1]$ denotes the bargaining weight of manufacturer $f$ when negotiating with the alliance $a$ in the post-alliances periods, and $\pi_{f, t}$ and $\pi_{a, t}$ are respectively the profit

\footnotetext{
${ }^{49}$ If retailer $r(j)$ has not formed any alliance with another retailer, I consider that $a(j)=r(j)$.

${ }^{50}$ To clarify notations, note that $w_{a(k), b(k), t} \neq w_{a, b, t}$ if product $k \notin \mathscr{J}_{a, t} \cap \mathscr{J}_{b, t}$. Indeed, $w_{a(k), b(k), t}$ denotes the wholesale price paid by the alliance $a(k)$ (possibly different from the alliance $a$ ) for a product sold under the brand $b(k)$ (possibly different from brand $b$ ).
} 
of manufacturer $f$ and the alliance $a$ when all agreements are formed:

$$
\begin{aligned}
& \pi_{f, t}=\sum_{h \in \mathscr{q}_{a, t} \cap \mathscr{F}_{b, t}}\left(w_{a, b, t}-\mu_{b, t}\right) M_{t} s_{h, t}\left(\mathbf{p}_{t} ; \theta^{d}\right)+\sum_{k \in \mathscr{F}_{f, t} \backslash\left\{\mathscr{F}_{a, t} \cap \mathscr{F}_{b, t}\right\}}\left(w_{a(k), b(k), t}^{*}-\mu_{b(k), t}\right) M_{t} s_{k, t}\left(\mathbf{p}_{t} ; \theta^{d}\right) \\
& \pi_{a, t}=\sum_{h \in \mathscr{I}_{a, t} \cap \mathscr{l}_{b, t}}\left(p_{h, t}-w_{a, b, t}-c_{h, t}\right) M_{t} s_{h, t}\left(\mathbf{p}_{t} ; \boldsymbol{\theta}^{d}\right)+\sum_{k \in \mathscr{I}_{a, t} \backslash \mathscr{g}_{b, t}}\left(p_{k, t}-w_{a, b(k), t}^{*}-c_{k, t}\right) M_{t} s_{k, t}\left(\mathbf{p}_{t} ; \boldsymbol{\theta}^{d}\right)
\end{aligned}
$$

where $w_{a(k), b(k), t}^{*}$ corresponds to the (anticipated) equilibrium wholesale price for brand $b(k)$ paid by the alliance $a(k)$. The terms $d_{f, t}^{-a, b}$ and $d_{a, t}^{-a, b}$ represent respectively the status quo payoffs of manufacturer $f$ and the alliance $a$ in the event of bilateral disagreement:

$$
\begin{aligned}
& d_{f, t}^{-a, b}=\sum_{k \in \mathscr{F}_{f, t} \backslash\left\{\mathscr{F}_{a, t} \cap \mathscr{F}_{b, t}\right\}}\left(w_{a(k), b(k), t}^{*}-\mu_{b(k), t}\right) M_{t} \tilde{s}_{k, t}^{-a, b}\left(\tilde{\mathbf{p}}_{t}^{-a, b} ; \theta^{d}\right) \\
& d_{a, t}^{-a, b}=\sum_{k \in \mathscr{J}_{a, t} \backslash \mathscr{\not}_{b, t}}\left(\tilde{p}_{k, t}^{-a, b}-w_{a, b(k), t}^{*}-c_{k, t}\right) M_{t} \tilde{\tilde{s}}_{k, t}^{-a, b}\left(\tilde{\mathbf{p}}_{t}^{-a, b} ; \theta^{d}\right)
\end{aligned}
$$

where $\tilde{\mathbf{p}}_{t}^{-a, b}$ denotes the $J_{t}$-dimensional vector of out-of-equilibrium retail prices when products purchased by the alliance $a$ and sold under the brand $b$ are no longer offered on the market: ${ }^{51}$

$$
\tilde{\mathbf{p}}_{t}^{-a, b}[k, 1]= \begin{cases}\infty & \text { if } k \in \mathscr{J}_{a, t} \cap \mathscr{J}_{b, t} \\ \tilde{p}_{k, t}^{-a, b} & \text { if } k \in \mathscr{J}_{a, t} \backslash \mathscr{J}_{b, t} \\ p_{k, t} & \text { otherwise }\end{cases}
$$

and $\tilde{s}_{k, t}^{-a, b}$ is the market share of each product $k$ remaining on the market:

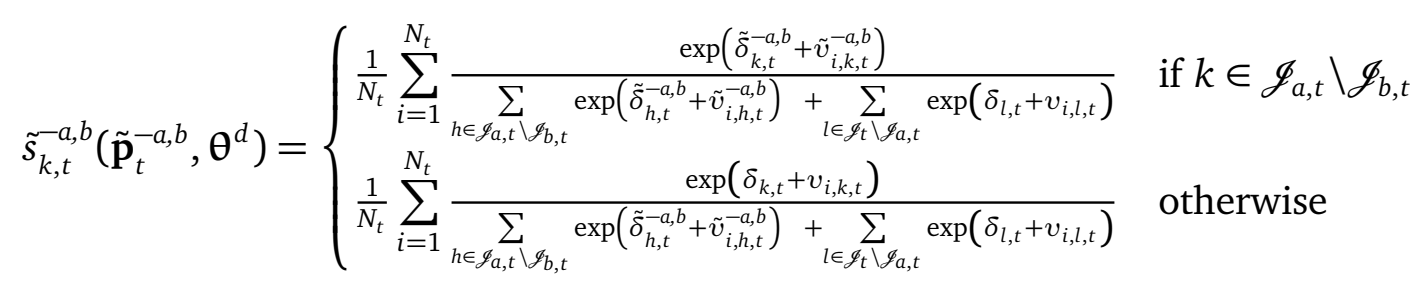

where $\tilde{v}_{i, k, t}^{-a, b} \equiv \psi_{g\left(a g e_{i}\right)} x_{\text {mineral }(k)}-\alpha_{g\left(y_{i}\right)} \tilde{p}_{k, t}^{-a, b}$ and $\tilde{\delta}_{k, t}^{-a, b} \equiv \phi x_{\text {spark }(k)}+\psi x_{\text {mineral }(k)}-\alpha \tilde{p}_{k, t}^{-a, b}+\beta_{0}+$ $\beta_{t}+\beta_{b(k)}+\beta_{r(k)}+\xi_{k, t}$. From (11), I can derive the set of first-order conditions characterizing the surplus division of each bilateral negotiation in market $t$ as follows:

$$
\left(1-\lambda_{f(j), a(j)}^{\text {post }}\right)\left(\pi_{f(j), t}-d_{f(j), t}^{-a(j), b(j)}\right) \frac{\partial \pi_{a(j), t}}{\partial w_{a(j), b(j), t}}+\lambda_{f(j), a(j)}^{\text {post }}\left(\pi_{a(j), t}-d_{a(j), t}^{-a(j), b(j)}\right) \frac{\partial \pi_{f(j), t}}{\partial w_{a(j), b(j), t}}=0
$$

\footnotetext{
${ }^{51}$ The joint delisting decision of the alliance $a$ implies that, in case of a bargaining breakdown, brand $b$ is not distributed by any of its retailers (thereby affecting their pricing behaviors in stage 2). Computational details about these out-of-equilibrium retail prices are given in Appendix G.2.
} 


$$
\forall j \in \mathscr{J}_{t} \backslash\{0\}
$$

By inverting this system of equations, I show in Appendix E.2.2 that one can obtain a closedform expression for the $J_{t}$-dimensional vector of manufacturers' price-cost margins in the post-alliances periods, denoted by $\boldsymbol{\Gamma}_{t}^{\text {post }}$. The $j$ th element of $\boldsymbol{\Gamma}_{t}^{\text {post }}$ is given by:

$$
w_{a(j), b(j), t}-\mu_{b(j), t}=\Gamma_{a(j), b(j), t}^{p o s t}\left(s_{t}, \mathbf{S}_{\mathbf{p}_{t}}, \mathbf{S}_{\mathbf{p}_{t} \mathbf{p}_{t}}, \tilde{\mathbf{S}}_{\Delta t}^{\text {post }} ; \lambda^{\text {post }}\right)
$$

where $\lambda^{\text {post }}$ is a $J_{t}$-dimensional vector of manufacturers' bargaining weight with $\lambda^{\text {post }}[j, 1]=$ $\lambda_{f(j), a(j)}^{\text {post }}$ and $\tilde{\mathbf{S}}_{\Delta t}^{\text {post }}$ is a $J_{t} \times J_{t}$ matrix of difference in market shares $s_{k, t}\left(\mathbf{p}_{t} ; \boldsymbol{\theta}^{d}\right)-\tilde{y}_{k, t}^{-a, b}\left(\tilde{\mathbf{p}}_{t}^{-a, b} ; \boldsymbol{\theta}^{d}\right)$.

In contrast to the price-cost margins of retailers which derive directly from estimates of demand parameters $\theta^{d}$ and the set of equations (6) characterizing necessary conditions for retailers' profit maximization, (10) and (12) show that the price-cost margins of manufacturers are identified up to two vectors of unknown parameters: $\lambda^{\text {pre }}$ and $\lambda^{\text {post }}$. In what follows, I describe my empirical strategy to estimate these parameters which allow to recover the price-cost margins of manufacturers and the division of surplus in the vertical chain before and after the formation of buyer alliances.

\subsubsection{Identification and estimation of bargaining stage}

To estimate $\lambda^{\text {pre }}$ and $\lambda^{\text {post }}$, I rely on an empirical approach that exploits the variation in marginal costs of retailers across products and markets. Given that wholesale prices and distribution costs enter additively into the marginal costs of retailers, I make use of the following decomposition:

$$
w_{j, t}+c_{j, t}=\underbrace{\left(w_{j, t}-\mu_{b(j), t}\right)}_{\text {upstream market power }}+\underbrace{\left(\mu_{b(j), t}+c_{j, t}\right)}_{\text {operational costs }} \forall j, t
$$

where the heterogeneity in marginal costs of retailers is explained by differences in costs of production and distribution $\left(\mu_{b(j), t}+c_{j, t}\right)$ and asymmetries in the ability of manufacturers to exert market power towards retailers $\left(w_{j, t}-\mu_{b(j), t}\right)$. Without further assumptions, these two components are not separately identified as there are $\sum_{t=1}^{T} J_{t}$ equations and $2 \sum_{t=1}^{T} J_{t}$ unknowns. I thus replace the upstream market power term by the closed-form expressions in (10) and (12) derived from the "Nash-in-Nash" bargaining solution before and after the formation of buyer alliances. Without additional information on the marginal costs of products, I impose restrictions on their structure as follows. In line with Gowrisankaran, Nevo and 
Town (2015), I assume that the constant marginal cost of production and distribution for product $j$ in market $t$ is given by:

$$
\mu_{b(j), t}+c_{j, t}=\kappa_{s} x_{s p a r k(j)}+\kappa_{m} x_{\text {mineral }(j)}+\kappa_{0}+\kappa_{t}+\kappa_{b(j)}+\omega_{j, t}
$$

where $\kappa_{0}$ denotes a constant term, $\kappa_{t}$ and $\kappa_{b(j)}$ are respectively market and brand fixed effects, and $\omega_{j, t}$ corresponds to an additive error term of unobserved cost factors (e.g., unobserved productivity). ${ }^{52}$ This yields the following marginal cost function of retailers for product $j$ in market $t$ :

$$
\begin{aligned}
w_{j, t}+c_{j, t}= & \left.\Gamma_{j, t}^{\text {pre }}(\lrcorner_{t}, \mathbf{S}_{\mathbf{p}_{t}}, \mathbf{S}_{\mathbf{p}_{t} \mathbf{p}_{t}}, \tilde{\mathbf{S}}_{\Delta t}^{\text {pre }} ; \lambda^{\text {pre }}\right) \times \mathbb{1}\{\text { pre-alliances }\}_{t} \\
& \left.+\Gamma_{a(j), b(j), t}^{\text {post }}(\lrcorner_{t}, \mathbf{S}_{\mathbf{p}_{t}}, \mathbf{S}_{\mathbf{p}_{t} \mathbf{p}_{t}}, \tilde{\mathbf{S}}_{\Delta t}^{\text {post }} ; \lambda^{\text {post }}\right) \times \mathbb{1}\{\text { post-alliances }\}_{t} \\
& +\kappa_{s} x_{\text {spark }(j)}+\kappa_{m} x_{\text {mineral }(j)}+\kappa_{0}+\kappa_{t}+\kappa_{b(j)}+\omega_{j, t}
\end{aligned}
$$

where supply parameters to be estimated are the vectors of bargaining weights $\lambda^{\text {pre }}$ and $\lambda^{\text {post }}$ and the vector of cost parameters $\kappa$. Note that retailer fixed effects are not included into (13) for reasons similar to Gowrisankaran, Nevo and Town (2015). It is indeed empirically difficult to identify firm-specific fixed effects and bargaining weights at the same level (e.g., retailer-specific bargaining weights and retailer fixed effects for marginal costs). Hence, after controlling for differences in the marginal cost of products across brands, markets, and type (mineral, sparkling), the remaining variation in $w_{j, t}+c_{j, t}$ is assumed to be explained by differences in bargaining power. However, the presence of $\omega_{j, t}$ allows to have a flexible specification for the marginal cost of products because the variation in $w_{j, t}+c_{j, t}$ that is left unexplained is attributed to unobserved cost factors. ${ }^{53}$

Identification assumptions. The main threat to identification of supply parameters comes from the potential endogeneity of market shares that enter nonlinearly into (14) through the price-cost margins of manufacturers. Indeed, whenever manufacturers and retailers observe marginal cost shocks before setting wholesale and retail prices, market shares are likely to be correlated with $\omega_{j, t}$. Market shares also depend on the unobserved quality $\xi_{j, t}$ which is likely to be correlated with unobserved cost factors in $\omega_{j, t}$. To address this concern, I adopt an instrumental variable approach which relies on two types of instruments that affect the

\footnotetext{
${ }^{52}$ This constant marginal cost specification is common in empirical work on food industries (see, e.g., VillasBoas, 2007; Miller and Weinberg, 2017; Michel and Weiergraeber, 2018).

${ }^{53}$ This relates to the cost specification in Gowrisankaran, Nevo and Town (2015). An alternative approach would be to specify the marginal costs of products in terms of data and parameters only, allowing the bargaining weights to depend on unobservables as in Grennan (2013).
} 
price-cost margins of manufacturers but not marginal costs of products.

A first identification strategy is to exploit the amount of competition that each product faces in characteristics space, which should explain differences in market shares across products and help identifying the bargaining weights of firms. ${ }^{54}$ Intuitively, after controlling for differences in the marginal costs of production and distribution, products that face little competition should have systematically higher wholesale prices (and hence higher retail marginal cost) if manufacturers are able to exert market power toward retailers (bargaining weights are close to 1). However, if the location of products in characteristics space does not explain differences in the marginal costs of retailers, this may reveal that they are able to mitigate the market power of manufacturers such that wholesale prices only reflect production costs (bargaining weights are close to 0 ). In practice, I use as an instrument the number of products belonging to the same type of water (e.g., mineral and sparkling) and sold by rival retailers. Validity of this instrument hinges on the common assumption that observed product characteristics are exogenous (e.g., Berry, Levinsohn and Pakes, 1995). Because the effect of this variable need not be uniform across products, I incorporate interactions with a fixed effect for retailers 1,3 , and 5 (large retailers), a fixed effect for retailers 2 , 4, and 6 (small retailers), and a fixed effect for retailers 7 and 8.

The second identification strategy is in line with assumptions used to identify consumer preferences for bottled water. I interpret the formation of buyer alliances as an exogenous shifter of the bargaining environment which directly affects the price-cost margins of manufacturers. Based on Kalai (1977), the variation provided by the alliances should be particularly helpful to identify changes in firms' relative bargaining abilities $\left(\lambda^{\text {post }}\right) .{ }^{55}$ The intuition is as follows. After controlling for common changes in the marginal costs of production and distribution before versus after the alliances, the remaining difference in the changes of $w_{j, t}+c_{j, t}$ between national brands purchased by an alliance and other products should indicate a shift in the bargaining weight of retailers involved in an alliance. In practice, I use the buyer alliances indicator variable $\left(\mathbb{1}\{\text { national brand }\}_{j, t} \times \mathbb{1} \text { \{inside alliances }\right\}_{j, t} \times$ $\mathbb{1}$ \{post-alliances $\}_{t}$ ) as well as the indicator variable for national brands remaining outside

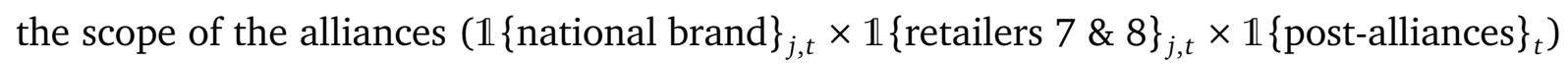
as instruments. Given the marginal cost specification (13), validity of these instruments hinges on two fundamental assumptions. First, I assume that changes in the unobserved

\footnotetext{
${ }^{54}$ This strategy builds on the Differentiation IVs developed by Gandhi and Houde (2020) to estimate consumer demand in differentiated products markets. See Michel and Weiergraeber (2018) for a related use of such instruments to analyze firms' conduct in oligopolistic industries.

${ }^{55}$ In a similar spirit, Miller and Weinberg (2017) use the MillerCoors joint venture as an exogenous shifter of the competitive environment to identify changes in firms' conduct after the joint venture.
} 
cost factors of national brands purchased by an alliance, before versus after the formation of the alliances, are not systematically different from changes in the unobserved cost factors of other products. ${ }^{56}$ Second, absent retailer fixed effects into (13), I assume that the unobserved cost factors of retailers involved in alliance are not systematically different from the unobserved cost factors of retailers 7 and $8 .{ }^{57}$ To add flexibility, I interact the buyer alliances indicator variable with a fixed effect for each alliance. I also interact the indicator variable for national brands remaining outside the scope of the alliances with fixed effects for retailer 7 and retailer 8 .

As the order condition requires at least one instrument for each bargaining weight to be estimated (whose number grows with the number of manufacturer-retailer pairs) I impose the following parameter restrictions. ${ }^{58}$ I consider that the bargaining weights of manufacturers when dealing with retailers 7 and 8 are identical and do not vary over time. For retailers involved in an alliance, I allow the bargaining weights to differ before and after the alliances. In the pre-alliances periods, I use a size-based restriction by considering that manufacturers have identical bargaining weights when negotiating with large retailers (retailers 1,3 , and 5) and with small retailers (retailers 2, 4, and 6) according to Table 1 . In the post-alliances periods, the bargaining weights are assumed to be alliance-specific (i.e., manufacturers have identical bargaining weights with respect to each buyer alliance).

Estimation procedure. Supply parameters $\lambda^{\text {pre }}, \lambda^{\text {post }}$, and $\kappa$ in (14) are estimated by continuous updating GMM (Hansen, Heaton and Yaron, 1996). As for the demand estimation procedure, I concentrate the cost parameters $\kappa$ out of the GMM objective function and search nonlinearly over the vector of bargaining weights $\lambda \equiv\left(\begin{array}{c}\lambda^{\text {pre }} \\ \lambda^{\text {post }}\end{array}\right)$. Formally, the resulting estimator is given by:

$$
\hat{\lambda} \equiv \underset{\lambda}{\operatorname{argmin}}\left(\mathbf{Z}^{s} \omega(\lambda, \kappa(\lambda))\right)^{\top} \mathbf{A}^{-1} \mathbf{Z}^{s} \omega(\lambda, \kappa(\lambda))
$$

\footnotetext{
${ }^{56}$ This assumption would be violated if, for instance, the alliances have generated cost efficiencies. For reasons stated at the beginning of Section 4.2 (see the remark on the contractual form) I argue that such efficiencies are unlikely to arise.

${ }^{57}$ This assumption would be violated if, for instance, the distribution system of every retailer involved in an alliance is systematically more (or less) efficient than that of retailers 7 and 8 .

${ }^{58}$ I have 21 manufacturer-retailer pairs in the pre-alliances periods and 15 manufacturer-alliance pairs in the post-alliances periods, resulting in a total of 36 bargaining weights. As it is hard to find enough instruments to identify each bargaining weight in practice, I follow prior empirical work by imposing restrictions to reduce the number of weights to be estimated (see also Gowrisankaran, Nevo and Town, 2015; Ho and Lee, 2017; Crawford et al., 2018).
} 
Table 2: Estimates of consumer demand

(a) Preference heterogeneity

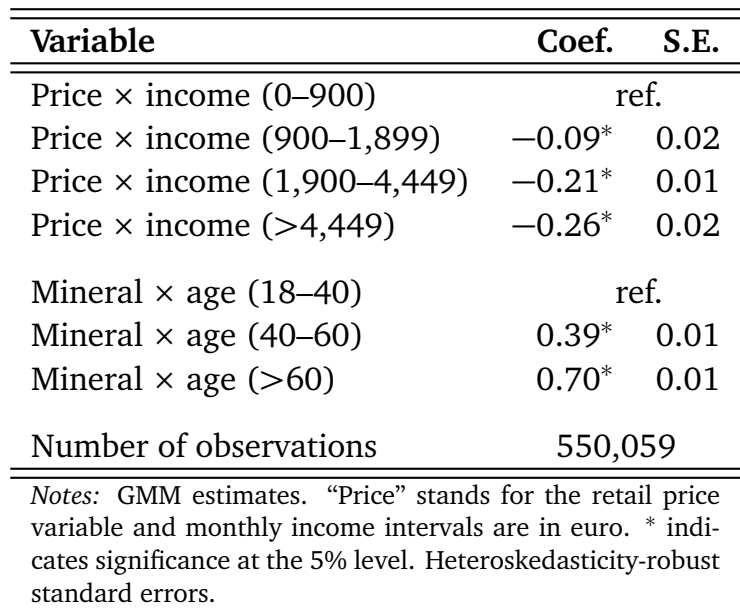

(b) Mean preferences

\begin{tabular}{|c|c|c|c|c|}
\hline \multirow[b]{2}{*}{ Variable } & \multicolumn{2}{|c|}{ OLS } & \multicolumn{2}{|c|}{ TSLS } \\
\hline & Coef. & S.E. & Coef. & S.E. \\
\hline Price & $3.74^{*}$ & 0.41 & $15.37^{*}$ & 3.12 \\
\hline Mineral & -0.09 & 0.10 & $0.64^{*}$ & 0.23 \\
\hline Sparkling & $-0.83^{*}$ & 0.10 & -0.23 & 0.20 \\
\hline Constant & $-4.24^{*}$ & 0.18 & $-2.48^{*}$ & 0.50 \\
\hline \multicolumn{5}{|c|}{ Brand fixed effects: } \\
\hline Brand 1 & $2.08^{*}$ & 0.16 & $6.47^{*}$ & 1.18 \\
\hline Brand 2 & $-0.63^{*}$ & 0.11 & 0.15 & 0.23 \\
\hline Brand 3 & $0.32^{*}$ & 0.12 & $3.12^{*}$ & 0.76 \\
\hline Brand 4 & $-0.49 *$ & 0.09 & -0.16 & 0.14 \\
\hline Brand 5 & $0.84^{*}$ & 0.16 & $5.17^{*}$ & 1.16 \\
\hline Brand 6 & $-0.15^{*}$ & 0.10 & $1.34^{*}$ & 0.41 \\
\hline Brand 7 & $-0.70^{*}$ & 0.09 & -0.11 & 0.19 \\
\hline Brand 8 & $0.43^{*}$ & 0.08 & $1.17^{*}$ & 0.21 \\
\hline Brand 9 & $1.25^{*}$ & 0.15 & $5.22^{*}$ & 1.07 \\
\hline Brand 10 & 0.01 & 0.12 & $-0.89^{*}$ & 0.27 \\
\hline Brand 11 & $-1.41^{*}$ & 0.09 & $-1.26^{*}$ & 0.11 \\
\hline Private label & \multicolumn{2}{|c|}{ ref. } & \multicolumn{2}{|c|}{ ref. } \\
\hline \multicolumn{5}{|c|}{ Retailer fixed effects: } \\
\hline Retailer 1 & $1.74^{*}$ & 0.16 & $2.39^{*}$ & 0.22 \\
\hline Retailer 2 & -0.25 & 0.16 & $0.55^{*}$ & 0.26 \\
\hline Retailer 3 & $1.15^{*}$ & 0.16 & $1.96^{*}$ & 0.25 \\
\hline Retailer 4 & $0.73^{*}$ & 0.16 & $1.38^{*}$ & 0.22 \\
\hline Retailer 5 & $1.25^{*}$ & 0.16 & $1.89^{*}$ & 0.21 \\
\hline Retailer 6 & $0.69^{*}$ & 0.16 & $1.51^{*}$ & 0.25 \\
\hline Retailer 7 & $1.68^{*}$ & 0.16 & $2.23^{*}$ & 0.19 \\
\hline Retailer 8 & \multicolumn{2}{|c|}{ ref. } & \multicolumn{2}{|c|}{ ref. } \\
\hline
\end{tabular}

Market fixed effects (not shown)

\begin{tabular}{l}
$F_{\text {eff }}$ \\
Number of observations \\
\hline \hline Notes: "Price" stands for the retail price variable. \\
Heteroskedasticity-robust standard errors. ${ }^{*}$ indicates sig- \\
nificance at the $5 \%$ level. $F_{\text {eff }}$ shows the robust F-stat of \\
Montiel Olea and Pflueger $(2013)$ for the TSLS estimates.
\end{tabular}

where $\boldsymbol{\omega}(\lambda, \boldsymbol{\kappa}(\lambda))$ is the $\sum_{t} J_{t}$-dimensional vector of unobserved cost factors, $\mathbf{Z}^{s}$ is a $K \times \sum_{t} J_{t}$ matrix of instrumental variables (with $K=8$ ), and $\mathbf{A}$ is a $K \times K$ weighting matrix. ${ }^{59}$

\subsection{Estimation results}

\subsubsection{Consumer demand estimates}

Table 2 presents the coefficient estimates and standard errors from the demand model described in Section 4.1. Estimates of the mean taste parameters are reported in Table 2b. Consistent with Berry (1994) and related literature, the OLS underestimate the retail price

\footnotetext{
${ }^{59}$ I use an exponential transformation to bound each bargaining weight between 0 and $1: \lambda=\frac{\exp \left(\lambda_{e}\right)}{1+\exp \left(\lambda_{e}\right)}$ where the search is over $\lambda_{e}$.
} 
Table 3: Estimates of own-price elasticitiy of demand

\begin{tabular}{lc}
\hline \hline Types of water & Value \\
\hline Still spring water & -2.24 \\
Sparkling spring water & -3.73 \\
Still mineral water & -5.34 \\
Sparkling mineral water & -7.72 \\
Total & -4.66 \\
\hline \hline Notes: Average own-price & elasticity \\
of products calculated using & quantity \\
weights. &
\end{tabular}

sensitivity compared to the TSLS. I thus focus on the TSLS estimates for the remainder of the article. The robust F-stat of Montiel Olea and Pflueger (2013) is well above the critical value of 6.36, indicating that instruments are not weakly correlated with the endogenous retail price variable (further details are provided in Table 11 of Appendix C). Most of the parameters are precisely estimated and have the expected sign. In line with Bonnet and Dubois (2015), I find that households have a positive mean valuation for mineral water. Brand fixed effects also show that there is an important heterogeneity in the mean valuation across brands of bottled water. Table 2a presents estimates of demand parameters capturing the heterogeneity in consumer preferences. While richer households are less price-sensitive than poorer households, I find that this difference is rather small. In contrast, there is a substantial heterogeneity in the valuation of mineral water where older households have a much higher valuation for mineral water than younger households.

Table 3 reports the estimated own-price elasticity of demand for each type of water. On average, the own-price elasticity equals -4.66 . This is consistent with Bonnet and Dubois (2015) who estimate demand for bottled water in France for the year 2006 and Zhang (2018) who analyzes the U.S. bottled water industry between 2006 and 2009. Furthermore, there is an important variation across types of bottled water. Indeed, the own-price elasticity of demand for mineral water is twice higher than that of spring water, which is also consistent with Bonnet and Dubois (2015). To a lesser extent, this difference is also present between still water and sparkling water products (Figure 7 in Appendix C reports the estimated density of the own-price elasticity of demand).

\subsubsection{Downstream competition and bargaining estimates}

Table 4 presents estimates of the marginal cost function of retailers described in (14). Cost parameters are precisely estimated and have the expected sign (e.g., both mineral and sparkling fixed effects contribute positively to marginal costs of products). In the prealliances periods, the estimated bargaining weights of manufacturers relative to retailers 
Table 4: Bargaining and marginal cost parameter estimates

\begin{tabular}{lcc}
\hline \hline Variable & Coefficient & S.E. \\
\hline Cost parameters: & 0.14 & 0.01 \\
Constant & 0.07 & 0.01 \\
Mineral & 0.05 & 0.01 \\
Sparkling & & \\
Brand fixed effects (not shown) & & \\
Market fixed effects (not shown) & & \\
& & 0.07 \\
Bargaining weights (pre-alliances): & 0.54 & 0.07 \\
Large retailers (retailers 1, 3, 5) & 0.73 & \\
Small retailers (retailers 2, 4, 6) & & 0.07 \\
Bargaining weights (post-alliances): & & 0.15 \\
Buyer alliance 1 (retailers 1, 2) & 0.37 & 0.06 \\
Buyer alliance 2 (retailers 3, 4) & 0.25 & 0.06 \\
Buyer alliance 3 (retailers 5, 6) & 0.00 & 0.01 \\
Retailers 7, 8 & & \\
& \multicolumn{2}{c}{2,192} \\
Number of observations & \\
\hline \hline Notes: Continuously updated GMM estimates. Heteroskedasticity- \\
robust standard errors. Each bargaining weight is bounded between \\
0 and 1 using an exponential transformation and standard errors are \\
from the delta method.
\end{tabular}

involved in an alliance are above 0.50. Moreover, manufacturers have a greater weight vis-à-vis small retailers. This result is in line with bargaining estimates of Crawford and Yurukoglu (2012) who find that small cable operators and satellite providers have lower bargaining weights than large cable operators in the multichannel television industry. In the post-alliances periods, estimates indicate that the bargaining weights of manufacturers vis-à-vis retailers involved in an alliance have been reduced. As described in Section 2, this is consistent with Kalai's (1977) theory according to which a coalition of bargainers should be treated more favorably by the Nash solution through asymmetric weights. Interestingly, this finding can also be related to Lewis and Pflum (2015) who provide evidence that hospital systems have higher bargaining weights vis-à-vis insurers than individual hospitals. Regarding the bargaining weight of manufacturers vis-à-vis retailers 7 and 8, I find an estimated value of roughly zero which suggests that they make take-it-or-leave-it offers to manufacturers. While the analysis of alliance formation is inherently complex and is left for future work, these bargaining estimates are particularly consistent with the fact that retailers 7 and 8 have not formed any buyer alliance (see Figure 3 for an illustrative example). Based on these parameter estimates, I compute the price-cost margins of manufacturers, marginal costs of products, and the surplus division between manufacturers and retailers before and after the formation of buyer alliances. Results are reported in Table 5.

In the pre-alliances periods, the table shows that the price-cost margins of retailers involved in an alliance are on average equal to $29.40 \%$, which is lower than other retail- 
Table 5: Price-cost margins, marginal costs, and surplus division

\begin{tabular}{|c|c|c|c|c|c|c|}
\hline & \multicolumn{2}{|c|}{ Inside alliances } & \multicolumn{2}{|c|}{ Outside alliances } & \multicolumn{2}{|c|}{ Total } \\
\hline & Pre & Post & Pre & Post & Pre & Post \\
\hline \multicolumn{7}{|l|}{ Price-cost margins: } \\
\hline Retailers: $\gamma$ & $\begin{array}{l}29.40 \\
(0.60)\end{array}$ & $\begin{array}{l}30.50 \\
(0.65)\end{array}$ & $\begin{array}{l}39.28 \\
(0.98)\end{array}$ & $\begin{array}{l}40.80 \\
(1.15)\end{array}$ & $\begin{array}{l}32.62 \\
(0.65)\end{array}$ & $\begin{array}{l}33.81 \\
(0.78)\end{array}$ \\
\hline Manufacturers: $\Gamma$ & $\begin{array}{c}16.87 \\
(0.52)\end{array}$ & $\begin{array}{c}7.62 \\
(0.25)\end{array}$ & $\begin{array}{c}0.85 \\
(0.08)\end{array}$ & $\begin{array}{c}0.44 \\
(0.04)\end{array}$ & $\begin{array}{c}12.88 \\
(0.44)\end{array}$ & $\begin{array}{c}5.91 \\
(0.20)\end{array}$ \\
\hline \multicolumn{7}{|l|}{ Marginal cost: } \\
\hline Retailers: $\mathbf{w}+\mathbf{c}$ & $\begin{array}{c}0.27 \\
(0.01)\end{array}$ & $\begin{array}{c}0.25 \\
(0.01)\end{array}$ & $\begin{array}{c}0.19 \\
(0.01)\end{array}$ & $\begin{array}{c}0.18 \\
(0.01)\end{array}$ & $\begin{array}{c}0.24 \\
(0.01)\end{array}$ & $\begin{array}{c}0.23 \\
(0.01)\end{array}$ \\
\hline Industry: $\mathbf{c}+\mu$ & $\begin{array}{c}0.24 \\
(0.01)\end{array}$ & $\begin{array}{c}0.24 \\
(0.01)\end{array}$ & $\begin{array}{c}0.19 \\
(0.01)\end{array}$ & $\begin{array}{c}0.18 \\
(0.01)\end{array}$ & $\begin{array}{c}0.22 \\
(0.01)\end{array}$ & $\begin{array}{c}0.22 \\
(0.01)\end{array}$ \\
\hline \multicolumn{7}{|l|}{ Division of surplus: } \\
\hline Retailers' share & $\begin{array}{r}62.48 \\
(0.16) \\
\end{array}$ & $\begin{array}{l}79.78 \\
(0.22) \\
\end{array}$ & $\begin{array}{l}97.27 \\
(0.19) \\
\end{array}$ & $\begin{array}{l}98.69 \\
(0.04) \\
\end{array}$ & $\begin{array}{r}68.87 \\
(0.30) \\
\end{array}$ & $\begin{array}{l}83.77 \\
(0.28) \\
\end{array}$ \\
\hline \multicolumn{7}{|c|}{$\begin{array}{l}\text { Notes: Standard deviation in parenthesis refer to variation across markets. Terms "Pre" and "Post" stand } \\
\text { respectively for the pre-alliances periods and the post-alliances periods. Columns labelled "Inside al- } \\
\text { liances" and "Outside alliances" present respectively results for retailers which have formed a buyer } \\
\text { alliance and for retailers } 7 \text { and } 8 \text { which have not formed a buyer alliance. Average price-cost margins } \\
\text { in percentage of retail prices and average marginal costs in euro per liter are calculated using quantity } \\
\text { weights. The last row corresponds to the average share of the surplus generated from bilateral agree- } \\
\text { ments that is captured by retailers (in percentage). }\end{array}$} \\
\hline
\end{tabular}

ers whose price-cost margins equal $39.28 \%$. These values remain fairly stable in the postalliances periods. In contrast, the price-cost margins of manufacturers fall from $12.88 \%$ to $5.91 \%$, which is mainly due to the sizeable decline in their margins over products sold by retailers involved in an alliance (see the two first columns). The surplus division between manufacturers and retailers is shown in the last row of this table which indicates the average share that retailers capture from the surplus generated by bilateral agreements with manufacturers. In the pre-alliances periods, I find that retailers involved in an alliance extract on average $62.48 \%$ of this surplus, implying that they have a stronger bargaining power than manufacturers. The second column shows that this bargaining power is reinforced in the post-alliances periods, where retailers capture $79.78 \%$ of the surplus resulting from bilateral agreements.

\section{Counterfactual analysis}

In this section, I use the estimated structural parameters to study the mechanisms through which a buyer alliance affects market outcomes in bilateral oligopolies. Following the theoretical insights of Section 2, I examine three counterfactual scenarios: (a) the buyer alliances do not occur (no alliance), (b) the buyer alliances occur but only with a status quo effect (joint delisting decision), and (c) the buyer alliances occur without affecting the bar- 
Table 6: Results of the counterfactual scenarios

\begin{tabular}{|c|c|c|c|c|c|c|c|c|}
\hline & \multirow{2}{*}{$\% \Delta$ Retail price } & \multicolumn{2}{|c|}{$\% \Delta$ Margins } & \multicolumn{3}{|c|}{$\% \Delta$ Profit } & \multicolumn{2}{|c|}{$\% \Delta$ Welfare } \\
\hline & & Retail. & Manuf. & Retail. & Manuf. & Industry & Cons. & Total \\
\hline \multicolumn{9}{|c|}{ Scenario A: No Alliance } \\
\hline Inside alliances & $\begin{array}{l}-8.59 \\
(0.18)\end{array}$ & $\begin{array}{c}1.47 \\
(0.07)\end{array}$ & $\begin{array}{c}-57.37 \\
(0.51)\end{array}$ & $\begin{array}{l}30.81 \\
(0.57)\end{array}$ & $\begin{array}{l}-44.82 \\
(0.30)\end{array}$ & $\begin{array}{c}2.43 \\
(0.27)\end{array}$ & - & - \\
\hline Outside alliances & $\begin{array}{l}-0.35 \\
(0.05)\end{array}$ & $\begin{array}{l}-0.26 \\
(0.06)\end{array}$ & $\begin{array}{c}-44.42 \\
(0.50)\end{array}$ & $\begin{array}{l}-9.06 \\
(0.21)\end{array}$ & $\begin{array}{c}-47.87 \\
(0.33)\end{array}$ & $\begin{array}{l}-9.63 \\
(0.22)\end{array}$ & - & - \\
\hline Total & $\begin{array}{l}-4.44 \\
(0.13)\end{array}$ & $\begin{array}{c}0.59 \\
(0.04)\end{array}$ & $\begin{array}{c}-54.11 \\
(0.52)\end{array}$ & $\begin{array}{c}7.00 \\
(0.21)\end{array}$ & $\begin{array}{c}-44.92 \\
(0.49)\end{array}$ & $\begin{array}{l}-3.41 \\
(0.16)\end{array}$ & $\begin{array}{l}11.40 \\
(0.23)\end{array}$ & $\begin{array}{c}4.33 \\
(0.11)\end{array}$ \\
\hline \multicolumn{9}{|c|}{ Scenario B: Joint delisting decision } \\
\hline Inside alliances & $\begin{array}{l}-3.43 \\
(0.09)\end{array}$ & $\begin{array}{c}0.21 \\
(0.03)\end{array}$ & $\begin{array}{l}-21.25 \\
(0.60)\end{array}$ & $\begin{array}{l}11.75 \\
(0.32)\end{array}$ & $\begin{array}{l}-16.35 \\
(0.12)\end{array}$ & $\begin{array}{c}1.21 \\
(0.17)\end{array}$ & - & - \\
\hline Outside alliances & $\begin{array}{l}-0.17 \\
(0.02)\end{array}$ & $\begin{array}{l}-0.20 \\
(0.02)\end{array}$ & $\begin{array}{l}-16.10 \\
(0.12)\end{array}$ & $\begin{array}{l}-3.78 \\
(0.11)\end{array}$ & $\begin{array}{l}-18.27 \\
(0.16)\end{array}$ & $\begin{array}{l}-4.00 \\
(0.11)\end{array}$ & - & - \\
\hline Total & $\begin{array}{l}-1.78 \\
(0.07)\end{array}$ & $\begin{array}{c}0.00 \\
(0.02)\end{array}$ & $\begin{array}{l}-19.95 \\
(0.48)\end{array}$ & $\begin{array}{c}2.47 \\
(0.10)\end{array}$ & $\begin{array}{l}-16.42 \\
(0.12)\end{array}$ & $\begin{array}{l}-1.31 \\
(0.08)\end{array}$ & $\begin{array}{c}4.61 \\
(0.11)\end{array}$ & $\begin{array}{c}1.78 \\
(0.07)\end{array}$ \\
\hline \multicolumn{9}{|c|}{ Scenario C: Joint-bargaining paradox } \\
\hline Inside alliances & $\begin{array}{l}-1.33 \\
(0.03)\end{array}$ & $\begin{array}{c}0.05 \\
(0.01)\end{array}$ & $\begin{array}{l}-7.42 \\
(0.27)\end{array}$ & $\begin{array}{c}4.06 \\
(0.19)\end{array}$ & $\begin{array}{l}-4.22 \\
(0.14)\end{array}$ & $\begin{array}{c}0.95 \\
(0.07)\end{array}$ & - & - \\
\hline Outside alliances & $\begin{array}{l}-0.06 \\
(0.00)\end{array}$ & $\begin{array}{l}-0.08 \\
(0.01)\end{array}$ & $\begin{array}{l}-4.11 \\
(0.14)\end{array}$ & $\begin{array}{l}-1.35 \\
(0.04)\end{array}$ & $\begin{array}{l}-5.06 \\
(0.16)\end{array}$ & $\begin{array}{l}-1.41 \\
(0.04)\end{array}$ & - & - \\
\hline Total & $\begin{array}{l}-0.68 \\
(0.02) \\
\end{array}$ & $\begin{array}{l}-0.02 \\
(0.01)\end{array}$ & $\begin{array}{l}-6.59 \\
(0.24)\end{array}$ & $\begin{array}{c}0.82 \\
(0.05) \\
\end{array}$ & $\begin{array}{l}-4.25 \\
(0.14)\end{array}$ & $\begin{array}{l}-0.19 \\
(0.02)\end{array}$ & $\begin{array}{c}1.60 \\
(0.06)\end{array}$ & $\begin{array}{c}0.75 \\
(0.03) \\
\end{array}$ \\
\hline
\end{tabular}

Notes: Rows "Inside alliances" and "Outside alliances" refer respectively to products within the scope of the alliances (national brands sold by retailers 1 to 6 ) and outside the scope of the alliances (all private labels and national brands sold by retailers 7 and 8). Standard deviation in parenthesis refer to variation across markets. Percentage changes in retail prices and price-cost margins are calculated using quantity weights.

gaining ability of firms (joint-bargaining paradox). Under each scenario, I compute a new market equilibrium in negotiated wholesale prices, retail prices, and market shares of products during the post-alliances periods by holding fixed the marginal costs of production and distribution, consumer preferences, product characteristics, and the manufacturer-retailer network structure. The iterative algorithm used to perform each counterfactual experiment is described in Appendix $\mathrm{H}$ and results are reported in Table $6 .{ }^{60}$

Scenario A: No Alliance. This counterfactual scenario simulates equilibrium market outcomes in the absence of buyer alliances to analyze their effects on both wholesale and retail prices. Results in Table 6 show that the observed quantity-weighted price-cost margins of manufacturers over national brands purchased by an alliance is $57.37 \%$ lower relative to the "No Alliance" scenario. Furthermore, by deteriorating the status quo position of manufacturers in their bargaining with retailers 7 and 8 , I find that the alliances also reduce the

\footnotetext{
${ }^{60}$ See Bonnet, Bouamra-Mechemache and Molina (2018) for a related procedure to compute counterfactual equilibria in bilateral oligopolies with bargaining. This is also similar in spirit to the iterative algorithm used in Ho and Lee (2017) and Crawford et al. (2018).
} 
quantity-weighted price-cost margins of manufacturers over national brands remaining outside their scope by $44.42 \% .{ }^{61}$ This downward shift in the price-cost margins of manufacturers (and hence wholesale prices) is passed on to consumers in the form of a $4.44 \%$ decrease in the quantity-weighted average retail price. Therefore, simulation results suggest that the formation of buyer alliances has generated a countervailing buyer power effect in line with Galbraith's (1952) view. Indeed, retailers involved in an alliance as well as consumers benefit from this countervailing force to the detriment of other retailers, manufacturers, and the industry which respectively experience a profit decrease of 9.06\%, 44.92\%, and 3.41\% relative to the "No Alliance" scenario. ${ }^{62}$ These findings are consistent with recent political debates about the effect of retailers' buyer power on the surplus generated by food industries and its division within the supply chain. ${ }^{63}$

A comparison of the retail price effect of the alliances obtained under the counterfactual simulation and the event-study analysis in Section 3.3 can provide some insights on the robustness of my estimates. First, simulation results indicate that the (unweighted) average retail price of private labels remain almost unaffected by the formation of buyer alliances $(+0.14 \%)$, which provides support for the identification assumption in the event study. Second, the simulation suggests that the alliances caused a decline of $7.10 \%$ in the (unweighted) average retail price of national brands purchased by an alliance, which aligns particularly well with the retail price decrease of $7.23 \%$ estimated in the event-study analysis. Third, while both approaches predict a fall in the average retail price of national brands sold by retailers 7 and 8 , this price reaction is not statistically significant in the event study and I find a value of $-0.79 \%$ in the simulation results. It is therefore reassuring that the counterfactual simulation and the event-study analysis provide qualitatively similar results regarding the average retail price effect of the alliances.

To my knowledge, this counterfactual simulation provides the first empirical evidence of a change in market structure that creates countervailing buyer power as envisioned by Galbraith (1952). In particular, this contrasts with the countervailing force identified in Ho and Lee (2017) which arises to the detriment of downstream firms (insurers) and only

\footnotetext{
${ }^{61}$ The status quo position of manufacturers in their bargaining with retailers 7 and 8 corresponds to the amount of profit they obtain from bilateral agreements with each buyer alliance. Hence, by decreasing this profit, the alliances reinforce the bargaining power of retailers 7 and 8 vis-à-vis manufacturers.

${ }^{62}$ I use the log-sum formula to compute the change in consumer surplus (e.g., Train, 2009, Chapter 3). Given that the utility specification (2) is a piece-wise linear spline function of income, this provides an accurate approximation of the true change in consumer surplus which does not admit any closed-form expression (see Morey, Sharma and Karlstrom, 2003).

${ }^{63}$ For instance, a National Food Conference involving all stakeholders (e.g., agrifood companies, food retailers, consumer organizations) was organized by the French government in 2017 with the purpose to revitalize the surplus generated by food industries and achieve a fairer division of this surplus along the supply chain.
} 
when downstream prices (premiums) are determined through negotiations with consumers (employer) ${ }^{64}$ Based on the theoretical insights developed in Section 2, I rely on two other counterfactual scenarios to analyze the determinants of countervailing buyer power.

Scenario B: Joint delisting decision. In this counterfactual simulation, I study the formation of buyer alliances where retailers keep negotiating wholesale prices separately and secretly and do not benefit from a bargaining ability effect (that is, bargaining weights of manufacturers remain similar to the pre-alliances periods). However, if a retailer involved in an alliance fails to reach an agreement with a manufacturer over one of its national brands, I consider that all retailers of the alliance jointly delist the manufacturer's brand from their shelves (see Appendix E.2.3 for further details). These modeling assumptions allow to isolate the status quo effect of the alliances described in Section 2. Results reported in Table 6 are interpreted relative to the "No Alliance" scenario. I find that the status quo effect of the alliances generates a decrease of $19.95 \%$ in the quantity-weighted price-cost margins of manufacturers relative to the situation without the alliances. This decline in wholesale prices is passed on into the quantity-weighted retail prices which fall by $1.78 \%$. Simulation results also indicate that profits of retailers involved in an alliance increase by $11.75 \%$ to the detriment of other retailers, manufacturers, and the industry profit. Table 13 of Appendix D provides further results for each retailer. In line with the theoretical insights from Section 2, this table shows that every retailer of a buyer alliance obtains lower wholesale prices relative to the "No Alliance" scenario. Interestingly, however, I find that retailer 1's profit decreases by $2.64 \%$. As illustrated in Figure 3, this suggests that the gain in status quo position of retailer 1 (the largest retailer) from forming an alliance with retailer 2 (the smallest retailer) is not enough to compensate for the losses from improving the competitiveness of retailer 2 on the downstream market. Consequently, an alliance with retailer 2 is never profitable for retailer 1 except if it benefits from a bargaining ability effect. In the last counterfactual scenario, I further explore the role of this bargaining effect on the countervailing force and the profitability of buyer alliances.

Scenario C: Joint-bargaining paradox. This counterfactual scenario simulates the formation of buyer alliances that do not affect the bargaining ability of firms (that is, the value of the bargaining weights in the post-alliances periods is equal to the value estimated in the pre-alliances periods). Consistent with the theoretical predictions from Section 2, simula-

\footnotetext{
${ }^{64}$ It also differs from Gowrisankaran, Nevo and Town (2015) who rely on an ex-ante analysis of hospital mergers to reveal the presence (but not the creation) of countervailing power exerted by insurers.
} 
tion results reported in Table 6 indicate that the countervailing force generated by the status quo effect of the alliances is substantially reduced. While the quantity-weighted price-cost margins of manufacturers fall by $6.59 \%$, the quantity-weighted retail prices remains (almost) unchanged relative to the "No Alliance" scenario. Results presented in Table 14 of Appendix D are even more striking. For each buyer alliance, I find that at least one retailer systematically gets lower profits relative to the situation when it bargains alone. As illustrated by the gray areas of Figure 3, this result is reminiscent of the Harsanyi's (1977) joint-bargaining paradox according to which a coalition of multiple bargainers who act in concert during negotiations obtains less favorable trading terms than what each bargainer is able to negotiate on his own. I show that factors underlying the unprofitability of group purchasing in bilateral oligopolies are twofold. First, buyer alliances make the purchasing conditions of retailers more uniform, which deprives some of them from having a competitive advantage on the downstream market. Second, the nondiscrimination effect generated by the alliances weakens the bargaining power of retailers vis-à-vis manufacturers which, in turn, undermines the countervailing force resulting from the status quo effect. Therefore, absent any increase in the bargaining ability of retailers, I find that the buyer alliances observed on the French food retail sector in 2014 would have not been formed. ${ }^{65}$ This result has important implications for the analysis of market structure changes. In particular, it provides direct evidence that a complete understanding of the effects of any market concentration on bargaining outcomes requires analyzing the impact on bargaining abilities, which to date has been largely ignored in the empirical literature.

\section{Concluding remarks}

Leveraging a unique case on the French food retail sector in which several large retailers joined forces to negotiate common wholesale prices with manufacturers through the formation of three buyer alliances, this article studies the determinants of buyer power and their effects on market outcomes. I shed light on three main economic forces: (i) a status quo effect which strengthens the bargaining position of retailers vis-à-vis manufacturers, (ii) a nondiscrimination effect which alters firms' relative costs of making price concessions to the benefit of manufacturers, and (iii) a bargaining ability effect which enhances the bargaining power of retailers. Using pre- and post-alliances data on household purchases of bottled water, I develop a structural model of bilateral oligopoly that allows to directly estimate the

\footnotetext{
${ }^{65}$ In an oligopoly framework with negotiated prices, Grennan (2013) derives similar conclusions regarding the profitability of a group purchasing organization formed by hospitals operating on different local markets.
} 
buyer alliances effect on each source of bargaining power in the vertical chain.

Estimates of the surplus division indicate that the bargaining power of retailers is higher than that of manufacturers and has been reinforced after the formation of buyer alliances. In a set of counterfactual experiments, I provide evidence of a countervailing buyer power effect that generates a retail price decrease of $7.10 \%$ for national brands purchased by a buyer alliance. Moreover, I find that changes in the bargaining ability of retailers play an important role on the emergence of this countervailing force as well as on the profitability of buyer alliances.

This article is subject to a certain number of limitations that I leave for future research. First, my empirical results suggest that the impact of changes in the bargaining ability of firms quantitatively matter in the analysis of market concentration. While my approach has the advantage of not imposing any particular structure on this source of bargaining power, a better understanding of its determinants constitutes an important research agenda (e.g., Grennan, 2014). Second, by focusing on the bottled water industry, this article offers a partial analysis of the formation of buyer alliances which covered other product categories as well (e.g., dairy products). A possible direction for future work is to combine the bilateral oligopoly framework developed in this article with a model of cross-pricing category (e.g., Thomassen et al., 2017) to study the implications of multi-category effects on buyer power. Finally, this article highlights that the countervailing force of buyer alliances arises to the detriment of both manufacturers and the industry surplus, which is likely to have long-run consequences. How the exercise of buyer power affects product variety and innovation raise important concerns for policymakers (European Commission, 2014). The lack of clear theoretical predictions on this topic (e.g., Montez, 2007; Caprice and Rey, 2015; Chen, 2019) offers an exciting avenue for empirical work. 


\section{Appendix}

\section{A Additional descriptive statistics}

Table 7: Descriptive statistics for brands

\begin{tabular}{|c|c|c|c|c|c|c|}
\hline & \multirow{2}{*}{ Mineral } & \multirow{2}{*}{ Sparkling } & \multicolumn{2}{|c|}{ Market share } & \multicolumn{2}{|c|}{ Retail price } \\
\hline & & & pre-alliances & post-alliances & pre-alliances & post-alliances \\
\hline \multicolumn{7}{|c|}{ National brands: } \\
\hline Brand 1 & Yes & Yes & $\begin{array}{c}4.38 \\
(0.64)\end{array}$ & $\begin{array}{c}4.66 \\
(0.61)\end{array}$ & $\begin{array}{c}0.72 \\
(0.02)\end{array}$ & $\begin{array}{c}0.68 \\
(0.03)\end{array}$ \\
\hline Brand 2 & Yes & No & $\begin{array}{c}3.43 \\
(0.28)\end{array}$ & $\begin{array}{c}3.28 \\
(0.40)\end{array}$ & $\begin{array}{c}0.36 \\
(0.02)\end{array}$ & $\begin{array}{c}0.32 \\
(0.01)\end{array}$ \\
\hline Brand 3 & Yes & No & $\begin{array}{c}3.21 \\
(0.30)\end{array}$ & $\begin{array}{c}3.89 \\
(0.32)\end{array}$ & $\begin{array}{c}0.53 \\
(0.01)\end{array}$ & $\begin{array}{c}0.50 \\
(0.01)\end{array}$ \\
\hline Brand 4 & Yes & No & $\begin{array}{c}3.24 \\
(0.34)\end{array}$ & $\begin{array}{c}3.40 \\
(0.34)\end{array}$ & $\begin{array}{c}0.31 \\
(0.02)\end{array}$ & $\begin{array}{c}0.28 \\
(0.01)\end{array}$ \\
\hline Brand 5 & Yes & Yes & $\begin{array}{c}1.43 \\
(0.35)\end{array}$ & $\begin{array}{c}1.49 \\
(0.19)\end{array}$ & $\begin{array}{c}0.75 \\
(0.03)\end{array}$ & $\begin{array}{c}0.65 \\
(0.01)\end{array}$ \\
\hline Brand 6 & Yes & No & $\begin{array}{c}3.46 \\
(0.24)\end{array}$ & $\begin{array}{c}3.09 \\
(0.23)\end{array}$ & $\begin{array}{c}0.41 \\
(0.02)\end{array}$ & $\begin{array}{c}0.40 \\
(0.02)\end{array}$ \\
\hline Brand 7 & Yes & No & $\begin{array}{c}2.52 \\
(0.32)\end{array}$ & $\begin{array}{c}2.58 \\
(0.19)\end{array}$ & $\begin{array}{c}0.33 \\
(0.01)\end{array}$ & $\begin{array}{c}0.33 \\
(0.01)\end{array}$ \\
\hline Brand 8 & Yes & Yes & $\begin{array}{c}2.53 \\
(0.18)\end{array}$ & $\begin{array}{c}2.68 \\
(0.13)\end{array}$ & $\begin{array}{c}0.41 \\
(0.01)\end{array}$ & $\begin{array}{c}0.38 \\
(0.00)\end{array}$ \\
\hline Brand 9 & Yes & Yes & $\begin{array}{c}2.35 \\
(0.30)\end{array}$ & $\begin{array}{c}2.22 \\
(0.20)\end{array}$ & $\begin{array}{c}0.70 \\
(0.03)\end{array}$ & $\begin{array}{c}0.64 \\
(0.05)\end{array}$ \\
\hline Brand 10 & No & No & $\begin{array}{l}11.62 \\
(0.67)\end{array}$ & $\begin{array}{l}13.19 \\
(0.86)\end{array}$ & $\begin{array}{c}0.13 \\
(0.00)\end{array}$ & $\begin{array}{c}0.13 \\
(0.00)\end{array}$ \\
\hline Brand 11 & Yes & No & $\begin{array}{c}1.47 \\
(0.15)\end{array}$ & $\begin{array}{c}1.52 \\
(0.18)\end{array}$ & $\begin{array}{c}0.31 \\
(0.00)\end{array}$ & $\begin{array}{c}0.27 \\
(0.01)\end{array}$ \\
\hline \multicolumn{7}{|c|}{ Private labels: } \\
\hline PL 1 & No & No & $\begin{array}{l}13.87 \\
(0.52)\end{array}$ & $\begin{array}{l}12.89 \\
(0.36)\end{array}$ & $\begin{array}{c}0.20 \\
(0.01)\end{array}$ & $\begin{array}{c}0.21 \\
(0.01)\end{array}$ \\
\hline PL 2 & No & Yes & $\begin{array}{c}0.66 \\
(0.06)\end{array}$ & $\begin{array}{c}0.43 \\
(0.03)\end{array}$ & $\begin{array}{c}0.25 \\
(0.01)\end{array}$ & $\begin{array}{c}0.26 \\
(0.02)\end{array}$ \\
\hline PL 3 & Yes & No & $\begin{array}{c}3.53 \\
(0.19)\end{array}$ & $\begin{array}{c}3.47 \\
(0.11)\end{array}$ & $\begin{array}{c}0.27 \\
(0.01)\end{array}$ & $\begin{array}{c}0.27 \\
(0.01)\end{array}$ \\
\hline PL 4 & Yes & Yes & $\begin{array}{c}5.34 \\
(0.26)\end{array}$ & $\begin{array}{c}4.53 \\
(0.24)\end{array}$ & $\begin{array}{c}0.32 \\
(0.02)\end{array}$ & $\begin{array}{c}0.32 \\
(0.01)\end{array}$ \\
\hline
\end{tabular}

Notes: Market shares in percentage are calculated according to the number of household purchases. Average retail prices (in euro per liter). Standard deviation depicts variation across markets. Brand 1 to 5 are produced by manufacturer 1 , brand 6 to 9 are produced by manufacturer 2, and brand 10 to 11 are produced by manufacturer 3 . Remark that I am not permitted to reveal names of brands due to confidentiality regarding Kantar WorldPanel data. 
Table 8: Descriptive statistics for national brands and private labels of retailers

\begin{tabular}{|c|c|c|c|c|c|c|c|c|}
\hline & \multicolumn{4}{|c|}{ Market share } & \multicolumn{4}{|c|}{ Retail price } \\
\hline & \multicolumn{2}{|c|}{ national brand } & \multicolumn{2}{|c|}{ private label } & \multicolumn{2}{|c|}{ national brand } & \multicolumn{2}{|c|}{ private label } \\
\hline & pre & post & pre & post & pre & post & pre & post \\
\hline Retailer 1 & $\begin{array}{l}11.27 \\
(0.33)\end{array}$ & $\begin{array}{l}11.45 \\
(0.46)\end{array}$ & $\begin{array}{c}3.58 \\
(0.22)\end{array}$ & $\begin{array}{c}2.76 \\
(0.25)\end{array}$ & $\begin{array}{c}0.46 \\
(0.01)\end{array}$ & $\begin{array}{c}0.41 \\
(0.02)\end{array}$ & $\begin{array}{c}0.26 \\
(0.01)\end{array}$ & $\begin{array}{c}0.26 \\
(0.01)\end{array}$ \\
\hline Retailer 2 & $\begin{array}{c}1.39 \\
(0.15)\end{array}$ & $\begin{array}{c}1.50 \\
(0.16)\end{array}$ & $\begin{array}{c}0.39 \\
(0.05)\end{array}$ & $\begin{array}{c}0.36 \\
(0.05)\end{array}$ & $\begin{array}{c}0.46 \\
(0.02)\end{array}$ & $\begin{array}{c}0.41 \\
(0.03)\end{array}$ & $\begin{array}{c}0.30 \\
(0.02)\end{array}$ & $\begin{array}{c}0.31 \\
(0.03)\end{array}$ \\
\hline Retailer 3 & $\begin{array}{c}5.94 \\
(0.38)\end{array}$ & $\begin{array}{c}6.06 \\
(0.47)\end{array}$ & $\begin{array}{c}1.37 \\
(0.10)\end{array}$ & $\begin{array}{c}1.15 \\
(0.08)\end{array}$ & $\begin{array}{c}0.46 \\
(0.02)\end{array}$ & $\begin{array}{c}0.43 \\
(0.02)\end{array}$ & $\begin{array}{c}0.28 \\
(0.01)\end{array}$ & $\begin{array}{c}0.29 \\
(0.01)\end{array}$ \\
\hline Retailer 4 & $\begin{array}{c}3.21 \\
(0.24)\end{array}$ & $\begin{array}{c}4.35 \\
(0.15)\end{array}$ & $\begin{array}{c}1.74 \\
(0.09)\end{array}$ & $\begin{array}{c}1.64 \\
(0.07)\end{array}$ & $\begin{array}{c}0.45 \\
(0.01)\end{array}$ & $\begin{array}{c}0.42 \\
(0.01)\end{array}$ & $\begin{array}{c}0.26 \\
(0.01)\end{array}$ & $\begin{array}{c}0.25 \\
(0.01)\end{array}$ \\
\hline Retailer 5 & $\begin{array}{c}4.43 \\
(0.70)\end{array}$ & $\begin{array}{c}4.78 \\
(0.33)\end{array}$ & $\begin{array}{c}4.54 \\
(0.17)\end{array}$ & $\begin{array}{c}4.16 \\
(0.23)\end{array}$ & $\begin{array}{c}0.45 \\
(0.01)\end{array}$ & $\begin{array}{c}0.41 \\
(0.02)\end{array}$ & $\begin{array}{c}0.28 \\
(0.01)\end{array}$ & $\begin{array}{c}0.26 \\
(0.01)\end{array}$ \\
\hline Retailer 6 & $\begin{array}{c}3.00 \\
(0.20)\end{array}$ & $\begin{array}{c}3.27 \\
(0.13)\end{array}$ & $\begin{array}{c}1.62 \\
(0.08)\end{array}$ & $\begin{array}{c}1.48 \\
(0.20)\end{array}$ & $\begin{array}{c}0.47 \\
(0.01)\end{array}$ & $\begin{array}{c}0.43 \\
(0.01)\end{array}$ & $\begin{array}{c}0.29 \\
(0.01)\end{array}$ & $\begin{array}{c}0.27 \\
(0.01)\end{array}$ \\
\hline Retailer 7 & $\begin{array}{c}9.65 \\
(0.57)\end{array}$ & $\begin{array}{c}9.94 \\
(0.46)\end{array}$ & $\begin{array}{c}4.83 \\
(0.31)\end{array}$ & $\begin{array}{c}4.23 \\
(0.11)\end{array}$ & $\begin{array}{c}0.44 \\
(0.01)\end{array}$ & $\begin{array}{c}0.40 \\
(0.01)\end{array}$ & $\begin{array}{c}0.25 \\
(0.00)\end{array}$ & $\begin{array}{c}0.29 \\
(0.03)\end{array}$ \\
\hline Retailer 8 & $\begin{array}{c}0.76 \\
(0.09) \\
\end{array}$ & $\begin{array}{c}0.65 \\
(0.09) \\
\end{array}$ & $\begin{array}{c}5.34 \\
(0.13) \\
\end{array}$ & $\begin{array}{c}5.54 \\
(0.25) \\
\end{array}$ & $\begin{array}{c}0.33 \\
(0.02) \\
\end{array}$ & $\begin{array}{c}0.32 \\
(0.01) \\
\end{array}$ & $\begin{array}{c}0.20 \\
(0.01) \\
\end{array}$ & $\begin{array}{c}0.20 \\
(0.02) \\
\end{array}$ \\
\hline
\end{tabular}

Notes: Terms "pre" and "post" stand respectively for the pre-alliances periods (2013) and the post-alliances periods (2015). Market shares in percentage are calculated according to the number of household purchases. Average retail prices are in euro per liter. Standard deviation in parenthesis refer to variation across markets for the year 2013 (pre-alliances) and 2015 (post-alliances). Remark that I am not permitted to reveal names of retailers due to confidentiality regarding Kantar WorldPanel data. 
Table 9: Descriptive statistics for household characteristics

\begin{tabular}{|c|c|c|c|c|c|c|}
\hline & \multicolumn{2}{|c|}{ Percentage } & \multicolumn{2}{|c|}{ Retail price } & \multicolumn{2}{|c|}{ Mineral } \\
\hline & pre & post & pre & post & pre & post \\
\hline \multicolumn{7}{|c|}{ Household income range: } \\
\hline 0-900 & $\begin{array}{c}2.21 \\
(0.09)\end{array}$ & $\begin{array}{c}1.97 \\
(0.11)\end{array}$ & $\begin{array}{c}0.29 \\
(0.01)\end{array}$ & $\begin{array}{c}0.31 \\
(0.01)\end{array}$ & $\begin{array}{l}52.66 \\
(2.43)\end{array}$ & $\begin{array}{l}59.21 \\
(2.29)\end{array}$ \\
\hline $900-1,899$ & $\begin{array}{l}22.28 \\
(0.54)\end{array}$ & $\begin{array}{l}21.65 \\
(0.57)\end{array}$ & $\begin{array}{c}0.30 \\
(0.01)\end{array}$ & $\begin{array}{c}0.29 \\
(0.01)\end{array}$ & $\begin{array}{l}56.89 \\
(1.14)\end{array}$ & $\begin{array}{l}55.68 \\
(0.96)\end{array}$ \\
\hline $1,900-4,449$ & $\begin{array}{l}54.30 \\
(0.51)\end{array}$ & $\begin{array}{l}54.61 \\
(0.39)\end{array}$ & $\begin{array}{c}0.32 \\
(0.01)\end{array}$ & $\begin{array}{c}0.30 \\
(0.01)\end{array}$ & $\begin{array}{l}57.67 \\
(1.37)\end{array}$ & $\begin{array}{l}57.38 \\
(1.08)\end{array}$ \\
\hline$>4,500$ & $\begin{array}{l}21.20 \\
(0.67)\end{array}$ & $\begin{array}{l}21.77 \\
(0.53)\end{array}$ & $\begin{array}{c}0.34 \\
(0.01)\end{array}$ & $\begin{array}{c}0.32 \\
(0.01)\end{array}$ & $\begin{array}{l}63.37 \\
(1.08)\end{array}$ & $\begin{array}{l}62.72 \\
(1.03)\end{array}$ \\
\hline \multicolumn{7}{|c|}{ Age of household head: } \\
\hline $18-40$ & $\begin{array}{l}27.96 \\
(1.04)\end{array}$ & $\begin{array}{l}27.44 \\
(0.85)\end{array}$ & $\begin{array}{c}0.29 \\
(0.01)\end{array}$ & $\begin{array}{c}0.28 \\
(0.01)\end{array}$ & $\begin{array}{l}50.05 \\
(1.43)\end{array}$ & $\begin{array}{l}49.78 \\
(1.60)\end{array}$ \\
\hline $40-60$ & $\begin{array}{l}46.03 \\
(0.50)\end{array}$ & $\begin{array}{l}46.23 \\
(0.77)\end{array}$ & $\begin{array}{c}0.32 \\
(0.01)\end{array}$ & $\begin{array}{c}0.30 \\
(0.01)\end{array}$ & $\begin{array}{l}58.74 \\
(1.14)\end{array}$ & $\begin{array}{l}58.16 \\
(0.74)\end{array}$ \\
\hline$>60$ & $\begin{array}{l}26.01 \\
(1.20)\end{array}$ & $\begin{array}{l}26.33 \\
(1.32)\end{array}$ & $\begin{array}{c}0.34 \\
(0.01)\end{array}$ & $\begin{array}{c}0.32 \\
(0.01)\end{array}$ & $\begin{array}{l}66.01 \\
(1.00)\end{array}$ & $\begin{array}{l}65.26 \\
(0.64)\end{array}$ \\
\hline \multicolumn{7}{|l|}{ All households: } \\
\hline & $\begin{array}{c}100 \\
-\end{array}$ & $\begin{array}{c}100 \\
-\end{array}$ & $\begin{array}{c}0.32 \\
(0.01)\end{array}$ & $\begin{array}{c}0.30 \\
(0.01)\end{array}$ & $\begin{array}{l}58.55 \\
(1.09)\end{array}$ & $\begin{array}{l}58.19 \\
(0.89)\end{array}$ \\
\hline \multicolumn{7}{|c|}{ Average number of households per market: $11,066.98$} \\
\hline $\begin{array}{l}\text { Notes: Terms "pre" } \\
\text { alliances periods ( } 2 \\
\text { the percentage of ea } \\
\text { retail price (in euro } \\
\text { shows the percentag } \\
\text { deviation in parenth } \\
\text { (post-alliances). }\end{array}$ & $\begin{array}{l}\text { "post" stan } \\
\text { Househol } \\
\text { ousehold } \\
\text { liter) of p } \\
\text { household } \\
\text { refer to va }\end{array}$ & $\begin{array}{l}\text { respectiv } \\
\text { income ra } \\
\text { coup in the }\end{array}$ & $\begin{array}{l}\text { in the pre- } \\
\text { in euro per } \\
\text { abase. Coll }\end{array}$ & $\begin{array}{l}\text { liances p } \\
\text { month. } \\
\text { mn "Reta }\end{array}$ & $\begin{array}{l}\text { (2013) } \\
\text { "Percen } \\
\text { " reports } \\
\text { p. Colun }\end{array}$ & $\begin{array}{l}\text { the post- } \\
\text { e" reports } \\
\text { e average } \\
\text { "Mineral" } \\
\text { Standard } \\
\text { and } 2015\end{array}$ \\
\hline
\end{tabular}

\section{B Event study analysis: Robustness to alternative specifi- cations}

In this section, I explore the robustness of the estimates obtained from the event-study analysis developed in Section 3.3.

\section{B.1 Pre- and post-alliances aggregation}

An alternative solution for addressing the serial correlation problem in the regression model (1) compared to clustering standard errors is to aggregate the data before and after the formation of buyer alliances (Bertrand, Duflo and Mullainathan, 2004). Based on this insight, I average the data pre- and post-alliances (panel of length 2) and consider the following regression model:

$$
\begin{aligned}
\overline{\ln }_{j, t}= & \beta_{\text {post }}^{\text {in }} \mathbb{1}\{\text { national brand }\}_{j, t} \times \mathbb{1}\{\text { alliance }\}_{j, t} \times \mathbb{1}\left\{{\text { post-alliances }\}_{t}}^{\text {out }}\right. \\
& +\beta_{\text {post }}^{\text {out }} \mathbb{1}\{\text { national brand }\}_{j, t} \times \mathbb{1}\{\text { retailers } 7 \& 8\}_{j, t} \times \mathbb{1}{\text { post-alliances }\}_{t}} \\
& +\beta_{j}+\beta_{\text {post }} \mathbb{1}\{\text { post-alliances }\}_{t}+\bar{u}_{j, t}
\end{aligned}
$$


Table 10: Results of the pre- and post-alliances aggregation

\begin{tabular}{|c|c|c|}
\hline Variable & Coefficient & S.E. \\
\hline \multicolumn{3}{|l|}{ Dependent variable: $\overline{\ln p}_{j, t}$} \\
\hline $\begin{array}{l}\mathbb{1}\{\text { national brand }\}_{j, t} \times \mathbb{1}\{\text { alliance }\}_{j, t} \times \mathbb{1} \text { ppost-alliances }_{t} \\
\left.\mathbb{1}\{\text { national brand }\}_{j, t} \times \mathbb{1} \text { \{retailers } 7 \& 8\right\}_{j, t} \times \mathbb{1}\{\text { post-alliances }\}_{t} \\
\mathbb{1}{\text { p post-alliances }\}_{t}}\end{array}$ & $\begin{array}{l}-0.076^{*} \\
-0.059^{*} \\
-0.006\end{array}$ & $\begin{array}{l}0.0215 \\
0.0242 \\
0.0192\end{array}$ \\
\hline \multicolumn{3}{|l|}{ Product fixed effects (not shown) } \\
\hline $\begin{array}{l}R^{2} \text { adjusted } \\
\text { Number of observations }\end{array}$ & \multicolumn{2}{|c|}{$\begin{array}{c}0.998 \\
220 \\
\end{array}$} \\
\hline \multicolumn{3}{|l|}{ Dependent variable: $\overline{\ln p_{j, t}^{\text {detrend }}}$} \\
\hline $\begin{array}{l}\mathbb{1}\{\text { national brand }\}_{j, t} \times \mathbb{1}\{\text { alliance }\}_{j, t} \times \mathbb{1}\{\text { post-alliances }\}_{t} \\
\left.\mathbb{1}\{\text { national brand }\}_{j, t} \times \mathbb{1} \text { \{retailers } 7 \& 8\right\}_{j, t} \times \mathbb{1} \text { p post-alliances }_{t} \\
\mathbb{1} \text { p post-alliances }_{t}\end{array}$ & $\begin{array}{l}-0.076^{*} \\
-0.017 \\
-0.006\end{array}$ & $\begin{array}{l}0.0215 \\
0.0242 \\
0.0192\end{array}$ \\
\hline \multicolumn{3}{|l|}{ Product fixed effects (not shown) } \\
\hline $\begin{array}{l}R^{2} \text { adjusted } \\
\text { Number of observations }\end{array}$ & \multicolumn{2}{|c|}{$\begin{array}{c}0.998 \\
220\end{array}$} \\
\hline
\end{tabular}

Notes: OLS estimates of the regression model (16) with either $\overline{\ln }_{j, t}$ or $\overline{\ln p_{j, t}^{\text {detrend }}}$ as dependent variable. Heteroskedasticity-robust standard errors. ${ }^{*}$ indicates significance at the $5 \%$ level. Percentage changes in retail prices can be obtained from the following transformation of the estimated parameters: $100(\exp (\beta)-1)$.

where $\overline{\ln }_{j, t}$ is the average $\log$ retail price of product $j$ before and after the alliance formation, $\beta_{j}$ are product fixed effects, $\beta_{\text {post }}$ is a fixed effect for the post-alliance period (2015), $\bar{u}_{j, t}$ is an error term, and $t=\{2013,2015\}$. The parameter $\beta_{\text {post }}^{\text {in }}$ measures how the (average) log retail price difference between private labels and national brands sold by a retailer involved in an alliance has changed after the formation of the alliances. Similarly, the parameter $\beta_{\text {post }}^{\text {out }}$ measures how the (average) log retail price difference between private labels and national brands sold by either retailer 7 or 8 has changed after the alliances. The OLS estimates of (16) are reported in the first part of Table 10. Results show that the retail prices of national brands sold by a member of an alliance have, on average, decreased by $7.32 \%$ relative to that of private labels. This price decrease is, moreover, statistically significant at the $5 \%$ level which is reassuring as to the validity of the estimates displayed in Figure 5a.

Interestingly, estimates reported in the first part of Table 10 also indicate that the reaction of retailers 7 and 8 to the alliances is statistically significant with a price decrease of $5.73 \%$, which differs from the estimates displayed in Figure 5b. This contrasting result is explained by the fact that the retail prices of national brands sold by retailers 7 and 8 trend downward in the pre-alliances periods (see Figure 4). By simply averaging the data pre- and post-alliances, the regression model (16) omits to account for such a trend and, in turn, overestimates the price reaction of retailers 7 and 8 to the alliances. To address this issue, I employ a 2-step procedure. First, I detrend the retail prices of national brands sold by retailers 7 and 8 by using the following regression model:

$$
\begin{aligned}
\ln p_{j, t}= & \bar{\beta} \mathbb{1}\{\text { national brand }\}_{j, t} \times \mathbb{1}\{\text { retailers } 7 \& 8\}_{j, t} \times \mathbb{1}\{\text { pre-alliances }\}_{t} \\
& +\beta_{t}^{\text {trend }} \mathbb{1}\{\text { national brand }\}_{j, t} \times \mathbb{1}\{\text { retailers } 7 \& 8\}_{j, t} \times \mathbb{1}\{\text { pre-alliances }\}_{t}+e_{j, t}
\end{aligned}
$$

where $\bar{\beta}$ captures the average retail price of national brands sold by retailers 7 and 8 in the pre-alliance periods, $\beta_{t}^{\text {trend }}$ are fixed effects capturing the downward trend (the last period before the alliances being 
the base period), and $e_{j, t}$ is an error term. Based on the OLS estimates of (17), I detrend the retail prices of national brands sold by retailers 7 and 8 as follows: $\ln p_{j, t}^{\text {detrend }}=\ln p_{j, t}-\hat{\beta}_{t}^{\text {trend }} \mathbb{1}\{\text { national brand }\}_{j, t} \times$ $\mathbb{1}\{\text { retailers } 7 \& 8\}_{j, t} \times \mathbb{1}\{\text { pre-alliances }\}_{t}$. Then, I average the data pre- and post-alliances and I estimate the regression model (16) using $\overline{\ln p_{j, t}^{\text {detrend }}}$ instead of $\overline{\ln }_{j, t}$ as dependent variable. The OLS estimates reported in the second part of Table 10 indicate a lower decrease in the retail prices of national brands sold by retailers 7 and 8 following the alliance formation $(-1.69 \%)$. Moreover, the price reaction of retailers 7 and 8 is not statistically significant, which is reassuring as to the validity of the estimates displayed in Figure $5 \mathrm{~b}$.

\section{B.2 Alliance-by-alliance event-study analysis}

To gain additional insights on the effect of the formation of the three buyer alliances on retail prices, I use an alliance-by-alliance event study. Based on the specification of the regression model (1), I estimate the following reduced-form pricing equation:

$$
\begin{aligned}
\ln p_{j, t}= & \beta_{j}+\beta_{t}+\beta_{1, t}^{\text {in }} \mathbb{1}\{\text { national brand }\}_{j, t} \times \mathbb{1}\{\text { alliance } 1\}_{j, t} \\
& +\beta_{2, t}^{\text {in }} \mathbb{1}\{\text { national brand }\}_{j, t} \times \mathbb{1}\{\text { alliance } 2\}_{j, t} \\
& +\beta_{3, t}^{\text {in }} \mathbb{1}\{\text { national brand }\}_{j, t} \times \mathbb{1}\{\text { alliance } 3\}_{j, t} \\
& +\beta_{t}^{\text {out }} \mathbb{1}\{\text { national brand }\}_{j, t} \times \mathbb{1}\{\text { retailers } 7 \& 8\}_{j, t}+u_{j, t}
\end{aligned}
$$

where $\mathbb{1}\{\text { alliance } a\}_{j, t}$, with $a=\{1,2,3\}$, is an indicator variable equals to 1 is product $j$ in market $t$ is sold by a retailer involved in the alliance $a$. The parameters of interest are the fixed effects $\beta_{1, t}^{\text {in }}$, $\beta_{2, t}^{\text {in }}$, and $\beta_{3, t}^{\text {in }}$ which respectively measure the evolution of the log retail price difference between private labels and national brands sold by retailers involved in the alliances 1,2 , and 3. I estimate the regression model (18) by OLS with standard errors clustered at the product level. Figures $6 \mathrm{a}, 6 \mathrm{~b}$, and $6 \mathrm{c}$ display the estimation results.

During the pre-alliances periods, every figure shows that the trend in retail prices of national brands sold by retailers involved in each buyer alliance is stable and not statistically different from that of private labels. In the post-alliances periods, Figures $6 \mathrm{a}$ and $6 \mathrm{c}$ depict a clear trend break where most parameters are negative and significantly different from zero. While the magnitude of the trend break displayed in Figure $6 \mathrm{c}$ is similar to that observed in Figure 5a, parameter values shown in Figure 6a are around -0.125. This suggests that the retail prices of national brands sold by retailers 1 and 2 which have formed the alliance 1 have decreased, on average, by $11.75 \%$ relative to the retail prices of private labels. Figure $6 \mathrm{~b}$ also indicates that the retail prices of retailers involved in the alliance 2 have decreased in the post-alliances periods. However, the estimates suggest that this price decrease is not only of a lower magnitude compared to the other alliances but it is also not statistically significant.

Two main results can thus be drawn from this alliance-by-alliance event study analysis. First, after the formation of the alliances, the national brands purchased by each buyer alliance has experienced a retail price drop relative to private labels. Second, the magnitude of this price drop varies across alliances. While the retail prices of national brands purchased by the alliances 1 and 3 have substantially declined (around $-11.75 \%$ and $-7.23 \%$, respectively), the retail prices of national brands purchased by the alliance 2 have not significantly decreased relative to the retail prices of private labels. 
Figure 6: Event study (alliance-by-alliance)

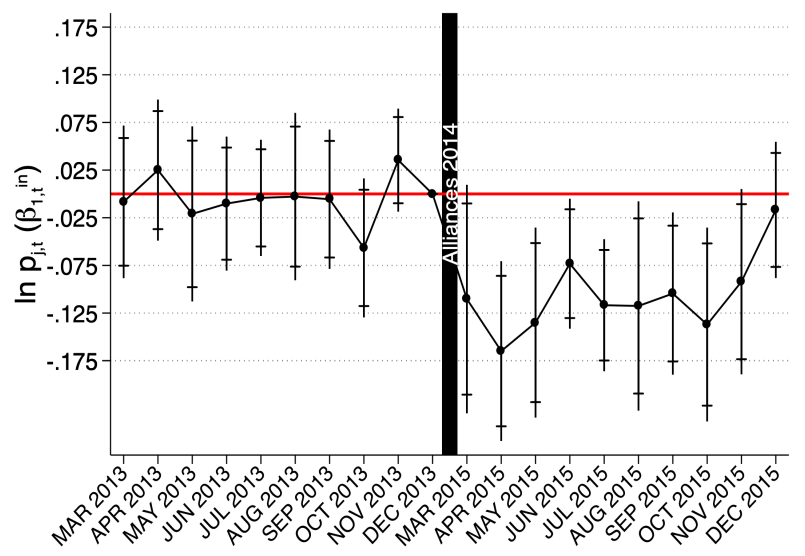

(a) Alliance 1: retailers $1 \& 2$

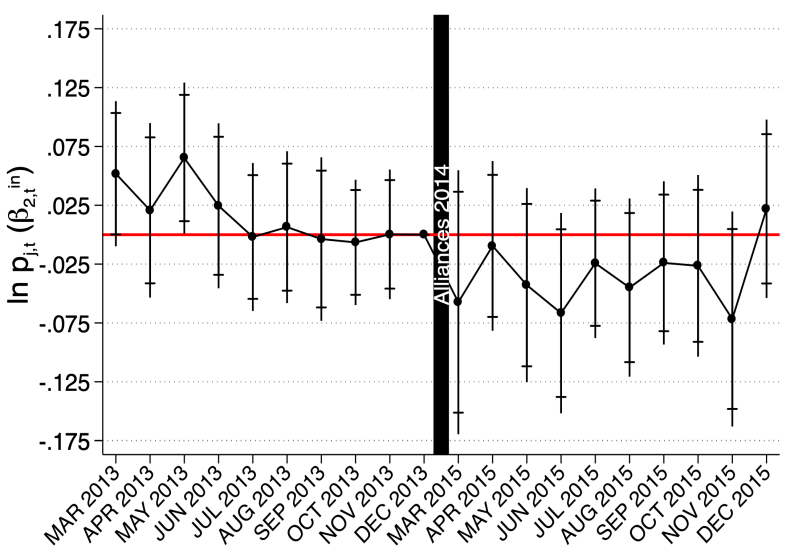

(b) Alliance 2: retailers $3 \& 4$

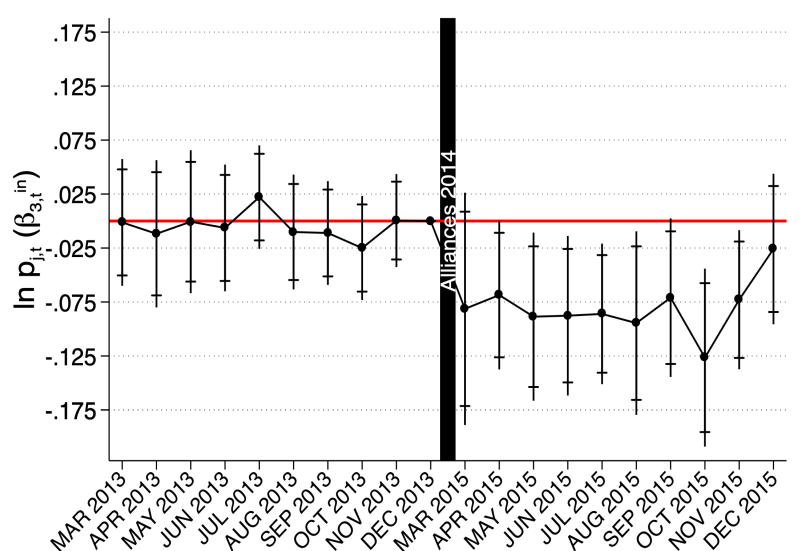

(c) Alliance 3: retailers $5 \& 6$

Notes: OLS estimates of the coefficients $\beta_{1, t}^{i n}, \beta_{2, t}^{i n}$, and $\beta_{3, t}^{i n}$ from the regression model (18). The number of observations is 2,192 and the $R^{2}$ adjusted equals 0.99 . Capped-bars and bars indicate respectively the $90 \%$ and $95 \%$ confidence intervals with standard errors clustered at the product level (111 clusters). The coefficients $\beta_{1, t}^{i n}, \beta_{2, t}^{i n}, \beta_{3, t}^{i n}$, and $\beta_{t}^{\text {out }}$ for December 2013 are normalized to zero (base period). Percentage changes in retail prices can be obtained from the following transformation of the estimated parameters: $100(\exp (\beta)-1)$. 


\section{Demand results: Additional tables and figures}

Table 11: First-stage regression (TSLS)

\begin{tabular}{|c|c|c|}
\hline Variable & Coefficient & S.E. \\
\hline Number of products sold by rival retailers & -0.004 & 0.004 \\
\hline $\mathbb{1}\{\text { national brand }\}_{j, t} \times \mathbb{1}\{\text { alliance }\}_{j, t} \times \mathbb{1}\{\text { post-alliances }\}_{t}$ & $-0.025^{*}$ & 0.004 \\
\hline \multicolumn{3}{|l|}{ Brand fixed effects (not shown) } \\
\hline \multicolumn{3}{|l|}{ Retailer fixed effects (not shown) } \\
\hline \multicolumn{3}{|l|}{ Market fixed effects (not shown) } \\
\hline$F_{\text {eff }}$ & 20.73 & \\
\hline$R^{2}$ adjusted & 0.986 & \\
\hline Number of observations & 2,192 & \\
\hline
\end{tabular}

Figure 7: Own-price elasticity of demand

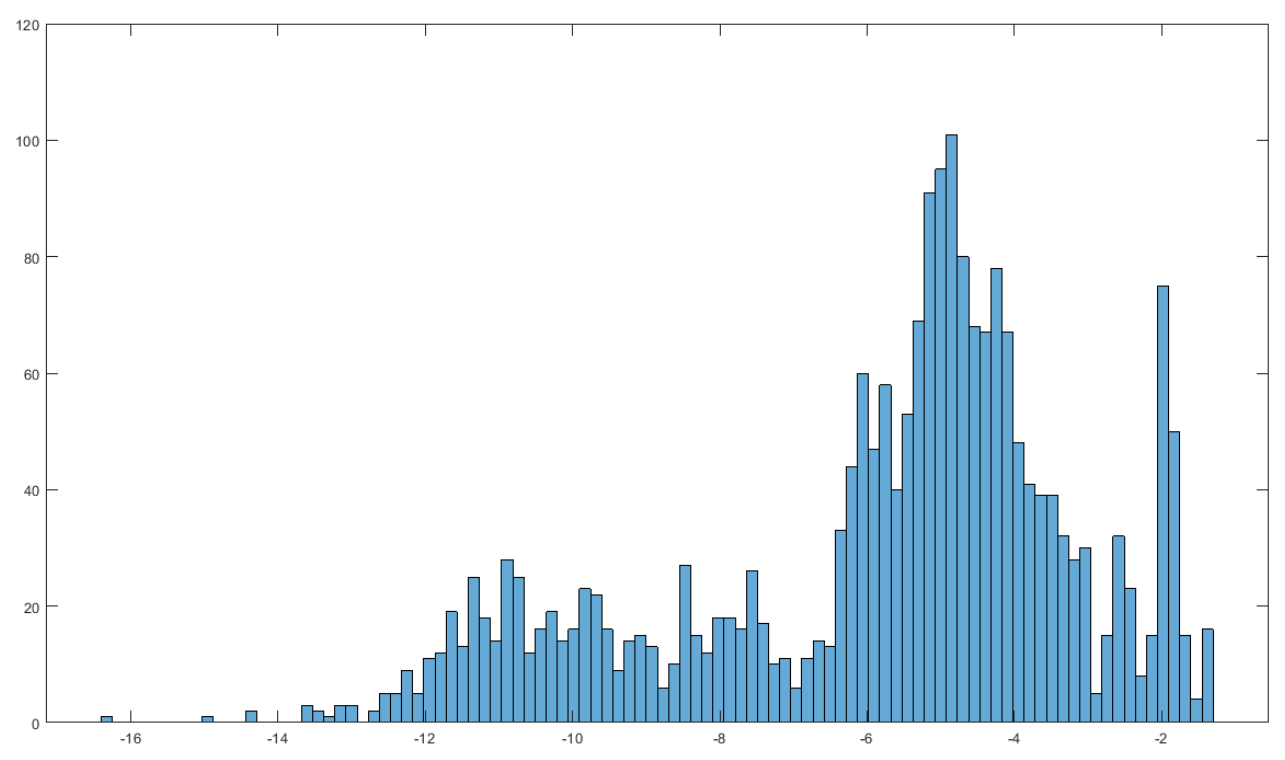




\section{Counterfactual simulations: Additional tables}

Table 12: Results of Scenario A "No Alliance" (by retailers)

\begin{tabular}{|c|c|c|c|c|}
\hline & \multirow{2}{*}{$\% \Delta$ Retail price } & \multicolumn{2}{|c|}{$\% \Delta$ Margins } & \multirow{2}{*}{$\% \Delta$ Profit of retailers } \\
\hline & & Retailers & Manufacturers & \\
\hline \multicolumn{5}{|c|}{ Inside alliances: } \\
\hline Retailer 1 & $\begin{array}{l}-9.87 \\
(0.24)\end{array}$ & $\begin{array}{c}2.89 \\
(0.13)\end{array}$ & $\begin{array}{c}-70.23 \\
(0.08)\end{array}$ & $\begin{array}{l}37.50 \\
(0.25)\end{array}$ \\
\hline Retailer 2 & $\begin{array}{c}-14.25 \\
(0.94)\end{array}$ & $\begin{array}{c}0.56 \\
(0.07)\end{array}$ & $\begin{array}{c}-77.07 \\
(0.11)\end{array}$ & $\begin{array}{l}65.90 \\
(0.34)\end{array}$ \\
\hline Retailer 3 & $\begin{array}{l}-5.48 \\
(0.16)\end{array}$ & $\begin{array}{c}0.42 \\
(0.04)\end{array}$ & $\begin{array}{c}-32.98 \\
(0.05)\end{array}$ & $\begin{array}{l}10.04 \\
(0.20)\end{array}$ \\
\hline Retailer 4 & $\begin{array}{l}-9.42 \\
(0.35)\end{array}$ & $\begin{array}{c}0.91 \\
(0.04)\end{array}$ & $\begin{array}{c}-48.95 \\
(0.06)\end{array}$ & $\begin{array}{l}32.86 \\
(0.23)\end{array}$ \\
\hline Retailer 5 & $\begin{array}{l}-5.80 \\
(0.28)\end{array}$ & $\begin{array}{c}0.49 \\
(0.06)\end{array}$ & $\begin{array}{c}-53.77 \\
(0.06)\end{array}$ & $\begin{array}{l}24.55 \\
(0.22)\end{array}$ \\
\hline Retailer 6 & $\begin{array}{c}-10.24 \\
(0.24)\end{array}$ & $\begin{array}{c}0.95 \\
(0.05)\end{array}$ & $\begin{array}{c}-64.92 \\
(0.06)\end{array}$ & $\begin{array}{l}50.56 \\
(0.30)\end{array}$ \\
\hline \multicolumn{5}{|c|}{ Outside alliances (national brands only): } \\
\hline Retailer 7 & $\begin{array}{l}-1.12 \\
(0.09)\end{array}$ & $\begin{array}{l}-1.27 \\
(0.06)\end{array}$ & $\begin{array}{c}-44.42 \\
(0.48)\end{array}$ & $\begin{array}{l}-7.58 \\
(0.17)\end{array}$ \\
\hline Retailer 8 & $\begin{array}{l}-0.64 \\
(0.05)\end{array}$ & $\begin{array}{l}-0.66 \\
(0.04)\end{array}$ & $\begin{array}{c}-44.45 \\
(0.71)\end{array}$ & $\begin{array}{l}-7.30 \\
(0.22)\end{array}$ \\
\hline
\end{tabular}

Notes: Standard deviation in parenthesis refer to variation across markets. Percentage changes in retail prices of national brands and price-cost margins over national brands relative to the "No Alliance" scenario are calculated using quantity weights. Percentage changes in profit of retailers over national brands (excluding private labels) relative to the "No Alliance" scenario. 
Table 13: Results of Scenario B "Joint delisting decision” (by retailers)

\begin{tabular}{|c|c|c|c|c|}
\hline & \multirow{2}{*}{$\% \Delta$ Retail price } & \multicolumn{2}{|c|}{ \% $\%$ Margins } & \multirow{2}{*}{$\% \Delta$ Profit of retailers } \\
\hline & & Retailers & Manufacturers & \\
\hline \multicolumn{5}{|c|}{ Inside alliances: } \\
\hline \multirow[t]{2}{*}{ Retailer 1} & -0.47 & -0.36 & -2.38 & -2.64 \\
\hline & $(0.11)$ & $(0.05)$ & $(0.98)$ & $(0.55)$ \\
\hline \multirow[t]{2}{*}{ Retailer 2} & -17.01 & 0.90 & -92.43 & 102.20 \\
\hline & (1.69) & $(0.04)$ & $(7.61)$ & $(12.32)$ \\
\hline \multirow[t]{2}{*}{ Retailer 3} & -4.35 & 0.75 & -29.44 & 14.64 \\
\hline & $(0.27)$ & $(0.04)$ & $(2.20)$ & (1.53) \\
\hline \multirow[t]{2}{*}{ Retailer 4} & -5.41 & 0.51 & -25.54 & 17.63 \\
\hline & $(0.51)$ & $(0.06)$ & $(2.25)$ & $(2.10)$ \\
\hline \multirow[t]{2}{*}{ Retailer 5} & -3.47 & 0.33 & -27.87 & 13.68 \\
\hline & $(0.26)$ & $(0.03)$ & $(2.10)$ & (1.47) \\
\hline \multirow[t]{2}{*}{ Retailer 6} & -3.23 & 0.32 & -24.95 & 17.48 \\
\hline & $(0.28)$ & $(0.04)$ & $(1.87)$ & (1.75) \\
\hline \multicolumn{5}{|c|}{ Outside alliances (national brands only): } \\
\hline \multirow[t]{2}{*}{ Retailer 7} & -0.43 & -0.54 & -16.12 & -3.23 \\
\hline & $(0.03)$ & $(0.02)$ & $(0.12)$ & $(0.09)$ \\
\hline \multirow[t]{2}{*}{ Retailer 8} & -0.24 & -0.28 & -15.75 & -3.15 \\
\hline & $(0.02)$ & $(0.02)$ & $(0.71)$ & $(0.10)$ \\
\hline
\end{tabular}

Notes: Standard deviation in parenthesis refer to variation across markets. Percentage changes in retail prices of national brands and price-cost margins over national brands relative to the "No Alliance" scenario are calculated using quantity weights. Percentage changes in profit of retailers over national brands (excluding private labels) relative to the "No Alliance" scenario.

Table 14: Results of Scenario C "Joint-bargaining paradox" (by retailers)

\begin{tabular}{|c|c|c|c|c|}
\hline & \multirow{2}{*}{$\% \Delta$ Retail price } & \multicolumn{2}{|c|}{ \% \% Margins } & \multirow{2}{*}{$\% \Delta$ Profit of retailers } \\
\hline & & Retailers & Manufacturers & \\
\hline \multicolumn{5}{|c|}{ Inside alliances: } \\
\hline \multirow[t]{2}{*}{ Retailer 1} & -0.12 & -0.14 & -0.54 & -1.10 \\
\hline & $(0.01)$ & $(0.01)$ & $(0.02)$ & $(0.03)$ \\
\hline \multirow[t]{2}{*}{ Retailer 2} & -4.36 & 0.17 & -23.56 & 12.56 \\
\hline & $(0.28)$ & $(0.02)$ & $(0.11)$ & $(0.67)$ \\
\hline \multirow[t]{2}{*}{ Retailer 3} & -0.13 & -0.08 & -0.61 & -1.08 \\
\hline & $(0.01)$ & $(0.00)$ & $(0.03)$ & $(0.05)$ \\
\hline \multirow[t]{2}{*}{ Retailer 4} & -4.63 & 0.62 & -24.31 & 12.00 \\
\hline & $(0.16)$ & $(0.02)$ & $(0.09)$ & $(0.25)$ \\
\hline \multirow[t]{2}{*}{ Retailer 5} & -0.07 & -0.11 & -0.46 & -1.17 \\
\hline & $(0.01)$ & $(0.01)$ & $(0.04)$ & $(0.03)$ \\
\hline \multirow[t]{2}{*}{ Retailer 6} & -3.85 & 0.41 & -24.40 & 19.51 \\
\hline & $(0.08)$ & $(0.02)$ & $(0.07)$ & $(0.06)$ \\
\hline \multicolumn{5}{|c|}{ Outside alliances (national brands only): } \\
\hline \multirow[t]{2}{*}{ Retailer 7} & -0.13 & -0.20 & -4.12 & -1.21 \\
\hline & $(0.01)$ & $(0.01)$ & $(0.14)$ & $(0.03)$ \\
\hline \multirow[t]{2}{*}{ Retailer 8} & -0.05 & -0.10 & -4.05 & -1.20 \\
\hline & $(0.00)$ & $(0.01)$ & $(0.17)$ & $(0.03)$ \\
\hline
\end{tabular}

Notes: Standard deviation in parenthesis refer to variation across markets. Percentage changes in retail prices of national brands and price-cost margins over national brands relative to the "No Alliance" scenario are calculated using quantity weights. Percentage changes in profit of retailers over national brands (excluding private labels) relative to the "No Alliance" scenario. 


\section{E Derivation of the price-cost margins}

\section{E.1 Price-cost margins of retailers}

This section provides details on the derivative of the price-cost margins of retailers. As described in Section 4.2.1, the maximization problem of each retailer gives rise to the following system of first-order conditions:

$$
s_{k, t}\left(\mathbf{p}_{t} ; \boldsymbol{\theta}^{d}\right)+\sum_{j \in \mathscr{I}_{r(k), t}}\left(p_{j, t}-w_{j, t}-c_{j, t}\right) \frac{\partial s_{j, t}}{\partial p_{k, t}}\left(\mathbf{p}_{t} ; \theta^{d}\right)=0 \quad \forall k \in \mathscr{J}_{t} \backslash\{0\}
$$

For computational ease, I rewrite (19) in vector-matrix notations:

$$
\boldsymbol{s}_{t}+\left(\mathbf{O}_{r, t} \circ \mathbf{S}_{\mathbf{p}_{t}}\right) \gamma_{t}=\mathbf{0}_{J_{t}}
$$

where $\gamma_{t}$ is the $J$-dimensional vector of price-cost margins of retailers with $\gamma_{t}[j, 1]=\gamma_{j, t}$, $\mathbf{O}_{r, t}$ denotes the $J_{t} \times J_{t}$ ownership matrix of retailers with $\mathbf{O}_{r, t}[j, k]=1$ if products $j$ and $k$ are sold by the same retailer in market $t$ and 0 otherwise, $\mathbf{S}_{\mathbf{p}_{t}}$ is the $J_{t} \times J_{t}$ matrix of first partial derivatives of market shares with respect to retail prices with $\mathbf{S}_{\mathbf{p}_{t}}[j, k]=\frac{\partial s_{k, t}}{\partial p_{j, t}}$, $\Delta_{t}$ is the $J_{t}$-dimensional vector of market shares with $s_{t}[j, 1]=s_{j, t}$, and the mathematical symbol "o" represents the Hadamard product operator (element-by-element multiplication). By inverting (20) as follows:

$$
\gamma_{t}=-\left(\mathbf{O}_{r, t} \circ \mathbf{S}_{\mathbf{p}_{t}}\right)^{-1} s_{t}
$$

one can recover the vector of price-cost margins of retailers in market $t$.

\section{E.2 Price-cost margins of manufacturers}

This section describes how to derive a closed-form expression for the price-cost margins of manufacturers in bilateral oligopolies under different bargaining situations. I first start with the pre-alliances periods where the derivatives are based on Bonnet, Bouamra-Mechemache and Molina (2018). Then, I consider the postalliances periods in which manufacturers negotiate with buyer alliances. Finally, I derive the price-cost margins of manufacturers in the joint delisting decision framework outlined in Section 5.

\section{E.2.1 Price-cost margins of manufacturers in the pre-alliances periods}

Consider the bilateral negotiation between manufacturer $f$ and retailer $r$ over the wholesale price of product $j \in \mathscr{J}_{f, t} \cap \mathscr{J}_{r, t}$, that is $w_{j, t}$.

Nash bargaining problem. Following Horn and Wolinsky (1988a), the equilibrium wholesale price $w_{j, t}^{*}$ is defined as maximizing the (asymmetric) Nash product of the bilateral negotiation between manufacturer $f$ 
and retailer $r$ taking as given the outcomes of other negotiations, that is:

$$
w_{j, t}^{*} \equiv \underset{w_{j, t}}{\operatorname{argmax}}\left(\pi_{f, t}-d_{f, t}^{-j}\right)^{\lambda_{f, r}^{\text {pre }}}\left(\pi_{r, t}-d_{r, t}^{-j}\right)^{1-\lambda_{f, r}^{\text {pre }}}
$$

The terms $\pi_{f, t}$ and $\pi_{r, t}$ denote respectively the profit of manufacturer $f$ and retailer $r$ if a bilateral agreement is formed:

$$
\begin{aligned}
\pi_{f, t}= & \left(w_{j, t}-\mu_{b(j), t}\right) M_{t} s_{j, t}\left(\mathbf{p}_{t}\left(w_{j, t}, \mathbf{w}_{-j, t}^{*}\right) ; \theta^{d}\right)+\sum_{k \in \mathscr{F}_{f, t}\{\{j\}}\left(w_{k, t}^{*}-\mu_{b(k), t}\right) M_{t} s_{k, t}\left(\mathbf{p}_{t}\left(w_{j, t}, \mathbf{w}_{-j, t}^{*}\right) ; \theta^{d}\right) \\
\pi_{r, t}= & \left(p_{j, t}\left(w_{j, t}, \mathbf{w}_{-j, t}^{*}\right)-w_{j, t}-c_{j, t}\right) M_{t} s_{j, t}\left(\mathbf{p}_{t}\left(w_{j, t}, \mathbf{w}_{-j, t}^{*}\right) ; \theta^{d}\right) \\
& +\sum_{k \in \mathscr{I}_{r, t}\{\{j\}}\left(p_{k, t}\left(w_{j, t}, \mathbf{w}_{-j, t}^{*}\right)-w_{k, t}^{*}-c_{k, t}\right) M_{t} s_{k, t}\left(\mathbf{p}_{t}\left(w_{j, t}, \mathbf{w}_{-j, t}^{*}\right) ; \theta^{d}\right)
\end{aligned}
$$

where $w_{k, t}^{*}$ corresponds to the (anticipated) equilibrium wholesale price of product $k \neq j$ and $\mathbf{w}_{-j, t}^{*}$ is the vector of (anticipated) wholesale prices negotiated by other pairs of firms. The terms $d_{f, t}^{-j}$ and $d_{r, t}^{-j}$ denote respectively the status quo payoffs of manufacturer $f$ and retailer $r$ in the event of bilateral disagreement which are specified as follows:

$$
\begin{aligned}
d_{f, t}^{-j} & =\sum_{k \in \mathscr{\not}_{f, t} \backslash\{j\}}\left(w_{k, t}^{*}-\mu_{b(k), t}\right) M_{t} \tilde{s}_{k, t}^{-j}\left(\tilde{\mathbf{p}}_{t}^{-j} ; \theta^{d}\right) \\
d_{r, t}^{-j} & =\sum_{k \in \mathscr{f}_{r, t} \backslash\{j\}}\left(\tilde{p}_{k, t}^{-j}\left(\infty, \mathbf{w}_{-j, t}^{*}\right)-w_{k, t}^{*}-c_{k, t}\right) M_{t} \tilde{\jmath}_{k, t}^{-j}\left(\tilde{\mathbf{p}}_{t}^{-j} ; \theta^{d}\right)
\end{aligned}
$$

where $\tilde{\mathbf{p}}_{t}^{-j}$ is the $J_{t}$-dimensional vector of out-of-equilibrium retail prices when product $j$ is no longer offered on market $t$ (see Appendix G.1) and $\tilde{s}_{k, t}^{-j}$ is the market share of each product $k$ remaining on the market which is computed as follows:

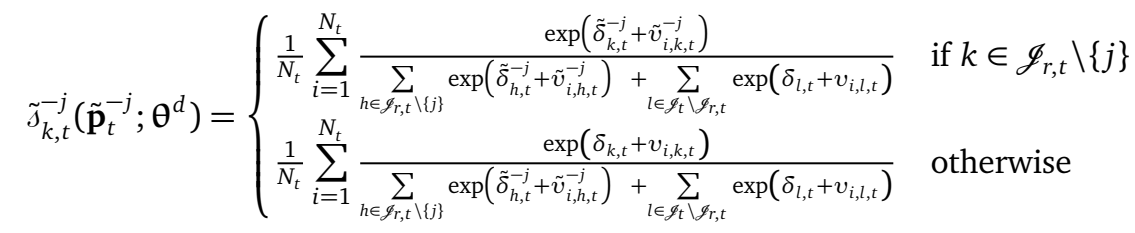

with $\tilde{\delta}_{k, t}^{-j} \equiv \phi x_{\text {spark }(k)}+\psi x_{\text {mineral }(k)}-\alpha \tilde{p}_{k, t}^{-j}+\beta_{0}+\beta_{t}+\beta_{b(k)}+\beta_{r(k)}+\xi_{k, t}$,

$$
\begin{gathered}
v_{i, k, t} \equiv \psi_{g\left(\text { age }_{i}\right)} x_{\text {mineral }(k)}-\alpha_{g\left(y_{i}\right)} p_{k, t}, \\
\tilde{v}_{i, k, t}^{-j} \equiv \psi_{g\left(a g e_{i}\right)} x_{\text {mineral }(k)}-\alpha_{g\left(y_{i}\right)} \tilde{p}_{k, t}^{-j} .
\end{gathered}
$$

First-order condition of the "Nash-in-Nash". The first-order condition of (22) which characterizes the division of surplus in this bilateral negotiation is derived as follows:

$$
\begin{gathered}
\left(1-\lambda_{f, r}^{p r e}\right)\left(\pi_{f, t}-d_{f, t}^{-j}\right) \frac{\partial \pi_{r, t}}{\partial w_{j, t}}+\lambda_{f, r}^{p r e}\left(\pi_{r, t}-d_{r, t}^{-j}\right) \frac{\partial \pi_{f, t}}{\partial w_{j, t}}=0 \\
\Leftrightarrow\left(\Gamma_{j, t}^{p r e} s_{j, t}\left(\mathbf{p}_{t} ; \theta^{d}\right)+\sum_{k \in \mathscr{I}_{f, t} \backslash\langle j\}} \Gamma_{k, t}^{p r e}\left(\jmath_{k, t}\left(\mathbf{p}_{t} ; \theta^{d}\right)-\tilde{s}_{k, t}^{-j}\left(\tilde{\mathbf{p}}_{t}^{-j} ; \theta^{d}\right)\right)\right)\left(\sum_{k \in \mathscr{I}_{r, t}} \frac{\partial p_{k, t}}{\partial w_{j, t}} s_{k, t}\left(\mathbf{p}_{t} ; \theta^{d}\right)-s_{j, t}\left(\mathbf{p}_{t} ; \theta^{d}\right)\right.
\end{gathered}
$$




$$
\begin{aligned}
& \left.+\sum_{h \in \mathscr{I}_{r, t}} \gamma_{h, t} \sum_{l \in \mathscr{f}_{r, t}} \frac{\partial s_{h, t}}{\partial p_{l, t}} \frac{\partial p_{l, t}}{\partial w_{j, t}}\right)+\frac{\lambda_{f, r}^{p r e}}{1-\lambda_{f, r}^{p r e}}\left(\gamma_{j, t} s_{j, t}\left(\mathbf{p}_{t} ; \theta^{d}\right)+\sum_{k \in \mathscr{I}_{r, t} \backslash\{j\}} \gamma_{k, t} s_{k, t}\left(\mathbf{p}_{t} ; \theta^{d}\right)-\tilde{\gamma}_{k, t}^{-j} \tilde{y}_{k, t}^{-j}\left(\tilde{\mathbf{p}}_{t}^{-j} ; \theta^{d}\right)\right) \\
& \left(s_{j, t}\left(\mathbf{p}_{t} ; \theta^{d}\right)+\sum_{k \in \mathscr{g}_{f, t}} \Gamma_{k, t}^{p r e} \sum_{l \in \mathscr{f}_{r, t}} \frac{\partial s_{k, t}}{\partial p_{l, t}} \frac{\partial p_{l, t}}{\partial w_{j, t}}\right)=0
\end{aligned}
$$

where $\Gamma_{j, t}^{p r e} \equiv w_{j, t}-\mu_{b(j), t}, \gamma_{j, t} \equiv p_{j, t}-w_{j, t}-c_{j, t}$, and $\tilde{\gamma}_{k, t}^{-j} \equiv \tilde{p}_{k, t}^{-j}-w_{k, t}^{*}-c_{k, t}$.

Manufacturers' price-cost margins. For each market $t$, there are a total of $J_{t}$ price-cost margins of manufacturers to recover, that is $\Gamma_{j, t}^{p r e} \forall j \in \mathscr{J}_{t}{ }^{66}$ To this end, I rely on a system of $J_{t}$ equations where (24) describes the $j$ th equation. In particular, it can be shown that the left-hand side of (24) is the $j$ th equation of the following system of "Nash-in-Nash" first-order conditions written in vector-matrix notations as follows:

$$
\begin{aligned}
& \left(\left(\mathbf{O}_{f, t} \circ \tilde{\mathbf{S}}_{\Delta t}^{p r e}\right) \boldsymbol{\Gamma}_{t}^{p r e}\right) \circ\left(\left(\mathbf{P}_{\mathbf{w}_{t}}^{p r e}-\mathbf{O}_{r, t} \circ \mathbf{I}_{t}\right) \boldsymbol{\Delta}_{t}+\mathbf{P}_{\mathbf{w}_{t}}^{p r e}\left(\mathbf{O}_{r, t} \circ \mathbf{S}_{\mathbf{p}_{t}}\right) \boldsymbol{\gamma}_{t}\right)+\Lambda^{p r e} \circ\left(\mathbf{O}_{r, t} \circ\left(\mathbf{1}_{J_{t}} \Delta_{t}^{\top}\right) \boldsymbol{\gamma}_{t}\right. \\
& \left.+\left(\mathbf{O}_{r, t} \circ\left(\tilde{\mathbf{S}}_{\Delta t}^{p r e}-\mathbf{1}_{J_{t}} \Delta_{t}^{\top}\right) \circ\left(\tilde{\boldsymbol{\gamma}}_{t}^{p r e}\right)^{\top}\right) \mathbf{1}_{J_{t}}\right) \circ\left(\Delta_{t}+\left(\left(\mathbf{P}_{\mathbf{w}_{t}}^{p r e} \mathbf{S}_{\mathbf{p}_{t}}\right) \circ \mathbf{O}_{f, t}\right) \mathbf{\Gamma}_{t}^{p r e}\right)=\mathbf{0}_{J_{t}}
\end{aligned}
$$

where the mathematical symbol "o" represents the Hadamard product operator (element-by-element multiplication), $\mathbf{O}_{f, t}$ is the $J_{t} \times J_{t}$ ownership matrix of manufacturers in market $t$ with $\mathbf{O}_{f, t}[j, k]=1$ if products $j$ and $k$ are produced by the same manufacturer in market $t$ and 0 otherwise, $\mathbf{I}_{t}$ is a $J_{t} \times J_{t}$ diagonal matrix, $\mathbf{1}_{J_{t}}$ is an all-ones vector of dimension $J_{t}$ (every element is equal to 1 ), $\Lambda^{\text {pre }}$ is a $J_{t}$-dimensional vector in which the $j$ th element is $\frac{\lambda_{f(j), r(j)}^{\text {pre }}}{1-\lambda_{f(j), r(j)}^{\text {Pr }}}, \tilde{\mathbf{s}}_{\Delta t}^{\text {pre }}$ is a $J_{t} \times J_{t}$ matrix given by:

$$
\tilde{\mathbf{S}}_{\Delta t}^{p r e}=\left(\begin{array}{cccc}
s_{1, t}\left(\mathbf{p}_{t} ; \theta^{d}\right) & -\Delta \tilde{\mathrm{J}}_{2, t}^{-1}\left(\tilde{\mathbf{p}}_{t}^{-1} ; \theta^{d}\right) & \cdots & -\Delta \tilde{J}_{J_{t}, t}^{-1}\left(\tilde{\mathbf{p}}_{t}^{-1} ; \theta^{d}\right) \\
-\Delta \tilde{y}_{1, t}^{-2}\left(\tilde{\mathbf{p}}_{t}^{-2} ; \theta^{d}\right) & s_{2, t}\left(\mathbf{p}_{t} ; \theta^{d}\right) & \cdots & -\Delta \tilde{J}_{J_{t}, t}^{-2}\left(\tilde{\mathbf{p}}_{t}^{-2} ; \theta^{d}\right) \\
\vdots & \vdots & \ddots & \vdots \\
-\Delta \tilde{y}_{1, t}^{-J_{t}}\left(\tilde{\mathbf{p}}_{t}^{-J_{t}} ; \theta^{d}\right) & -\Delta \tilde{\jmath}_{2, t}^{-J_{t}}\left(\tilde{\mathbf{p}}_{t}^{-J_{t}} ; \theta^{d}\right) & \cdots & s_{J_{t}, t}\left(\mathbf{p}_{t} ; \theta^{d}\right)
\end{array}\right)
$$

with $-\Delta \tilde{y}_{k, t}^{-j}\left(\tilde{\mathbf{p}}_{t}^{-j} ; \theta^{d}\right)=s_{k, t}\left(\mathbf{p}_{t} ; \theta^{d}\right)-\tilde{s}_{k, t}^{-j}\left(\tilde{\mathbf{p}}_{t}^{-j} ; \theta^{d}\right), \tilde{\gamma}_{t}^{p r e}$ is a $J_{t} \times J_{t}$ matrix given by:

$$
\tilde{\gamma}_{t}^{p r e}[k, j]= \begin{cases}\infty & \text { if } k=j \\ \tilde{\gamma}_{k, t}^{-j}=\tilde{p}_{k, t}^{-j}+\gamma_{k, t}-p_{k, t} & \text { if } k \neq j \text { and } j, k \in \mathscr{J}_{r, t} \\ \gamma_{k, t} & \text { otherwise }\end{cases}
$$

and $\mathbf{P}_{\mathbf{w}_{t}}^{\text {pre }}$ is the $J_{t} \times J_{t}$ matrix of retail pass-through defined by (40) in Appendix F.1.

Define $\left.\quad \mathbf{V}_{t}^{p r e} \equiv\left(\mathbf{P}_{\mathbf{w}_{t}}^{p r e}-\mathbf{O}_{r, t} \circ \mathbf{I}_{t}\right)\right\lrcorner_{t}+\mathbf{P}_{\mathbf{w}_{t}}^{p r e}\left(\mathbf{O}_{r, t} \circ \mathbf{S}_{\mathbf{p}_{t}}\right) \gamma_{t} ; \mathbf{M}_{t}^{p r e} \equiv \mathbf{O}_{f, t} \circ \tilde{\mathbf{S}}_{\Delta t}^{p r e} ;$

$$
\tilde{\mathbf{V}}_{t}^{p r e} \equiv \mathbf{O}_{r, t} \circ\left(\mathbf{1}_{J_{t}} \Delta_{t}^{\top}\right) \boldsymbol{\gamma}_{t}+\left(\mathbf{O}_{r, t} \circ\left(\tilde{\mathbf{S}}_{\Delta t}^{p r e}-\mathbf{1}_{J_{t}} s_{t}^{\top}\right) \circ\left(\tilde{\boldsymbol{\gamma}}_{t}^{p r e}\right)^{\top}\right) \mathbf{1}_{J_{t}} ; \tilde{\mathbf{M}}_{t}^{p r e} \equiv\left(\mathbf{P}_{\mathbf{w}_{t}}^{p r e} \mathbf{S}_{\mathbf{p}_{t}}\right) \circ \mathbf{O}_{f, t} ;
$$

and rewrite the system of $J_{t}$ equations (25) as follows:

$$
\mathbf{V}_{t}^{p r e} \circ\left(\mathbf{M}_{t}^{p r e} \boldsymbol{\Gamma}_{t}^{p r e}\right)+\Lambda^{p r e} \circ \tilde{\mathbf{V}}_{t}^{p r e} \circ \unlhd_{t}+\Lambda^{p r e} \circ \tilde{\mathbf{V}}_{t}^{p r e} \circ\left(\tilde{\mathbf{M}}_{t}^{p r e} \boldsymbol{\Gamma}_{t}^{p r e}\right)=\mathbf{0}_{J_{t}}
$$

\footnotetext{
${ }^{66}$ For the sake of exposition, I omit private label products for which $\Gamma_{j, t}^{p r e}=0$.
} 
From (26), Bonnet, Bouamra-Mechemache and Molina (2018) have shown that the $J_{t}$-dimensional vector of price-cost margins of manufacturers can be derived as follows:

$$
\boldsymbol{\Gamma}_{t}^{\text {pre }}=-\left(\left(\mathbf{V}_{t}^{\text {pre }} \mathbf{1}_{J_{t}}^{\top}\right) \circ \mathbf{M}_{t}^{\text {pre }}+\left(\left(\Lambda^{\text {pre }} \circ \tilde{\mathbf{V}}_{t}^{\text {pre }}\right) \mathbf{1}_{J_{t}}^{\top}\right) \circ \tilde{\mathbf{M}}_{t}^{\text {pre }}\right)^{-\mathbf{1}}\left(\Lambda^{\text {pre }} \circ \tilde{\mathbf{V}}_{t}^{\text {pre }} \circ \triangleleft_{t}\right)
$$

\section{E.2.2 Price-cost margins of manufacturers in the post-alliances periods}

In the post-alliances periods, each manufacturer engages in bilateral negotiations with alliances of retailers to determine wholesale prices. Before considering the resolution of the bargaining stage, I introduce the following notations. Let $a(j)$ denote the alliance of retailers purchasing product $j,{ }^{67} \mathscr{J}_{a, t}$ is the set of products purchased by the alliance $a$, and $\mathscr{J}_{b, t}$ is the set of products sold under the brand name $b$. I consider that a buyer alliance aims at maximizing the joint profits of its members. Furthermore, retailers involved in the alliance $a$ obtain nondiscriminatory trading terms when purchasing brand $b$ : e.g., $w_{j, t}=w_{k, t}=w_{a, b, t} \forall j, k \in$ $\mathscr{J}_{a, t} \cap \mathscr{J}_{b, t}$. In what follows, I describe the bilateral bargaining between manufacturer $f$ and the alliance $a$ over the wholesale price of product $j \in \mathscr{J}_{a, t} \cap \mathscr{J}_{b, t}$, where brand $b$ is sold by manufacturer $f$.

Nash bargaining problem. Following Horn and Wolinsky (1988a), the equilibrium wholesale price $w_{a, b, t}^{*}$ maximizes the (asymmetric) Nash product of the bilateral negotiation between manufacturer $f$ and the alliance $a$ taking as given the outcomes of other bilateral negotiations, that is:

$$
w_{a, b, t}^{*} \equiv \underset{w_{a, b, t}}{\operatorname{argmax}}\left(\pi_{f, t}-d_{f, t}^{-a, b}\right)^{\lambda_{f, a}^{\text {post }}}\left(\pi_{a, t}-d_{a, t}^{-a, b}\right)^{1-\lambda_{f, a}^{\text {post }}}
$$

The terms $\pi_{f, t}$ and $\pi_{a, t}$ denote respectively the profit of manufacturer $f$ and the alliance $a$ in case of bilateral agreement:

$$
\begin{aligned}
& \pi_{f, t}=\sum_{j \in \mathscr{q}_{a, t} \cap \mathscr{F}_{b, t}}\left(w_{a, b, t}-\mu_{b, t}\right) M_{t} s_{j, t}\left(\mathbf{p}_{t}\left(w_{a, b, t}, \mathbf{w}_{-a, b, t}^{*}\right) ; \theta^{d}\right) \\
& +\sum_{k \in \mathscr{F}_{f, t}\left\{\left\{\mathscr{q}_{a, t} \cap \mathscr{g}_{b, t}\right\}\right.}\left(w_{a(k), b(k), t}^{*}-\mu_{b(k), t}\right) M_{t} s_{k, t}\left(\mathbf{p}_{t}\left(w_{a, b, t}, \mathbf{w}_{-a, b, t}^{*}\right) ; \theta^{d}\right) \\
& \pi_{a, t}=\sum_{j \in \mathscr{q}_{a, t} \cap \mathscr{q}_{b, t}}\left(p_{j, t}\left(w_{a, b, t}, \mathbf{w}_{-a, b, t}^{*}\right)-w_{a, b, t}-c_{j, t}\right) M_{t} s_{h, t}\left(\mathbf{p}_{t}\left(w_{a, b, t}, \mathbf{w}_{-a, b, t}^{*}\right) ; \theta^{d}\right) \\
& +\sum_{k \in \mathscr{I}_{a, t} \backslash \mathscr{g}_{b, t}}\left(p_{k, t}\left(w_{a, b, t}, \mathbf{w}_{-a, b, t}^{*}\right)-w_{a, b(k), t}^{*}-c_{k, t}\right) M_{t} s_{k, t}\left(\mathbf{p}_{t}\left(w_{a, b, t}, \mathbf{w}_{-a, b, t}^{*}\right) ; \theta^{d}\right)
\end{aligned}
$$

where $\mathbf{w}_{-a, b, t}^{*}$ denotes the (anticipated) equilibrium wholesale price vector of products other than those belonging to brand $b$ and purchased by the alliance $a$. The terms $d_{f, t}^{-a, b}$ and $d_{a, t}^{-a, b}$ are respectively the status quo payoffs of manufacturer $f$ and of the alliance $a$ in the event of disagreement:

$$
\begin{aligned}
& d_{f, t}^{-a, b}=\sum_{k \in \mathscr{F}_{f, t} \backslash\left\{\mathscr{q}_{a, t} \cap \mathscr{F}_{b, t}\right\}}\left(w_{a(k), b(k), t}^{*}-\mu_{b(k), t}\right) M_{t} \tilde{s}_{k, t}^{-a, b}\left(\tilde{\mathbf{p}}_{t}^{-a, b} ; \theta^{d}\right) \\
& d_{a, t}^{-a, b}=\sum_{k \in \mathscr{\mathscr { F }}_{a, t} \backslash \mathscr{q}_{b, t}}\left(\tilde{p}_{k, t}^{-a, b}-w_{a, b(k), t}^{*}-c_{k, t}\right) M_{t} \tilde{s}_{k, t}^{-a, b}\left(\tilde{\mathbf{p}}_{t}^{-a, b} ; \theta^{d}\right)
\end{aligned}
$$

\footnotetext{
${ }^{67}$ If retailer $r(j)$ has not formed any alliance, I consider that $a(j)=r(j)$.
} 
where $\tilde{\mathbf{p}}_{t}^{-a, b}$ is the $J_{t}$-dimensional vector of out-of-equilibrium retail prices when all product $j \in \mathscr{J}_{a, t} \cap \mathscr{J}_{b, t}$ are no longer offered on market $t$ (see Appendix G.2) and $\tilde{s}_{k, t}^{-a, b}$ is the market share of each product $k$ remaining on the market, which is computed as follows:

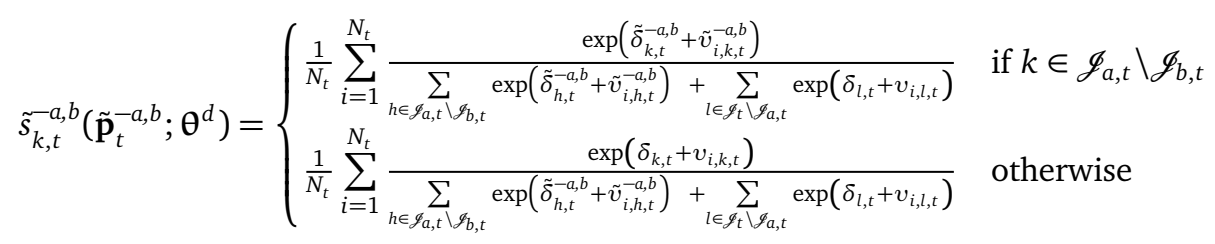

with $\tilde{\delta}_{k, t}^{-a, b} \equiv \phi x_{\text {spark }(k)}+\psi x_{\text {mineral }(k)}-\alpha \tilde{p}_{k, t}^{-a, b}+\beta_{0}+\beta_{t}+\beta_{b(k)}+\beta_{r(k)}+\xi_{k, t}$,

$$
\tilde{v}_{i, k, t}^{-a, b} \equiv \psi_{g\left(a g e_{i}\right)} x_{\text {mineral }(k)}-\alpha_{g\left(y_{i}\right)} \tilde{p}_{k, t}^{-a, b} .
$$

First-order condition of the "Nash-in-Nash". The first-order condition of (27) which characterizes the surplus division in the bilateral negotiation is derived as follows:

$$
\begin{aligned}
& \left(1-\lambda_{f, a}^{\text {post }}\right)\left(\pi_{f, t}-d_{f, t}^{-a, b}\right) \frac{\partial \pi_{a, t}}{\partial w_{a, b, t}}+\lambda_{f, a}^{\text {post }}\left(\pi_{a, t}-d_{a, t}^{-a, b}\right) \frac{\partial \pi_{f, t}}{\partial w_{a, b, t}}=0 \\
& \Leftrightarrow\left(\sum_{j \in \mathscr{g}_{a, t} \cap \mathscr{F}_{b, t}} \Gamma_{a, b, t}^{\text {post }} s_{j, t}\left(\mathbf{p}_{t} ; \theta^{d}\right)+\sum_{k \in \mathscr{f}_{f, t} \backslash\left\{\mathscr{f}_{a, t} \cap \mathscr{q}_{b, t}\right\}} \Gamma_{a(k), b(k), t}^{\text {post }}\left(s_{k, t}\left(\mathbf{p}_{t} ; \theta^{d}\right)-\tilde{y}_{k, t}^{-a, b}\left(\tilde{\mathbf{p}}_{t}^{-a, b} ; \theta^{d}\right)\right)\right) \\
& \left(\sum_{j \in \mathscr{I}_{a, t}} \frac{\partial p_{j, t}}{\partial w_{a, b, t}} s_{j, t}\left(\mathbf{p}_{t} ; \theta^{d}\right)-\sum_{k \in \mathscr{I}_{a, t} \cap \mathscr{g}_{b, t}} s_{k, t}\left(\mathbf{p}_{t} ; \theta^{d}\right)+\sum_{h \in \mathscr{I}_{a, t}} \gamma_{h, t} \sum_{l \in \mathscr{I}_{a, t}} \frac{\partial s_{h, t}}{\partial p_{l, t}} \frac{\partial p_{l, t}}{\partial w_{a, b, t}}\right) \\
& +\frac{\lambda_{f, a}}{1-\lambda_{f, a}}\left(\sum_{j \in \mathscr{g}_{a, t} \cap \mathscr{g}_{b, t}} \gamma_{j, t} s_{j, t}\left(\mathbf{p}_{t} ; \theta^{d}\right)+\sum_{k \in \mathscr{q}_{a, t} \backslash \mathscr{b}_{b, t}} \gamma_{k, t} s_{k, t}\left(\mathbf{p}_{t} ; \theta^{d}\right)-\tilde{\gamma}_{k, t}^{-a, b} \tilde{\jmath}_{k, t}^{-a, b}\left(\tilde{\mathbf{p}}_{t}^{-a, b} ; \theta^{d}\right)\right)
\end{aligned}
$$

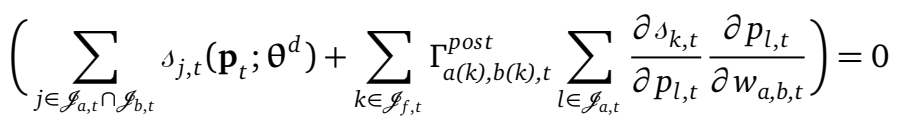

where $\Gamma_{a(j), b(j), t}^{p o s t} \equiv w_{a(j), b(j), t}-\mu_{b(j), t}$ and $\tilde{\gamma}_{k, t}^{-a, b} \equiv \tilde{p}_{k, t}^{-a, b}-w_{a(k), b(k), t}^{*}-c_{k, t}$.

Manufacturers' price-cost margins. Let $B_{a, t}^{*}$ be the number of national brands purchased by the alliance $a$ in market $t$. For each market $t$, there are a total of $\sum_{a} B_{a, t}^{*}$ price-cost margins of manufacturers to recover, that is $\Gamma_{a(j), b(j), t}^{p o s t} \forall j \in \mathscr{J}_{t}{ }^{68}$ To this end, I rely on a system of $\sum_{a} B_{a, t}^{*}$ equations where the $a(j) \times b(j)$ th equation is described by (29). In particular, it can be shown that the left-hand side of (29) is the $a(j) \times b(j)$ th equation of the following system of "Nash-in-Nash" first-order conditions written in vector-matrix notations as follows:

$$
\begin{aligned}
& \left(\mathbf{U}_{t}^{*}\left(\mathbf{O}_{f, t} \circ \tilde{\mathbf{S}}_{\Delta t}^{\text {post }}\right) \mathbf{U}_{t}^{\top} \boldsymbol{\Gamma}_{t}^{\text {post }}\right) \circ\left(\mathbf{U}_{t}^{*}\left(\mathbf{P}_{\mathbf{w}_{t}}^{\text {post }} \boldsymbol{s}_{t}-\left(\mathbf{O}_{a, t} \circ \mathbf{O}_{b, t}\right) s_{t}+\mathbf{P}_{\mathbf{w}_{t}}^{\text {post }}\left(\mathbf{O}_{a, t} \circ \mathbf{S}_{\mathbf{p}_{t}}\right) \boldsymbol{\gamma}_{t}\right)\right) \\
& +\boldsymbol{\Lambda}^{\text {post }} \circ\left(\mathbf{U}_{t}^{*}\left(\left(\mathbf{O}_{a, t} \circ\left(\mathbf{1}_{J_{t}} \Delta_{t}^{\top}\right)\right) \boldsymbol{\gamma}_{t}+\mathbf{O}_{a, t} \circ\left(\tilde{\mathbf{S}}_{\Delta t}^{\text {post }}-\mathbf{1}_{J_{t}} \boldsymbol{\Delta}_{t}^{\top}\right) \circ\left(\tilde{\boldsymbol{\gamma}}_{t}^{\text {post }}\right)^{\top} \mathbf{1}_{J_{t}}\right)\right) \\
& \circ\left(\mathbf{U}_{t}^{*}\left(\left(\mathbf{O}_{a, t} \circ \mathbf{O}_{b, t}\right) \Delta_{t}+\left(\mathbf{P}_{\mathbf{w}_{t}}^{\text {post }} \mathbf{S}_{\mathbf{p}_{t}}\right) \circ \mathbf{O}_{f, t} \mathbf{U}_{t}^{\top} \boldsymbol{\Gamma}_{t}^{\text {post }}\right)\right)=\mathbf{0}_{\sum_{a} B_{a, t}^{*}}
\end{aligned}
$$

\footnotetext{
${ }^{68}$ Again, for the sake of exposition I omit private label products for which $\Gamma_{a(j), b(j), t}^{p o s t}=0$.
} 
where the mathematical symbol "o" represents the Hadamard product operator (element-by-element multiplication), $\mathbf{U}_{t}$ is a $\sum_{a} B_{a, t}^{*} \times J_{t}$ matrix in which the element in row $j$ and column $k$ equals 1 if $k \in \mathscr{J}_{a(j), t} \cap \mathscr{J}_{b(j), t}$ and 0 otherwise, $\mathbf{U}_{t}^{*}$ is a matrix similar to $\mathbf{U}_{t}$ except that, for each row, there is only one element equals to $1, \mathbf{1}_{\sum_{a} B_{a, t}^{*}}$ is an all-ones vector of dimension $\sum_{a} B_{a, t}^{*}$ (every element is equal to 1 ), $\mathbf{O}_{a, t}$ is the $J_{t} \times J_{t}$ ownership matrix of the buyer alliances in market $t$ with $\mathbf{O}_{a, t}[j, k]=1$ if product $j$ and $k$ are purchased by the same alliance and 0 otherwise, $\mathbf{O}_{b, t}$ is the $J_{t} \times J_{t}$ ownership matrix of the brands with $\mathbf{O}_{b, t}[j, k]=1$ if products $j$ and $k$ are sold under the same brand name and 0 otherwise, $\Lambda^{\text {post }}$ is a $J_{t}$-dimensional vector in which the $j$ th element is $\frac{\lambda_{f(f), r(j)}^{\text {post }}}{1-\lambda_{f(j), r(j)}^{\text {pos }}}, \tilde{\mathbf{S}}_{\Delta t}^{\text {post }}$ is a $J_{t} \times J_{t}$ matrix given by:

$$
\tilde{\mathbf{s}}_{\Delta t}^{\text {post }}[j, k]= \begin{cases}s_{k, t}\left(\mathbf{p}_{t} ; \boldsymbol{\theta}^{d}\right) & \text { if } j, k \in \mathscr{J}_{a, t} \cap \mathscr{I}_{b, t} \\ \jmath_{k, t}\left(\mathbf{p}_{t} ; \theta^{d}\right)-\tilde{s}_{k, t}^{-a, b}\left(\tilde{\mathbf{p}}_{t}^{-a, b} ; \theta^{d}\right) & \text { otherwise }\end{cases}
$$

$\tilde{\boldsymbol{\gamma}}_{t}^{\text {post }}$ corresponds to a $J_{t} \times J_{t}$ matrix described as follows:

$$
\tilde{\boldsymbol{\gamma}}_{t}^{\text {post }}[k, j]= \begin{cases}\infty & \text { if } j, k \in \mathscr{J}_{a, t} \cap \mathscr{J}_{b, t} \\ \tilde{\boldsymbol{\gamma}}_{t}^{-a, b}[k, 1] & \text { if } k \in \mathscr{J}_{a, t} \backslash \mathscr{J}_{b, t} \text { with } \tilde{\boldsymbol{\gamma}}_{t}^{-a, b}=-\left(\mathbf{O}_{r, t} \circ \tilde{\mathbf{S}}_{\tilde{\mathbf{p}}_{t}^{-a, b}}\right)^{-1} \delta_{t}^{-a, b}\left(\tilde{\mathbf{p}}_{t}^{-a, b}\right) \\ \gamma_{t}[k, 1] & \text { otherwise }\end{cases}
$$

and $\mathbf{P}_{\mathbf{w}_{t}}^{\text {post }}$ is the $J_{t} \times J_{t}$ matrix of retail pass-through defined by (44) in Appendix F.2.

Define $\mathbf{V}_{t}^{\text {post }} \equiv \mathbf{U}_{t}^{*}\left(\mathbf{P}_{\mathbf{w}_{t}}^{\text {post }} \boldsymbol{s}_{t}-\left(\mathbf{O}_{a, t} \circ \mathbf{O}_{b, t}\right) \boldsymbol{s}_{t}+\mathbf{P}_{\mathbf{w}_{t}}^{\text {post }}\left(\mathbf{O}_{a, t} \circ \mathbf{S}_{\mathbf{p}_{t}}\right) \boldsymbol{\gamma}_{t}\right)$;

$$
\begin{aligned}
\mathbf{M}_{t}^{\text {post }} & \equiv \mathbf{U}_{t}^{*}\left(\mathbf{O}_{f, t} \circ \tilde{\mathbf{S}}_{\Delta t}^{\text {post }}\right) \mathbf{U}_{t}^{\top} ; \\
\tilde{\mathbf{V}}_{t}^{\text {post }} & \equiv \mathbf{U}_{t}^{*}\left(\left(\mathbf{O}_{a, t} \circ\left(\mathbf{1}_{J_{t}} S_{t}^{\top}\right)\right) \boldsymbol{\gamma}_{t}+\mathbf{O}_{a, t} \circ\left(\tilde{\mathbf{S}}_{\Delta t}^{\text {post }}-\mathbf{1}_{J_{t}} \boldsymbol{S}_{t}^{\top}\right) \circ\left(\tilde{\boldsymbol{\gamma}}_{t}^{\text {post }}\right)^{\top} \mathbf{1}_{J_{t}}\right) ; \\
\tilde{\mathbf{M}}_{t}^{\text {post }} & \equiv \mathbf{U}_{t}^{*}\left(\left(\mathbf{P}_{\mathbf{w}_{t}}^{\text {post }} \mathbf{S}_{\mathbf{p}_{t}}\right) \circ \mathbf{O}_{f, t} \mathbf{U}_{t}^{\top}\right) ;
\end{aligned}
$$

and rewrite the system of $\sum_{a} B_{a, t}^{*}$ equations (30) as follows:

$$
\mathbf{V}_{t}^{\text {post }} \circ\left(\mathbf{M}_{t}^{\text {post }} \boldsymbol{\Gamma}_{t}^{\text {post }}\right)+\boldsymbol{\Lambda}^{\text {post }} \circ \tilde{\mathbf{V}}_{t}^{\text {post }} \circ\left(\mathbf{U}_{t}^{*}\left(\mathbf{O}_{a, t} \circ \mathbf{O}_{b, t}\right) \triangleleft_{t}\right)+\Lambda^{\text {post }} \circ \tilde{\mathbf{V}}_{t}^{\text {post }} \circ\left(\tilde{\mathbf{M}}_{t}^{\text {post }} \boldsymbol{\Gamma}_{t}^{\text {post }}\right)=\mathbf{0}_{J_{t}}
$$

It can be shown that (31) can be rewritten as:

$$
\left(\left(\mathbf{V}_{t}^{\text {post }} \mathbf{1}_{\sum_{a}^{\top} B_{a, t}^{*}}\right) \circ \mathbf{M}_{t}^{\text {post }}\right) \boldsymbol{\Gamma}_{t}^{\text {post }}+\left(\left(\left(\boldsymbol{\Lambda}^{\text {post }} \circ \tilde{\mathbf{V}}_{t}^{\text {post }}\right) \mathbf{1}_{\sum_{a}^{\top} B_{a, t}^{*}}^{\top}\right) \circ \tilde{\mathbf{M}}_{t}^{\text {post }}\right) \boldsymbol{\Gamma}_{t}^{\text {post }}=-\boldsymbol{\Lambda}^{\text {post }} \circ \tilde{\mathbf{V}}_{t}^{\text {post }} \circ\left(\mathbf{U}_{t}^{*}\left(\mathbf{O}_{a, t} \circ \mathbf{O}_{b, t}\right) \Delta_{t}\right)
$$

and that the $\sum_{a} B_{a, t}^{*}$-dimensional vector of price-cost margins of manufacturers is derived as follows:

$$
\boldsymbol{\Gamma}_{t}^{\text {post }}=-\left(\left(\mathbf{V}_{t}^{\text {post }} \mathbf{1}_{\sum_{a}^{\top} B_{a, t}^{*}}^{\top}\right) \circ \mathbf{M}_{t}^{\text {post }}+\left(\left(\Lambda^{\text {post }} \circ \tilde{\mathbf{V}}_{t}^{\text {post }}\right) \mathbf{1}_{\sum_{a} B_{a, t}^{*}}^{\top}\right) \circ \tilde{\mathbf{M}}_{t}^{\text {post }}\right)^{-1}\left(\Lambda^{\text {post }} \circ \tilde{\mathbf{V}}_{t}^{\text {post }} \circ\left(\mathbf{U}_{t}^{*}\left(\mathbf{O}_{a, t} \circ \mathbf{O}_{b, t}\right) \Delta_{t}\right)\right)
$$




\section{E.2.3 Price-cost margins of manufacturers in the joint delisting decision framework}

In the joint delisting decision framework, each manufacturer engages in secret bilateral negotiations with each retailer (even those involved in the same buyer alliance). While retailers of an alliance negotiate wholesale prices separately and secretly, they are able to coordinate their purchasing decision by jointly delisting a manufacturer's brand from their shelves. Using notations introduced in Appendix E.2.1 and E.2.2, I consider the bilateral negotiation between manufacturer $f$ and retailer $r$ involved in the alliance $a$ over the wholesale price of product $j \in \mathscr{J}_{f, t} \cap \mathscr{J}_{r, t}$ sold under the brand name $b$.

Nash bargaining problem. Following Horn and Wolinsky (1988a), the equilibrium wholesale price $w_{j, t}^{*}$ is defined as maximizing the (asymmetric) Nash product of the bilateral negotiation between manufacturer $f$ and retailer $r$ taking as given the outcomes of other negotiations, that is:

$$
w_{j, t}^{*} \equiv \underset{w_{j, t}}{\operatorname{argmax}}\left(\pi_{f, t}-d_{f, t}^{-a, b}\right)^{\lambda_{f, r}}\left(\pi_{r, t}-d_{r, t}^{-a, b}\right)^{1-\lambda_{f, r}}
$$

The terms $\pi_{f, t}$ and $\pi_{r, t}$ denote respectively the profit of manufacturer $f$ and retailer $r$ if a bilateral agreement is reached:

$$
\begin{aligned}
\pi_{f, t}= & \left(w_{j, t}-\mu_{b(j), t}\right) M_{t} s_{j, t}\left(\mathbf{p}_{t}\left(w_{j, t}, \mathbf{w}_{-j, t}^{*}\right) ; \boldsymbol{\theta}^{d}\right)+\sum_{k \in \mathscr{I}_{f, t} \backslash\{j\}}\left(w_{k, t}^{*}-\mu_{b(k), t}\right) M_{t} s_{k, t}\left(\mathbf{p}_{t}\left(w_{j, t}, \mathbf{w}_{-j, t}^{*}\right) ; \boldsymbol{\theta}^{d}\right) \\
\pi_{r, t}= & \left(p_{j, t}\left(w_{j, t}, \mathbf{w}_{-j, t}^{*}\right)-w_{j, t}-c_{j, t}\right) M_{t} s_{j, t}\left(\mathbf{p}_{t}\left(w_{j, t}, \mathbf{w}_{-j, t}^{*}\right) ; \boldsymbol{\theta}^{d}\right) \\
& +\sum_{k \in \mathscr{I}_{r, t} \backslash\{j\}}\left(p_{k, t}\left(w_{j, t}, \mathbf{w}_{-j, t}^{*}\right)-w_{k, t}^{*}-c_{k, t}\right) M_{t} s_{k, t}\left(\mathbf{p}_{t}\left(w_{j, t}, \mathbf{w}_{-j, t}^{*}\right) ; \theta^{d}\right)
\end{aligned}
$$

The terms $d_{f, t}^{-a, b}$ and $d_{r, t}^{-a, b}$ denote respectively the status quo payoffs of manufacturer $f$ and retailer $r$ in the event of disagreement. Because the alliance $a$ coordinates the purchasing policy of its retailers, a bilateral disagreement precipitates bargaining breakdowns between manufacturer $f$ and every retailer of the alliance over any product sold under the brand name $b$ (i.e., the brand name of product $j$ ), implying that:

$$
\begin{aligned}
& d_{f, t}^{-a, b}=\sum_{k \in \mathscr{J}_{f, t} \backslash\left\{\mathscr{F}_{a, t} \cap \mathscr{F}_{b, t}\right\}}\left(w_{k, t}^{*}-\mu_{b(k), t}\right) M_{t} \tilde{s}_{k, t}^{-a, b}\left(\tilde{\mathbf{p}}_{t}^{-a, b} ; \theta^{d}\right) \\
& d_{r, t}^{-a, b}=\sum_{k \in \mathscr{F}_{r, t} \backslash\{j\}}\left(\tilde{p}_{k, t}^{-a, b}-w_{k, t}^{*}-c_{k, t}\right) M_{t} \tilde{s}_{k, t}^{-a, b}\left(\tilde{\mathbf{p}}_{t}^{-a, b} ; \theta^{d}\right)
\end{aligned}
$$

where $\tilde{\mathbf{p}}_{t}^{-a, b}$ is the $J_{t}$-dimensional vector of out-of-equilibrium retail prices when all product $j \in \mathscr{J}_{a, t} \cap \mathscr{J}_{b, t}$ are no longer offered on the market (see Appendix G.2) and $\tilde{s}_{k, t}^{a, b}$ is the market share of each product $k$ remaining on the market as defined in Appendix E.2.2.

First-order condition of the "Nash-in-Nash". The first-order condition of (22) which characterizes the division of surplus in this bilateral negotiation is derived as follows:

$$
\left(1-\lambda_{f, r}\right)\left(\pi_{f, t}-d_{f, t}^{-a, b}\right) \frac{\partial \pi_{r, t}}{\partial w_{j, t}}+\lambda_{f, r}\left(\pi_{r, t}-d_{r, t}^{-a, b}\right) \frac{\partial \pi_{f, t}}{\partial w_{j, t}}=0
$$




$$
\begin{aligned}
\Leftrightarrow & \left(\Gamma_{j, t} s_{j, t}\left(\mathbf{p}_{t} ; \theta^{d}\right)+\sum_{k \in \mathscr{I}_{f, t} \mid\left\{\mathscr{q}_{a, t} \cap \mathscr{g}_{b, t}\right\}} \Gamma_{k, t}\left(s_{k, t}\left(\mathbf{p}_{t} ; \theta^{d}\right)-\tilde{s}_{k, t}^{-a, b}\left(\tilde{\mathbf{p}}_{t}^{-a, b} ; \theta^{d}\right)\right)\right)\left(\sum_{k \in \mathscr{q}_{r, t}} \frac{\partial p_{k, t}}{\partial w_{j, t}} s_{k, t}\left(\mathbf{p}_{t} ; \theta^{d}\right)-s_{j, t}\left(\mathbf{p}_{t} ; \theta^{d}\right)\right. \\
& \left.+\sum_{k \in \mathscr{q}_{r, t}} \gamma_{k, t} \sum_{l \in \mathscr{q}_{r, t}} \frac{\partial s_{k, t}}{\partial p_{l, t}} \frac{\partial p_{l, t}}{\partial w_{j, t}}\right)+\frac{\lambda_{f, r}}{1-\lambda_{f, r}}\left(\gamma_{j, t} s_{j, t}\left(\mathbf{p}_{t} ; \theta^{d}\right)+\sum_{k \in \mathscr{q}_{r, t} t\{j\}} \gamma_{k, t} s_{k, t}\left(\mathbf{p}_{t} ; \theta^{d}\right)-\tilde{\gamma}_{k, t}^{-a, b} \tilde{s}_{k, t}^{-a, b}\left(\tilde{\mathbf{p}}_{t}^{-a, b} ; \theta^{d}\right)\right) \\
& \left(s_{j, t}\left(\mathbf{p}_{t} ; \theta^{d}\right)+\sum_{k \in \mathscr{f}_{f, t}} \Gamma_{k, t} \sum_{l \in \mathscr{q}_{r, t}} \frac{\partial s_{k, t}}{\partial p_{l, t}} \frac{\partial p_{l, t}}{\partial w_{j, t}}\right)=0
\end{aligned}
$$

where $\Gamma_{j, t} \equiv w_{j, t}-\mu_{b(j), t}, \gamma_{j, t} \equiv p_{j, t}-w_{j, t}-c_{j, t}$, and $\tilde{\gamma}_{k, t}^{-a, b} \equiv \tilde{p}_{k, t}^{-a, b}-w_{k, t}^{*}-c_{k, t}$. Note that only status quo payoffs of firms differ between (24) and (33).

Manufacturers' price-cost margins. For each market $t$, there are a total of $J_{t}$ price-cost margins of manufacturers to recover, that is $\Gamma_{j, t} \forall j \in \mathscr{J}_{t} \cdot{ }^{69}$ It can be shown that the left-hand side of (33) is the $j$ th equation of the following system of "Nash-in-Nash" first-order conditions written in vector-matrix notations as follows:

$$
\begin{aligned}
& \left(\left(\mathbf{O}_{f, t} \circ \tilde{\mathbf{S}}_{\Delta t}^{\text {post }}\right) \boldsymbol{\Gamma}_{t}\right) \circ\left(\left(\mathbf{P}_{\mathbf{w}_{t}}^{\text {pre }}-\mathbf{O}_{r, t} \circ \mathbf{I}_{t}\right) \delta_{t}+\mathbf{P}_{\mathbf{w}_{t}}^{\text {pre }}\left(\mathbf{O}_{r, t} \circ \mathbf{S}_{\mathbf{p}_{t}}\right) \boldsymbol{\gamma}_{t}\right)+\Lambda^{\text {pre }} \circ\left(\mathbf{O}_{a, t} \circ\left(\mathbf{1}_{J_{t}} \boldsymbol{\Delta}_{t}^{\top}\right) \boldsymbol{\gamma}_{t}\right. \\
& \left.+\left(\mathbf{O}_{a, t} \circ\left(\tilde{\mathbf{S}}_{\Delta t}^{\text {post }}-\mathbf{1}_{J_{t}} \boldsymbol{S}_{t}^{\top}\right) \circ\left(\tilde{\boldsymbol{\gamma}}_{t}^{\text {post }}\right)^{\top}\right) \mathbf{1}_{J_{t}}\right) \circ\left(\boldsymbol{s}_{t}+\left(\left(\mathbf{P}_{\mathbf{w}_{t}}^{\text {pre }} \mathbf{S}_{\mathbf{p}_{t}}\right) \circ \mathbf{O}_{f, t}\right) \boldsymbol{\Gamma}_{t}\right)=\mathbf{0}_{J_{t}}
\end{aligned}
$$

Define $\mathbf{V}_{t} \equiv\left(\mathbf{P}_{\mathbf{w}_{t}}^{\text {pre }}-\mathbf{O}_{r, t} \circ \mathbf{I}_{t}\right) \boldsymbol{s}_{t}+\mathbf{P}_{\mathbf{w}_{t}}^{\text {pre }}\left(\mathbf{O}_{r, t} \circ \mathbf{S}_{\mathbf{p}_{t}}\right) \gamma_{t} ; \mathbf{M}_{t} \equiv \mathbf{O}_{f, t} \circ \tilde{\mathbf{S}}_{\Delta t}^{\text {post }}$

$$
\tilde{\mathbf{V}}_{t} \equiv \mathbf{O}_{a, t} \circ\left(\mathbf{1}_{J_{t}} \Delta_{t}^{\top}\right) \boldsymbol{\gamma}_{t}+\left(\mathbf{O}_{a, t} \circ\left(\tilde{\mathbf{S}}_{\Delta t}^{\text {post }}-\mathbf{1}_{J_{t}} \Delta_{t}^{\top}\right) \circ\left(\tilde{\boldsymbol{\gamma}}_{t}^{\text {post }}\right)^{\top}\right) \mathbf{1}_{J_{t}} ; \quad \tilde{\mathbf{M}}_{t} \equiv\left(\mathbf{P}_{\mathbf{w}_{t}}^{\text {pre }} \mathbf{S}_{\mathbf{p}_{t}}\right) \circ \mathbf{O}_{f, t} ;
$$

and rewrite the system of $J_{t}$ equations (34) as follows:

$$
\mathbf{V}_{t} \circ\left(\mathbf{M}_{t} \boldsymbol{\Gamma}_{t}\right)+\Lambda^{p r e} \circ \tilde{\mathbf{V}}_{t} \circ s_{t}+\Lambda^{p r e} \circ \tilde{\mathbf{V}}_{t} \circ\left(\tilde{\mathbf{M}}_{t} \boldsymbol{\Gamma}_{t}\right)=\mathbf{0}_{J_{t}}
$$

It can be shown that (35) can be rewritten as:

$$
\left(\left(\mathbf{V}_{t} \mathbf{1}_{J_{t}}^{\top}\right) \circ \mathbf{M}_{t}\right) \boldsymbol{\Gamma}_{t}+\left(\left(\left(\Lambda^{p r e} \circ \tilde{\mathbf{V}}_{t}\right) \mathbf{1}_{J_{t}}^{\top}\right) \circ \tilde{\mathbf{M}}_{t}\right) \boldsymbol{\Gamma}_{t}=-\Lambda^{p r e} \circ \tilde{\mathbf{V}}_{t} \circ \Delta_{t}
$$

and that the $J_{t}$-dimensional vector of price-cost margins of manufacturers is derived as follows:

$$
\Gamma_{t}=-\left(\left(\mathbf{V}_{t} \mathbf{1}_{J_{t}}^{\top}\right) \circ \mathbf{M}_{t}+\left(\left(\Lambda^{\text {pre }} \circ \tilde{\mathbf{V}}_{t}\right) \mathbf{1}_{J_{t}}^{\top}\right) \circ \tilde{\mathbf{M}}_{t}\right)^{-1}\left(\Lambda^{\text {pre }} \circ \tilde{\mathbf{V}}_{t} \circ J_{t}\right)
$$

\section{F Derivation of the retail pass-through}

This section derives the retail pass-through when retailers compete on the downstream market with "interim unobservability". Based on Bonnet, Bouamra-Mechemache and Molina (2018), I first start with the pre-alliances periods. Then, I consider the post-alliances periods in which retailers negotiate through buyer alliances.

\footnotetext{
${ }^{69}$ For the sake of exposition, I omit private label products for which $\Gamma_{j, t}=0$.
} 


\section{F.1 Retail pass-through in the pre-alliances periods}

The retail pass-through in the pre-alliances periods is derived as in Bonnet, Bouamra-Mechemache and Molina (2018). The first-order condition which characterizes the pricing behavior of retailer $r$ for product $j \in \mathscr{J}_{r, t}$ is given by:

$$
s_{j, t}\left(\mathbf{p}_{t} ; \theta^{d}\right)+\sum_{k \in \mathscr{g}_{r, t}}\left(p_{k, t}-w_{k, t}-c_{k, t}\right) \frac{\partial s_{k, t}\left(\mathbf{p}_{t} ; \theta^{d}\right)}{\partial p_{j, t}}=0
$$

Taking into account that retailers compete on the downstream market with "interim unobservability", I can differentiate (36) with respect to the wholesale price of product $l \in \mathscr{J}_{r, t}$ as follows:

$$
\begin{gathered}
\frac{\partial}{\partial w_{l, t}}\left(s_{j, t}\right)+\sum_{k \in \mathscr{I}_{r, t}} \frac{\partial}{\partial w_{l, t}}\left(p_{k, t}-w_{k, t}-c_{k, t}\right) \frac{\partial s_{k, t}}{\partial p_{j, t}}+\sum_{k \in \mathscr{I}_{r, t}}\left(p_{k, t}-w_{k, t}-c_{k, t}\right) \frac{\partial}{\partial w_{l, t}}\left(\frac{\partial s_{k, t}}{\partial p_{j, t}}\right)=0 \\
\Leftrightarrow \sum_{k \in \mathscr{q}_{r, t}} \frac{\partial s_{j, t}}{\partial p_{k, t}} \frac{\partial p_{k, t}}{\partial w_{l, t}}+\sum_{k \in \mathscr{I}_{r, t}} \frac{\partial p_{k, t}}{\partial w_{l, t}} \frac{\partial s_{k, t}}{\partial p_{j, t}}-\frac{\partial s_{l, t}}{\partial p_{j, t}}+\sum_{k \in \mathscr{I}_{r, t}} \sum_{h \in \mathscr{I}_{r, t}}\left(p_{k, t}-w_{k, t}-c_{k, t}\right) \frac{\partial^{2} s_{k, t}}{\partial p_{j, t} \partial p_{h, t}} \frac{\partial p_{h, t}}{\partial w_{l, t}}=0
\end{gathered}
$$

It can be shown that the left-hand side of equation (37) corresponds to the $l \times j$ element of the following $J_{t} \times J_{t}$ matrix:

$$
\mathbf{P}_{\mathbf{w}_{t}}^{p r e}\left(\mathbf{O}_{r, t} \circ \mathbf{S}_{\mathbf{p}_{t}}\right)+\mathbf{P}_{\mathbf{w}_{t}}^{p r e}\left(\mathbf{O}_{r, t} \circ \mathbf{S}_{\mathbf{p}_{t}}^{\top}\right)-\mathbf{O}_{r, t} \circ \mathbf{S}_{\mathbf{p}_{t}}^{\top}+\mathbf{P}_{\mathbf{w}_{t}}^{p r e}\left(\mathbf{O}_{r, t} \circ \ddot{\mathbf{S}}_{\mathbf{p}_{t} \mathbf{p}_{t}}^{p r e}\right)
$$

where $\mathbf{P}_{\mathbf{w}_{t}}^{\text {pre }}$ is the $J_{t} \times J_{t}$ matrix of the first derivatives of retail prices with respect to wholesale prices, that is:

$$
\mathbf{P}_{\mathbf{w}_{t}}^{\text {pre }}[j, k]= \begin{cases}\frac{\partial p_{k, t}}{\partial w_{j, t}} & \text { if } j, k \in \mathscr{J}_{r, t} \\ 0 & \text { otherwise }\end{cases}
$$

and $\ddot{\mathbf{S}}_{\mathbf{p}_{t} \mathbf{p}_{t}}^{\text {pre }}$ represents a $J_{t} \times J_{t}$ matrix with the $k$ th column being equals to $\ddot{\mathbf{S}}_{\mathbf{p}_{t} \mathbf{p}_{t}}^{\text {pre }}[\cdot, k]=\left(\mathbf{O}_{r, t} \circ \mathbf{S}_{\mathbf{p}_{k, t} \mathbf{p}_{t}}\right) \gamma_{t}$ where $\mathbf{S}_{\mathbf{p}_{k, t} \mathbf{p}_{t}}$ denotes the following $J_{t} \times J_{t}$ matrix:

$$
\mathbf{S}_{\mathbf{p}_{k, t} \mathbf{p}_{t}}=\left(\begin{array}{ccc}
\frac{\partial^{2}{ }_{1, t}}{\partial p_{k, t} \partial p_{1, t}} & \cdots & \frac{\partial^{2} \jmath_{J, t}}{\partial p_{k, t} \partial p_{1, t}} \\
\vdots & \ddots & \vdots \\
\frac{\partial^{2}{\jmath_{1, t}}}{\partial p_{k, t} \partial p_{J, t}} & \cdots & \frac{\partial^{2} \jmath_{J, t}}{\partial p_{k, t} \partial p_{J, t}}
\end{array}\right)
$$

Given (37) and (38), $\mathbf{P}_{\mathbf{w}_{t}}^{\text {pre }}$ can be obtained as follows:

$$
\begin{aligned}
& \mathbf{P}_{\mathbf{w}_{t}}^{p r e}\left(\mathbf{O}_{r, t} \circ\left(\mathbf{S}_{\mathbf{p}_{t}}+\mathbf{S}_{\mathbf{p}_{t}}^{\top}+\ddot{\mathbf{S}}_{\mathbf{p}_{t} \mathbf{p}_{t}}^{p r e}\right)\right)-\mathbf{O}_{r, t} \circ \mathbf{S}_{\mathbf{p}_{t}}^{\top}=\mathbf{O}_{J_{t} \times J_{t}} \\
\Leftrightarrow & \mathbf{P}_{\mathbf{w}_{t}}^{p r e}=\left(\mathbf{O}_{r, t} \circ \mathbf{S}_{\mathbf{p}_{t}}^{\top}\right)\left(\mathbf{O}_{r, t} \circ\left(\mathbf{S}_{\mathbf{p}_{t}}+\mathbf{S}_{\mathbf{p}_{t}}^{\top}+\ddot{\mathbf{S}}_{\mathbf{p}_{t} \mathbf{p}_{t}}^{p r e}\right)\right)^{-1}
\end{aligned}
$$

Note that because manufacturers of private labels are vertically integrated with retailers, $\mathbf{P}_{\mathbf{w}_{t}}^{\text {pre }}$ is derived as follows:

$$
\mathbf{P}_{\mathbf{w}_{t}}^{p r e}=\left(\mathbf{O}_{r, t}^{*} \circ \mathbf{S}_{\mathbf{p}_{t}}^{\top}\right)\left(\mathbf{O}_{r, t} \circ\left(\mathbf{S}_{\mathbf{p}_{t}}+\mathbf{S}_{\mathbf{p}_{t}}^{\top}+\ddot{\mathbf{S}}_{\mathbf{p}_{t} \mathbf{p}_{t}}^{p r e}\right)\right)^{-1}
$$


where $\mathbf{O}_{r, t}^{*}$ is the ownership matrix of retailers in which rows for private labels are set to 0 , that is: $\mathbf{O}_{r, t}^{*}[j, \cdot]=$ $\mathbf{0}_{J_{t}}^{\top}$ if product $j$ is a private label.

\section{F.2 Retail pass-through in the post-alliances periods}

The first-order condition which characterizes the pricing behavior of retailer $r$ for product $j \in \mathscr{J}_{r, t}$ in the post-alliances periods is given by:

$$
s_{j, t}\left(\mathbf{p}_{t} ; \theta^{d}\right)+\sum_{k \in \mathscr{f}_{r, t}}\left(p_{k, t}-w_{a(k), b(k), t}-c_{k, t}\right) \frac{\partial s_{k, t}}{\partial p_{j, t}}\left(\mathbf{p}_{t} ; \theta^{d}\right)=0
$$

Taking into account that all retailers belonging to the alliance $a(l)$ observe every trading terms negotiated by the alliance, I can differentiate (41) with respect to the wholesale price of product $l \in \mathscr{J}_{r, t}$, denoted by $w_{a(l), b(l), t}$, as follows: ${ }^{70}$

$$
\begin{gathered}
\quad \frac{\partial s_{j, t}}{\partial w_{a(l), b(l), t}}+\sum_{k \in \mathscr{g}_{r, t}} \frac{\partial}{\partial w_{a(l), b(l), t}}\left(p_{k, t}-w_{a(k), b(k), t}-c_{k, t}\right) \frac{\partial s_{k, t}}{\partial p_{j, t}} \\
+\sum_{k \in \mathscr{I}_{r, t}}\left(p_{k, t}-w_{a(k), b(k), t}-c_{k, t}\right) \frac{\partial}{\partial w_{a(l), b(l), t}}\left(\frac{\partial s_{k, t}}{\partial p_{j, t}}\right)=0 \\
\Leftrightarrow \quad \sum_{k \in \mathscr{I}_{a(l), t}} \frac{\partial s_{j, t}}{\partial p_{k, t}} \frac{\partial p_{k, t}}{\partial w_{a(l), b(l), t}}+\sum_{k \in \mathscr{I}_{r, t}} \frac{\partial p_{k, t}}{\partial w_{a(l), b(l), t}} \frac{\partial s_{k, t}}{\partial p_{j, t}}-\frac{\partial s_{l, t}}{\partial p_{j, t}} \\
+\sum_{k \in \mathscr{g}_{r, t}} \sum_{h \in \mathscr{g}_{a(l), t}}\left(p_{k, t}-w_{a(k), b(k), t}-c_{k, t}\right) \frac{\partial^{2} s_{k, t}}{\partial p_{j, t} \partial p_{h, t}} \frac{\partial p_{h, t}}{\partial w_{a(l), b(l), t}}=0
\end{gathered}
$$

It can be shown that the left-hand side of equation (42) corresponds to the $l \times j$ element of the following $J_{t} \times J_{t}$ matrix:

$$
\mathbf{P}_{\mathbf{w}_{t}}^{\text {post }}\left(\mathbf{O}_{a, t} \circ \mathbf{S}_{\mathbf{p}_{t}}\right)+\mathbf{P}_{\mathbf{w}_{t}}^{\text {post }}\left(\mathbf{O}_{r, t} \circ \mathbf{S}_{\mathbf{p}_{t}}^{\top}\right)-\left(\left(\mathbf{O}_{r, t} \circ \mathbf{S}_{\mathbf{p}_{t}}^{\top}\right)+\left(\mathbf{O}_{b, t} \circ\left(\mathbf{O}_{a, t}-\mathbf{O}_{r, t}\right)\right)\left(\mathbf{O}_{r, t} \circ \mathbf{S}_{\mathbf{p}_{t}}^{\top}\right)\right)+\mathbf{P}_{\mathbf{w}_{t}}^{\text {post }} \ddot{\mathbf{S}}_{\mathbf{p}_{t} \mathbf{p}_{t}}^{\text {post }}
$$

where $\mathbf{P}_{\mathbf{w}_{t}}^{\text {post }}$ is a $J_{t} \times J_{t}$ matrix of the first derivatives of retail prices with respect to wholesale prices in the post-alliances periods, that is:

$$
\mathbf{P}_{\mathbf{w}_{t}}^{\text {post }}[j, k]= \begin{cases}\frac{\partial p_{k, t}}{\partial w_{a(j), b(j), t}} & \text { if } j, k \in \mathscr{J}_{a, t} \\ 0 & \text { otherwise }\end{cases}
$$

$\ddot{\mathbf{S}}_{\mathbf{p}_{\mathbf{t}} \mathbf{p}_{t}}^{\text {post }}$ refers to a $J_{t} \times J_{t}$ matrix with the $k$ th column being equals to $\ddot{\mathbf{S}}_{\mathbf{p}_{t} \mathbf{p}_{t}}^{\text {post }}[\cdot, k]=\left(\mathbf{O}_{a, t} \circ \mathbf{S}_{\mathbf{p}_{k, t} \mathbf{p}_{t}}\right)\left(\mathbf{O}_{r, t}[\cdot, k] \circ \gamma_{t}\right)$. Given (42) and (43), $\mathbf{P}_{\mathbf{w}_{t}}^{\text {post }}$ can be derived as follows:

$$
\begin{aligned}
& \mathbf{P}_{\mathbf{w}_{t}}^{\text {post }}\left(\mathbf{O}_{a, t} \circ \mathbf{S}_{\mathbf{p}_{t}}+\mathbf{O}_{r, t} \circ \mathbf{S}_{\mathbf{p}_{t}}^{\top}+\ddot{\mathbf{S}}_{\mathbf{p}_{t} \mathbf{p}_{t}}^{\text {post }}\right)-\left(\left(\mathbf{O}_{r, t} \circ \mathbf{S}_{\mathbf{p}_{t}}^{\top}\right)+\left(\mathbf{O}_{b, t} \circ\left(\mathbf{O}_{a, t}-\mathbf{O}_{r, t}\right)\right)\left(\mathbf{O}_{r, t} \circ \mathbf{S}_{\mathbf{p}_{t}}^{\top}\right)\right)=\mathbf{0}_{J_{t} \times J_{t}} \\
\Leftrightarrow & \mathbf{P}_{\mathbf{w}_{t}}^{\text {post }}=\left(\left(\mathbf{O}_{r, t} \circ \mathbf{S}_{\mathbf{p}_{t}}^{\top}\right)+\left(\mathbf{O}_{b, t} \circ\left(\mathbf{O}_{a, t}-\mathbf{O}_{r, t}\right)\right)\left(\mathbf{O}_{r, t} \circ \mathbf{S}_{\mathbf{p}_{t}}^{\top}\right)\right)\left(\mathbf{O}_{a, t} \circ \mathbf{S}_{\mathbf{p}_{t}}+\mathbf{O}_{r, t} \circ \mathbf{S}_{\mathbf{p}_{t}}^{\top}+\ddot{\mathbf{S}}_{\mathbf{p}_{t} \mathbf{p}_{t}}^{\text {post }}\right)^{-1}
\end{aligned}
$$

\footnotetext{
${ }^{70}$ Note that, due to the nondiscrimination effect, a change in $w_{a(l), b(l), t}$ implies a similar change in $w_{a(h), b(h), t} \forall h \in \mathscr{J}_{a(l)} \cap \mathscr{J}_{b(l)}$.
} 
Note that because manufacturers of private labels are vertically integrated with retailers, $\mathbf{P}_{\mathbf{w}_{t}}^{\text {post }}$ is derived as follows:

$$
\mathbf{P}_{\mathbf{w}_{t}}^{\text {post }}=\left(\left(\mathbf{O}_{r, t}^{*} \circ \mathbf{S}_{\mathbf{p}_{t}}^{\top}\right)+\left(\mathbf{O}_{b, t} \circ\left(\mathbf{O}_{a, t}-\mathbf{O}_{r, t}\right)\right)\left(\mathbf{O}_{r, t}^{*} \circ \mathbf{S}_{\mathbf{p}_{t}}^{\top}\right)\right)\left(\mathbf{O}_{a, t} \circ \mathbf{S}_{\mathbf{p}_{t}}+\mathbf{O}_{r, t} \circ \mathbf{S}_{\mathbf{p}_{t}}^{\top}+\ddot{\mathbf{S}}_{\mathbf{p}_{t} \mathbf{p}_{t}}^{\text {post }}\right)^{-1}
$$

where $\mathbf{O}_{r, t}^{*}$ is the ownership matrix of retailers in which rows for private labels are set to 0 , that is: $\mathbf{O}_{r, t}^{*}[j, \cdot]=$ $\mathbf{0}_{J_{t}}^{\top}$ if product $j$ is a private label.

\section{G Computation of the out-of-equilibrium retail prices}

This section describes how the out-of-equilibrium retail prices are derived to construct status quo payoffs of firms in (23a), (23b), (28a), and (28b).

\section{G.1 Out-of-equilibrium retail prices in the pre-alliances periods}

To construct the status quo payoffs in (23a) and (23b), I derive the out-of-equilibrium retail prices following a bargaining breakdown over the wholesale price of product $j \in \mathscr{J}_{r, t}$ as in Bonnet, Bouamra-Mechemache and Molina (2018). Under the assumption that wholesale prices and distribution costs of other products remain unchanged, price-cost margins of retailers and out-of-equilibrium price-cost margins of retailers over product $k \in \mathscr{J}_{r, t} \backslash\{j\}$ are respectively given by: $\gamma_{k, t}=p_{k, t}-w_{k, t}-c_{k, t}$ and $\tilde{\gamma}_{k, t}^{-j}=\tilde{p}_{k, t}^{-j}-w_{k, t}-c_{k, t}$. It is straightforward to see that the following equality holds: $\tilde{p}_{k, t}^{-j}-\tilde{\gamma}_{k, t}^{-j}-\left(p_{k, t}-\gamma_{k, t}\right)=0 \forall k \in \mathscr{J}_{r, t} \backslash\{j\}$. Therefore, I can define a system of $J_{t}$ nonlinear equations such that:

$$
\tilde{\mathbf{p}}_{t}^{-j}-\tilde{\gamma}_{t}^{-j}-\left(\mathbf{p}_{t}-\gamma_{t}\right)=\mathbf{0}_{J_{t}}
$$

where $\mathbf{0}_{J_{t}}$ is a $J_{t}$-dimensional vector with all entries being equal to $0, \tilde{\mathbf{p}}_{t}^{-j}$ is a $J_{t}$-dimensional vector of out-ofequilibrium retail prices when product $j$ is removed from the market whose $k$ th element equals:

$$
\tilde{\mathbf{p}}_{t}^{-j}[k, 1]= \begin{cases}\infty & \text { if } j=k \\ \tilde{p}_{k, t}^{-j} & \text { if } k \in \mathscr{I}_{r, t} \\ p_{k, t} & \text { if } k \notin \mathscr{J}_{r, t} \text { (interim unobservability) }\end{cases}
$$

and $\tilde{\gamma}_{r, t}^{-j}$ is a $J_{t}$-dimensional vector of out-of-equilibrium price-cost margins of retailers when product $j$ is removed from the market and whose $k$ th element being equal to:

$$
\tilde{\gamma}_{t}^{-j}[k, 1]= \begin{cases}\infty & \text { if } k=j \\ \tilde{\gamma}_{t}^{-j}[k, 1] & \text { if } j, k \in \mathscr{J}_{r, t} \text { with } \tilde{\gamma}_{t}^{-j}=-\left(\mathbf{o}_{r, t} \circ \tilde{\mathbf{S}}_{\tilde{\mathbf{p}}_{t}^{-j}}\right)^{-1} \tilde{s}_{t}^{-j}\left(\tilde{\mathbf{p}}_{t}^{-j}\right) \\ \gamma_{k, t} & \text { otherwise }\end{cases}
$$

To solve the system (45) and recover the vector of out-of-equilibrium retail prices $\tilde{\mathbf{p}}_{t}^{-j}$, I employ a trust-region dogleg method using the equilibrium retail prices as an initial guess for the out-of-equilibrium retail prices 
parameters (that is, $\left.\tilde{\mathbf{p}}_{t}^{-j,(0)}=\mathbf{p}_{t}\right)^{71}$

\section{G.2 Out-of-equilibrium retail prices in the post-alliances periods}

Similar to Appendix G.1, I make use of the assumption that marginal costs of retailers for products remaining on the market are not affected by a bargaining breakdown to construct status quo payoffs in (28a) and (28b). Hence, the vector of out-of-equilibrium retail prices that results from a bargaining breakdown over the wholesale prices of all products $j \in \mathscr{J}_{a, t} \cap \mathscr{J}_{b, t}$, that is $w_{a, b, t}$, can be recovered by solving the following system of $J_{t}$ nonlinear equations:

$$
\tilde{\mathbf{p}}_{t}^{-a, b}-\tilde{\boldsymbol{\gamma}}_{t}^{-a, b}-\left(\mathbf{p}_{t}-\gamma_{t}\right)=\mathbf{0}_{J_{t}}
$$

where $\mathbf{p}_{t}^{-a, b}$ is the $J_{t}$-dimensional vector of out-of-equilibrium retail prices when products belonging to $\mathscr{J}_{a, t} \cap$ $\mathscr{J}_{b, t}$ are removed from the market and its $k$ th element equals:

$$
\tilde{\mathbf{p}}_{t}^{-a, b}[k, 1]= \begin{cases}\infty & \text { if } k \in \mathscr{J}_{a, t} \cap \mathscr{\mathscr { l }}_{b, t} \\ \tilde{p}_{k, t}^{-a, b} & \text { if } k \in \mathscr{J}_{a, t} \backslash \mathscr{L}_{b, t} \\ p_{k, t} & \text { otherwise }\end{cases}
$$

and $\tilde{\gamma}_{t}^{-a, b}$ is the resulting $J_{t}$-dimensional vector of out-of-equilibrium price-cost margins of retailers whose $k$ th element being equal to:

$$
\tilde{\boldsymbol{\gamma}}_{t}^{-a, b}[k, 1]= \begin{cases}\infty & \text { if } k \in \mathscr{J}_{a, t} \cap \mathscr{J}_{b, t} \\ \tilde{\gamma}_{t}^{-a, b}[k, 1] & \text { if } j, k \in \mathscr{J}_{a, t} \backslash \mathscr{J}_{b, t} \text { with } \tilde{\gamma}_{t}^{-a, b}=-\left(\mathbf{O}_{r, t} \circ \tilde{\mathbf{S}}_{\tilde{\mathbf{p}}_{t}^{-a, b}}\right)^{-1} \tilde{\boldsymbol{g}}_{t}^{-a, b}\left(\tilde{\mathbf{p}}_{t}^{-a, b}\right) \\ \gamma_{k, t} & \text { otherwise }\end{cases}
$$

To solve the system (46) and recover the vector of out-of-equilibrium retail prices $\tilde{\mathbf{p}}_{t}^{-a, b}$, I employ a trustregion dogleg method using the equilibrium retail prices as an initial guess for the out-of-equilibrium retail prices parameters (that is, $\left.\tilde{\mathbf{p}}_{t}^{-a, b,(0)}=\mathbf{p}_{t}\right) .^{72}$

\section{H Counterfactual algorithm}

I describe the algorithm used in Section 5 to simulate a new market equilibrium in negotiated wholesale prices, retail prices, and market shares of products in the post-alliances periods (e.g., no buyer alliances).

Iterative estimation algorithm. For each market $t$, I compute a new vector of retail prices under the assumption that consumer preferences, product characteristics, marginal costs of production and distribution, and the manufacturer-retailer network structure remain unchanged.

\footnotetext{
${ }^{71}$ The search for a numerical root is performed with the MATLAB fsolve function.

${ }^{72}$ The search for a numerical root is performed with the MATLAB $f$ solve function.
} 
1. Initialization: The parameters to be estimated are the vector of counterfactual retail price equilibrium $\left(\hat{\mathbf{p}}_{t}\right)$ and all vectors of counterfactual out-of-equilibirum retail prices when removing every product $j \in$ $\mathscr{J}_{t} \backslash\{0\}$ from the market (that is, $\hat{\tilde{\mathbf{p}}}_{t}^{-1}, \ldots, \hat{\tilde{\mathbf{p}}}_{t}^{-J_{t}}$ ). I use the vector of observed retail prices as an initial guess for the vector of counterfactual retail prices - i.e., $\hat{\mathbf{p}}_{t}^{(0)}=\mathbf{p}_{t}-$ as well as for every vector of counterfactual out-of-equilibrium retail prices when removing each product $j \in \mathscr{J}_{t} \backslash\{0\}-$ e.g., $\hat{\tilde{\mathbf{p}}}_{t}^{-j,(0)}=\mathbf{p}_{t} \forall j \in \mathscr{J}_{t} \backslash\{0\}$.

2. At the $i$ th iteration, I make a guess of all vectors of counterfactual out-of-equilibrium retail prices which, in turn, allows me to compute the matrix of counterfactual out-of-equilibrium retail margins $\hat{\gamma}_{t}$ - by solving $J_{t}$ systems of nonlinear equations. For instance, the vector of counterfactual outof-equilibrium retail prices when product $j$ is removed from the market $\left(\hat{\tilde{\mathbf{p}}}_{t}^{-j,(i)}\right)$ solves the following system:

$$
\underbrace{\hat{\tilde{\mathbf{p}}}_{t}^{-j,(i)}-\hat{\tilde{\gamma}}_{t}^{-j,(i)}}_{\mathbf{w}_{t}^{(i)}-\mathbf{c}_{t}}-(\underbrace{\hat{\mathbf{p}}_{t}^{(i-1)}-\hat{\gamma}_{t}^{(i-1)}}_{\mathbf{w}_{t}^{(i-1)}-\mathbf{c}_{t}})=\mathbf{0}_{J_{t}}
$$

where $\hat{\gamma}_{t}^{(i-1)}=-\left(\mathbf{O}_{r, t} \circ \mathbf{S}_{\hat{\mathbf{p}}_{t}^{(i-1)}}\right)^{-1} s_{t}\left(\hat{\mathbf{p}}_{t}^{(i-1)}\right), \hat{\tilde{\gamma}}_{t}^{-j,(i)}$ is a $J_{t}$-dimensional vector in which the $k$ th element equals:

$$
\hat{\tilde{\gamma}}_{t}^{-j,(i)}[k, 1]= \begin{cases}\infty & \text { if } k=j \\ \hat{\tilde{\gamma}}_{t}^{-j,(i)}[k, 1] & \text { if } k \in \mathscr{J}_{r(j), t} \text { with } \hat{\tilde{\gamma}}_{t}^{-j,(i)}=-\left(\mathbf{O}_{r, t} \circ \mathbf{S}_{\hat{\mathbf{p}}_{t}^{-j,(i)}}\right)^{-1} \Delta_{t}\left(\hat{\mathbf{p}}_{t}^{-j,(i)}\right) \\ \hat{\gamma}_{t}^{(i-1)}[k, 1] & \text { otherwise }\end{cases}
$$

and $\hat{\tilde{\mathbf{p}}}_{t}^{-j,(i)}$ is a $J_{t}$-dimensional vector whose $k$ th element being equal to:

$$
\hat{\tilde{\mathbf{p}}}_{t}^{-j,(i)}[k, 1]= \begin{cases}\infty & \text { if } k=j \\ \hat{\tilde{p}}_{k, t}^{-j,(i)} & \text { if } k \in \mathscr{J}_{r(j), t} \\ \hat{p}_{k, t}^{(i-1)} & \text { otherwise }\end{cases}
$$

Note that before each iteration $\hat{\tilde{\mathbf{p}}}_{t}^{-j,(i)}$ is updated using $\hat{\tilde{\mathbf{p}}}_{t}^{-j,(i-1)}$ as starting point $\forall j \in \mathscr{J}_{t} \backslash\{0\}$.

3. Given the guess of each vector of out-of-equilibrium retail prices from step 2 and $\hat{\mathbf{p}}_{t}^{(i-1)}$, I construct the matrices $\hat{\tilde{\mathbf{S}}}_{\Delta t}^{(i)}$ and $\hat{\mathbf{P}}_{w_{t}}^{(i)}$ using derivatives from Appendix F.

4. The vector of counterfactual equilibrium retail prices $\hat{\mathbf{p}}_{t}^{(i)}$ is the solution to the following system of nonlinear equations:

$$
\underbrace{\hat{\mathbf{p}}_{t}^{(i)}-\left(\hat{\gamma}_{t}^{(i)}+\hat{\boldsymbol{\Gamma}}_{t}^{(i)}\right)}_{\mathbf{c}_{t}+\boldsymbol{\mu}_{t}}-\underbrace{\left(\mathbf{p}_{t}-\left(\gamma_{t}+\Gamma_{t}\right)\right)}_{\mathbf{c}_{t}+\boldsymbol{\mu}_{t}}=\mathbf{0}
$$

where $\hat{\Gamma}_{t}^{(i)}$ is derived following Appendix E.2. Note that before each iteration, $\hat{\mathbf{p}}_{t}^{(i)}$ is updated using $\hat{\mathbf{p}}_{t}^{(i-1)}$ as starting point.

I iteratively apply steps 2 to 4 until convergence, i.e. $\left\|\hat{\mathbf{p}}_{t}^{(i)}-\hat{\mathbf{p}}_{t}^{(i-1)}\right\|<e$, where in practice I use $e=10^{-06}$. 


\section{References}

Allain, Marie-Laure, Claire Chambolle, and Stéphane Turolla. 2019. "The Effect of Input Price Discrimination on Retail Prices: Theory and Evidence from France." Unpublished. Available at: http://chambolle.io/wp-content/uploads/2017/03/ACT-discrim_ 22_04_19Bergen.pdf.

Allain, Marie-Laure, Rémi Avignon, and Claire Chambolle. 2020. "Purchasing Alliances and Product Variety." forthcoming at International Journal of Industrial Organization.

Armstrong, Timothy B. 2016. "Large Market Asymptotics for Differentiated Product Demand Estimators with Economic Models of Supply." Econometrica, 84(5): 1961-1980.

Arons, Robert, Nikolay Doudchenko, and Ali Yurukoglu. 2019. "Size Effects and Bargaining Power in the Multichannel Television Industry." Unpublished. Available at: https://editorialexpress.com/cgi-bin/conference/download.cgi?db_name=EARIE19\& paper_id=609.

Ashenfelter, Orley C., and Daniel S. Hosken. 2010. "The Effect of Mergers on Consumer Prices: Evidence from Five Mergers on the Enforcement Margin." Journal of Law \& Economics, 53(3): 417-466.

Ashenfelter, Orley C., Daniel S. Hosken, and Matthew C. Weinberg. 2015. "Efficiencies brewed: pricing and consolidation in the US beer industry." RAND Journal of Economics, 46(2): 328-361.

Autorité de la concurrence. 2015. "Avis $\mathrm{n}^{\circ} 15-\mathrm{A}-06$ du 31 mars 2015 relatif au rapprochement des centrales d'achat et de référencement dans le secteur de la grande distribution." Link to Press Release (English version).

Berry, Steven T. 1994. "Estimating Discrete-Choice Models of Product Differentiation." RAND Journal of Economics, 25(2): 242-262.

Berry, Steven T., and Philip A. Haile. 2014. "Identification in Differentiated Products Markets Using Market Level Data." Econometrica, 82(5): 1749-1797.

Berry, Steven T., James Levinsohn, and Ariel Pakes. 1995. "Automobile Prices in Market Equilibrium." Econometrica, 63(4): 841-890.

Berry, Steven T., James Levinsohn, and Ariel Pakes. 2004. "Differentiated Products Demand Systems from a Combination of Micro and Macro Data: The New Car Market." Journal of Political Economy, 112(1): 68-105.

Bertrand, Marianne, Esther Duflo, and Sendhil Mullainathan. 2004. "How Much Should We Trust Differences-In-Differences Estimates?" Quarterly Journal of Economics, 119(1): 249-275.

Binmore, Kenneth George, Ariel Rubinstein, and Asher Wolinsky. 1986. "The Nash Bargaining Solution in Economic Modelling." RAND Journal of Economics, 17(2): 176-188. 
Bonnet, Céline, and Pierre Dubois. 2010. "Inference on vertical contracts between manufacturers and retailers allowing for nonlinear pricing and resale price maintenance." RAND Journal of Economics, 41(1): 139-164.

Bonnet, Céline, and Pierre Dubois. 2015. "Identifying Two Part Tariff Contracts with Buyer Power: Empirical Estimation on Food Retailing." Unpublished. Available at: https: //www.tse-fr.eu/sites/default/files/TSE/documents/doc/wp/2015/wp_tse_575.pdf.

Bonnet, Céline, Zohra Bouamra-Mechemache, and Hugo Molina. 2018. "The Downstream Competition Effects in Bilateral Oligopolies: A Structural Bargaining Approach with Limited Data." Unpublished. Available at: https://pastel.archives-ouvertes.fr/ tel-01755505/document.

Burns, Lawton R., and J. Andrew Lee. 2008. "Hospital purchasing alliances: Utilization, services, and performance." Health Care Management Review, 33(3): 203-215.

Caprice, Stéphane, and Patrick Rey. 2015. "Buyer Power from Joint Listing Decision." Economic Journal, 125(589): 1677-1704.

Carlton, Dennis W., and Mark Israel. 2011. "Proper Treatment of Buyer Power in Merger Review." Review of Industrial Organization, 39(1/2): 127-136.

Chae, Suchan, and Paul Heidhues. 2004a. "Buyers' Alliances for Bargaining Power." Journal of Economics \& Management Strategy, 13(4): 731-754.

Chae, Suchan, and Paul Heidhues. 2004b. "A group bargaining solution." Mathematical Social Sciences, 48(1): 37-53.

Chen, Yuxin, and Xinxin Li. 2013. "Group Buying Commitment and Sellers' Competitive Advantages." Journal of Economics \& Management Strategy, 22(1): 164-183.

Chen, Zhiqi. 2019. "Supplier Innovation in the Presence of Buyer Power." International Economic Review, 60(1): 329-353.

Chipty, Tasneem, and Christopher M. Snyder. 1999. "The Role of Firm Size in Bilateral Bargaining: A Study of the Cable Television Industry." Review of Economics and Statistics, 81(2): 326-340.

Colen, Liesbeth, Zohra Bouamra-Mechemache, Victoria Daskalova, and Kjersti Nes. 2020. "Retail alliances in the agricultural and food supply chain." EUR 30206 EN, European Commission, ISBN 978-92-76-18585-7, doi:10.2760/33720, JRC120271.

Collard-Wexler, Allan, Gautam Gowrisankaran, and Robin S. Lee. 2019. "'Nash-inNash" Bargaining: A Microfoundation for Applied Work." Journal of Political Economy, 127(1): 163-195.

Craig, Stuart V., Matthew Grennan, and Ashley Swanson. 2021. "Mergers and Marginal Costs: New Evidence on Hospital Buyer Power." RAND Journal of Economics, 52(1): 151178.

Crawford, Gregory S., and Ali Yurukoglu. 2012. "The Welfare Effects of Bundling in Multichannel Television Markets." American Economic Review, 102: 643-685. 
Crawford, Gregory S., Robin S. Lee, Michael D. Whinston, and Ali Yurukoglu. 2018. "The Welfare Effects of Vertical Integration in Multichannel Television Markets." Econometrica, 86(3): 891-954.

Dana, James D. 2012. "Buyer groups as strategic commitments." Games and Economic Behavior, 74(2): 470-485.

DiNardo, John, and David S. Lee. 2004. "Economic Impacts of New Unionization on Private Sector Employers: 1984-2001." Quarterly Journal of Economics, 119(4): 1383-1441.

Dobson, Paul W., and Michael Waterson. 1997. "Countervalling Power and Consumer Prices." Economic Journal, 107(441): 418-430.

Draganska, Michaela, Daniel Klapper, and Sofia Berto Villas-Boas. 2010. "A Larger Slice or a Larger Pie? An Empirical Investigation of Bargaining Power in the Distribution Channel." Marketing Science, 29(1): 57-74.

Dubois, Pierre, Yassine Lefouili, and Stéphane Straub. 2021. "Pooled Procurement of Drugs in Low and Middle Income Countries." European Economic Review, 132: 103655.

Ellison, Sara Fisher, and Christopher M. Snyder. 2010. "Countervailing Power in Wholesale Pharmaceuticals." Journal of Industrial Economics, 58(1): 32-53.

European Commission. 2014. "The economic impact of modern retail on choice and innovation in the EU food sector." European Commission, DG COMP.

Focarelli, Dario, and Fabio Panetta. 2003. "Are Mergers Beneficial to Consumers? Evidence from the Market for Bank Deposits." American Economic Review, 93(4): 1152-1172.

Galbraith, John Kenneth. 1952. American Capitalism: The Concept of Countervailing Power. Houghton Mifflin.

Gandhi, Amit, and Jean-François Houde. 2020. "Measuring Substitution Patterns in Differentiated Products Industries." Unpublished. Available at: https://www.dropbox.com/ s/98h94s7rasvnnnr/GH_submission_ecma.pdf?dl=0.

Gaudin, Germain. 2018. "Vertical Bargaining and Retail Competition: What Drives Countervailing Power?" Economic Journal, 128(614): 2380-2413.

Goolsbee, Austan, and Amil Petrin. 2004. "The Consumer Gains from Direct Broadcast Satellites and the Competition with Cable TV." Econometrica, 72(2): 351-381.

Gowrisankaran, Gautam, Aviv Nevo, and Robert Town. 2015. "Mergers When Prices Are Negotiated: Evidence from the Hospital Industry." American Economic Review, 105(1): 172-203.

Grennan, Matthew. 2013. "Price Discrimination and Bargaining: Empirical Evidence from Medical Devices." American Economic Review, 103(1): 145-177.

Grennan, Matthew. 2014. "Bargaining Ability and Competitive Advantage: Empirical Evidence from Medical Devices." Management Science, 60(12): 3011-3025. 
Grennan, Matthew, and Ashley Swanson. 2020. "Transparency and Prices: The Value of Information in Hospital-Supplier Bargaining." Journal of Political Economy, 128(4): 12431268.

Hansen, Lars Peter. 1982. "Large Sample Properties of Generalized Method of Moments Estimators." Econometrica, 50(4): 1029-1054.

Hansen, Lars Peter, John Heaton, and Amir Yaron. 1996. "Finite-Sample Properties of Some Alternative GMM Estimators." Journal of Business \& Economic Statistics, 14(3): 262280.

Harsanyi, John C. 1977. Rational Behaviour and Bargaining Equilibrium in Games and Social Situations. Cambridge University Press.

Hemphill, C. Scott, and Nancy L. Rose. 2018. "Mergers that Harm Sellers." Yale Law Journal, 127(7): 2078-2109.

Ho, Katherine, and Robin S. Lee. 2017. "Insurer Competition in Health Care Markets." Econometrica, 85(2): 379-417.

Horn, Henrik, and Asher Wolinsky. 1988a. "Bilateral Monopolies and Incentives for Merger." RAND Journal of Economics, 19(3): 408-419.

Horn, Henrik, and Asher Wolinsky. 1988b. "Worker Substitutability and Patterns of Unionisation." Economic Journal, 98(391): 484-497.

Hortaçsu, Ali, and Chad Syverson. 2015. "The Ongoing Evolution of US Retail: A Format Tug-of-War." Journal of Economic Perspectives, 29(4): 89-112.

Inderst, Roman, and Greg Shaffer. 2007. "Retail Mergers, Buyer Power and Product Variety." Economic Journal, 117(516): 45-67.

Inderst, Roman, and João V. Montez. 2019. "Buyer power and mutual dependency in a model of negotiations." RAND Journal of Economics, 50(1): 29-56.

Iozzi, Alberto, and Tommaso Valletti. 2014. "Vertical Bargaining and Countervailing Power." American Economic Journal: Microeconomics, 6(3): 106-135.

Jeon, Doh-Shin, and Domenico Menicucci. 2017. "The Benefits of Diverse Preferences in Library Consortia." Journal of Industrial Economics, 65(1): 105-135.

Jeon, Doh-Shin, and Domenico Menicucci. 2019. "On the unprofitability of buyer groups when sellers compete." Games and Economic Behavior, 115: 265-288.

Jun, Byoung Heon. 1989. "Non-cooperative Bargaining and Union Formation." Review of Economic Studies, 56(1): 59-76.

Kalai, Ehud. 1977. "Nonsymmetric Nash Solutions and Replications of 2-Person Bargaining." International Journal of Game Theory, 6(3): 129-133.

Lewis, Matthew S., and Kevin E. Pflum. 2015. "Diagnosing Hospital System Bargaining Power in Managed Care Networks." American Economic Journal: Economic Policy, 7(1): 243-274. 
Lewis, Matthew S., and Kevin E. Pflum. 2017. "Hospital systems and bargaining power: evidence from out-of-market acquisitions." RAND Journal of Economics, 48(3): 579-610.

Luco, Fernando, and Guillermo Marshall. 2020. "The Competitive Impact of Vertical Integration by Multiproduct Firms." American Economic Review, 110(7): 2041-2064.

McAfee, R. Preston, and Marius Schwartz. 1994. "Opportunism in Multilateral Vertical Contracting: Nondiscrimination, Exclusivity, and Uniformity." American Economic Review, 84(1): 210-230.

Michel, Christian, and Stefan Weiergraeber. 2018. "Estimating Industry Conduct in Differentiated Products Markets." Unpublished. Available at: http://christianmichel.net/ wp-content/uploads/2018/11/conduct_cereal.pdf.

Miller, Nathan H., and Matthew C. Weinberg. 2017. "Understanding the Price Effects of the MillerCoors Joint Venture." Econometrica, 85(6): 1763-1791.

Montez, João V. 2007. “Downstream mergers and producer's capacity choice: why bake a larger pie when getting a smaller slice?” RAND Journal of Economics, 38(4): 948-966.

Montiel Olea, José, and Carolin Pflueger. 2013. "A Robust Test for Weak Instruments." Journal of Business \& Economic Statistics, 31(3): 358-369.

Morey, Edward R., Vijaya R. Sharma, and Anders Karlstrom. 2003. "A Simple Method of Incorporating Income Effects into Logit and Nested-Logit Models: Theory and Application." American Journal of Agricultural Economics, 85(1): 248-253.

Nash, John F. 1950. “The Bargaining Problem.” Econometrica, 18(2): 155-162.

O'Brien, Daniel P. 2014. "The welfare effects of third-degree price discrimination in intermediate good markets: the case of bargaining." RAND Journal of Economics, 45(1): 92-115.

Rey, Patrick, and Thibaud Vergé. 2004. "Bilateral control with vertical contracts." RAND Journal of Economics, 35(4): 728-746.

Rey, Patrick, and Thibaud Vergé. 2020. "Secret contracting in multilateral relations." Unpublished. Available at: https://www.tse-fr.eu/sites/default/files/TSE/documents/doc/ by/rey/744_version2020.pdf.

Roth, Alvin E. 1979. Axiomatic Models of Bargaining. Vol. 170 of Lecture Notes in Economics and Mathematical Systems, Springer-Verlag Berlin Heidelberg.

Segal, Ilya. 2003. "Collusion, Exclusion, and Inclusion in Random-Order Bargaining." Review of Economic Studies, 70(2): 439-460.

Snyder, Christopher M. 2008. "Countervailing Power." In The New Palgrave Dictionary of Economics. 1-3. Palgrave Macmillan UK.

Sorensen, Alan T. 2003. "Insurer-Hospital Bargaining: Negotiated Discounts in PostDeregulation Connecticut." Journal of Industrial Economics, 51(4): 469-490.

Spengler, Joseph J. 1950. "Vertical Integration and Antitrust Policy." Journal of Political Economy, 58(4): 347-352. 
Thomassen, Øyvind, Howard Smith, Stephan Seiler, and Pascale Schiraldi. 2017. "Multi-Category Competition and Market Power: A Model of Supermarket Pricing." American Economic Review, 107(8): 2308-2351.

Train, Kenneth. 2009. "Discrete Choice Methods with Simulation." Second ed.

Villas-Boas, Sofia Berto. 2007. "Vertical Relationships between Manufacturers and Retailers: Inference with Limited Data." Review of Economic Studies, 74(2): 625-652.

Villas-Boas, Sofia Berto. 2009. "An empirical investigation of the welfare effects of banning wholesale price discrimination." RAND Journal of Economics, 40(1): 20-46.

Weinberg, Matthew C., and Daniel S. Hosken. 2013. "Evidence on the Accuracy of Merger Simulations." Review of Economics and Statistics, 95(5): 1584-1600.

Zhang, Jun. 2018. "What Makes a Good Merger? An Analysis of Merger Efficiencies in the U.S. Bottled Water Industry.” Unpublished. Available at: https://papers.ssrn.com/sol3/ papers.cfm?abstract_id=3284249. 